\title{
Development of a Spherical Micro-Indentation Test Methodology for Creep Analysis and On-set of Tertiary Creep for Solder Alloys
}

Dumbi Azubuike Otunyo

Follow this and additional works at: https://researchrepository.wvu.edu/etd

\section{Recommended Citation}

Otunyo, Dumbi Azubuike, "Development of a Spherical Micro-Indentation Test Methodology for Creep Analysis and On-set of Tertiary Creep for Solder Alloys" (2017). Graduate Theses, Dissertations, and Problem Reports. 6362.

https://researchrepository.wvu.edu/etd/6362

This Dissertation is protected by copyright and/or related rights. It has been brought to you by the The Research Repository @ WVU with permission from the rights-holder(s). You are free to use this Dissertation in any way that is permitted by the copyright and related rights legislation that applies to your use. For other uses you must obtain permission from the rights-holder(s) directly, unless additional rights are indicated by a Creative Commons license in the record and/ or on the work itself. This Dissertation has been accepted for inclusion in WVU Graduate Theses, Dissertations, and Problem Reports collection by an authorized administrator of The Research Repository @ WVU.

For more information, please contact researchrepository@mail.wvu.edu. 


\title{
Development of a spherical micro-indentation test methodology for creep analysis and on-set of tertiary creep for solder alloys
}

\author{
Dumbi Azubuike Otunyo \\ Thesis submitted \\ to the Benjamin M. Statler College of \\ Engineering and Mineral Resources \\ at West Virginia University \\ in partial fulfillment of the requirements for the degree of \\ Doctor of Philosophy \\ in \\ Mechanical Engineering \\ Bruce Kang, Ph.D., Chair \\ Edward Sabolsky, Ph.D. \\ Steven Woodruff, Ph.D. \\ Xuyean Song, Ph.D. \\ Jacky C. Prucz, Ph.D. \\ Department of Mechanical and Aerospace Engineering \\ Morgantown, West Virginia \\ 2017
}

Keywords: load-depth sensing indentation, constant load indentation, 


\begin{abstract}

\section{Development of a spherical micro-indentation test methodology} for creep analysis and on-set of tertiary creep for solder alloys
\end{abstract}

\author{
Dumbi Azubuike Otunyo
}

The continuous miniaturization of electronic devices and systems demands more understanding of the creep deformation and stress relaxation of solder alloys in order to improve the structural integrity of electronic devices and systems. Creep is characterized by a slow, time-dependent deformation of the material under constant stress or force. These solder alloys are often subjected to time-dependent deformation during service conditions, hence strain-time relationships obtained from creep experiments are used to analyze the deformation mechanism of mechanical structures and electronic interconnects under stress controlled conditions. Recently, instrumented indentation methods were proposed to study creep deformation mechanism as well as determining creep parameters. Instrumented indentation is advantageous when the material is only available as small test pieces or the area of interest is limited to a small area or feature. Soft materials such as lead alloys present difficulties when machining samples for use in traditional material property evaluation tests such as tensile tests. Therefore instrumented indentation can provide a simple testing methodology for investigating creep mechanical properties of solder alloys.

In this research, material time-dependent behavior of $\mathrm{Sn} 3.5 \mathrm{Ag}$, Sn37Pb and $\mathrm{Sn} 5 \mathrm{Sb}$ solder alloys were studied by a unique depth sensing micro-indentation method at room temperature. Stress exponent values were determined through a constant loading process utilizing a spherical micro indentation method, where the strain rate is extracted from the indentation rate. The measured stress exponent values are in good agreement with conventional creep experiments. Utilizing a multiple loading and partial unloading micro-indentation testing procedure, time-dependent stiffness changes of these materials could be measured. This continuous stiffness responses during a creep test can be correlated to test materials micro structural changes during creep, therefore making it capable to predict onset of tertiary creep failure. Test results show a correlation between measured continuous stiffness response and creep damage with the capability to predict the onset of tertiary creep of these solder alloys. 


\section{ACKNOWLEDGMENTS}

I would like to thank my advisor Dr. Bruce Kang for giving me such a wonderful opportunity to work with him on such an exciting topic. I would also like to thank my thesis committee members, Dr Edward Sabolsky, Dr. Steven Woodruff, Dr. Xuyean Song and Dr. Jacky C. Prucz for their help and technical support

I would also like to thank my friends, family and the Benjamin M. Statler College of Engineering for their support during my tenure as a graduate student at the West Virginia University. 


\section{TABLE OF CONTENTS}

Page

ACKNOWLEDGMENTS. . . . . . . . . . . . . . . . . . iii

LIST OF FIGURES . . . . . . . . . . . . . . . . . . . . viii

\section{Chapter}

1. INTRODUCTION . . . . . . . . . . . . . . . . . . . 1

1.1 Background. . . . . . . . . . . . . . . . . .

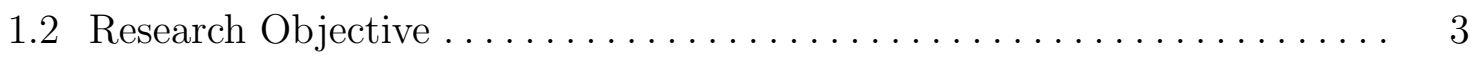

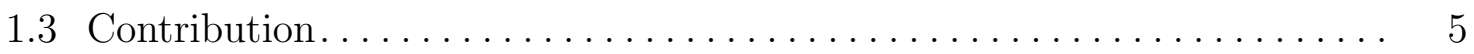

2. CONTACT MECHANICS . . . . . . . . . . . . . . . . 6

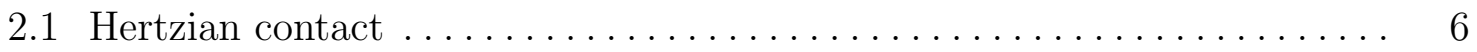

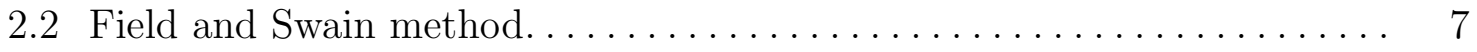

2.3 Doerner and Nix method $\ldots \ldots \ldots \ldots \ldots \ldots \ldots \ldots \ldots \ldots \ldots \ldots \ldots$

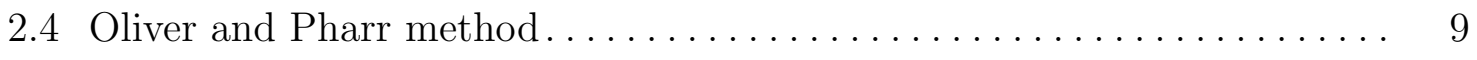

2.5 Elastic-plastic regime in indentation $\ldots \ldots \ldots \ldots \ldots \ldots \ldots \ldots \ldots \ldots$

3. INSTRUMENTED INDENTATION . . . . . . . . . . . . . . . . 13

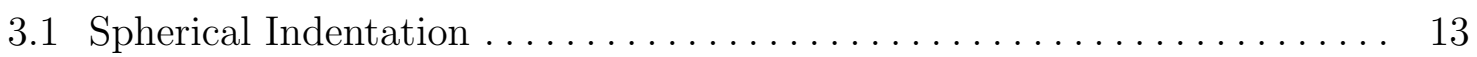

3.2 Instrumented Indentation Data Analysis . . . . . . . . . . . . . 15

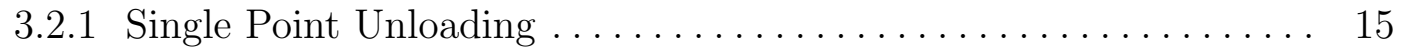

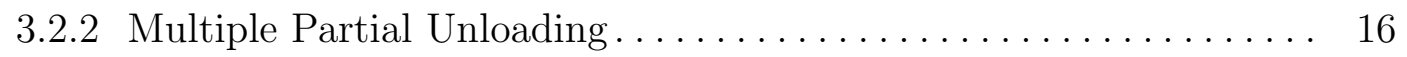

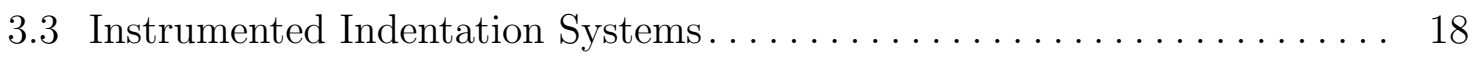

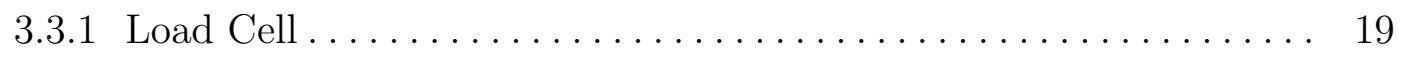

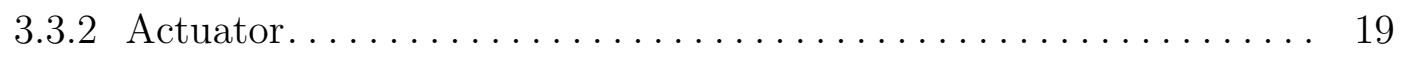

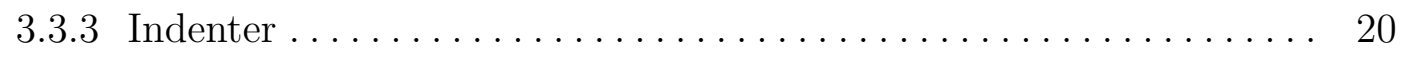

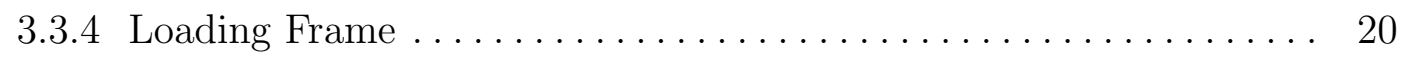

3.4 High Temperature Indentation $\ldots \ldots \ldots \ldots \ldots \ldots \ldots \ldots \ldots \ldots \ldots \ldots \ldots \ldots \ldots$

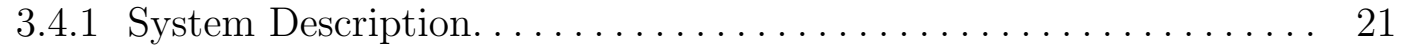


4. CREEP ..................... . . . 23

4.1 Power-Law Creep................................... 25

4.2 Creep Steady State Microstructure ......................... 26

4.3 Room Temperature Indentation Creep Literature Review ........... . 27

4.3.1 Indentation Creep from Vickers Hardness ................. 27

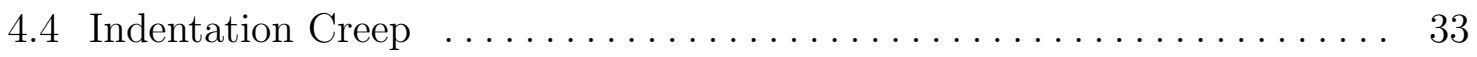

4.4.1 Indentation Load Relaxation (ILR) .................... 37

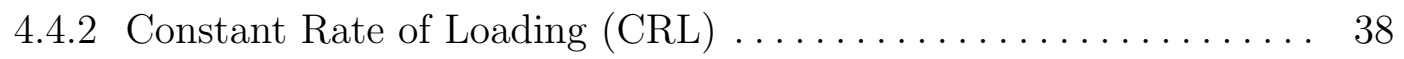

4.4.3 Step Constant Indentation Strain Rate . . . . . . . . . . . . . . . 39

4.4.4 Constant Load- Hold ................................... 41

4.5 Development of Constant Load-Hold $\ldots \ldots \ldots \ldots \ldots \ldots \ldots \ldots \ldots \ldots . \ldots 2$

4.5.1 Development of Constant Load-Hold Lab View Software IV . . . . 42

4.5.2 Development of Constant Load-Hold Lab View Software IV Block

Diagram ..................................... 44

4.6 Development of Constant Load-Hold with multiple partial unloading . . 48

5. RESULTS AND CONCLUSIONS . . . . . . . . . . . 52

5.1 Close-Loop Load Control.................................... 52

5.2 Indentation Creep Stress Exponent determination ............... 53

5.3 Traditional Tensile Creep test ............................... 55

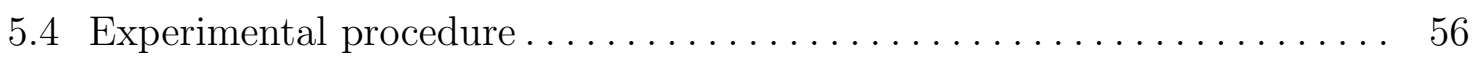

5.5 Creep Continuous Stiffness Response CCSR. ................... 60

5.6 Remaining Life Creep Continuous Stiffness Response CCSR. . . . . . . . . 65

5.7 Conclusions..................................... 67

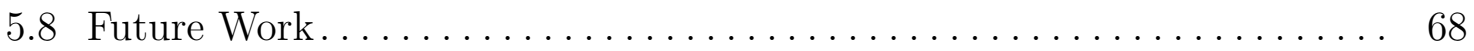

REFERENCES. . . . . . . . . . . . . . . . 69 


\section{LIST OF FIGURES}

Figure 2.1 Geometry of impression by indentation ................. 8

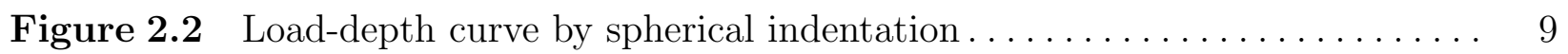

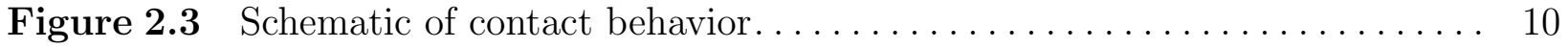

Figure 3.1 Contact deformation between two spheres $\ldots \ldots \ldots \ldots \ldots \ldots \ldots \ldots \ldots$

Figure 3.2 Pile-up and sink-in (not simultaneously) occurring during spherical

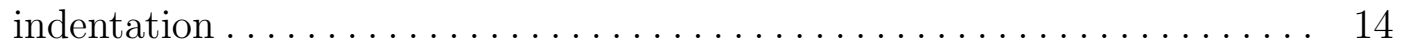

Figure 3.3 Load displacement curve for single point unloading algorithm... . . . . 16

Figure 3.4 Load displacement curve for multiple partial unloading algorithm. . . . . 17

Figure 3.5 Instrumented indentation system loading chain schematic . . . . . . . 19

Figure 3.6 High temperature indentation system loading frame design; a) i: glass fiber insulation, ii: furnace heating element, iii: sample, iv: spherical sapphire $750 \mu \mathrm{m}$ radius indenter, v: alumina indenter rod, vi: $0.8 \mathrm{~nm}$ resolution Physik Instrumente P-246.7S 120 $\mu \mathrm{m}$ piezoelectric actuator, vii: $0.1 \%$ accuracy Honeywell Model 75100 lb. load cell and b) optical

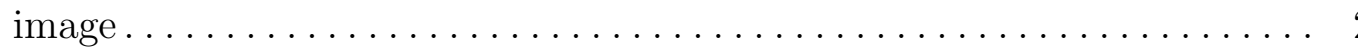

Figure 4.1 Creep diagram in uniaxial tension: primary (unsteady) creep (I)

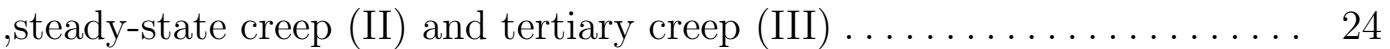

Figure 4.2 Indentation creep curves at different temperatures $\ldots \ldots \ldots \ldots \ldots \ldots$

Figure 4.3 Indentation creep curves at different temperatures $\ldots \ldots \ldots \ldots \ldots \ldots \ldots$

Figure 4.4 Indentation creep curves at different temperatures $\ldots \ldots \ldots \ldots \ldots \ldots \ldots 2$

Figure 4.5 Derivation of stress exponent by the Juhasz et al. method . . . . . . . . 32

Figure 4.6 Derivation of stress exponent by the Juhasz et al. method . . . . . . . 33

Figure 4.7 Derivation of stress exponent by the Juhasz et al. method . . . . . . . . 34 
Figure 4.8 Derivation of stress exponent by the Mulhearn-Tabor method . . . . . . 35

Figure 4.9 Derivation of stress exponent by the Mulhearn-Tabor method . . . . . 36

Figure 4.10 Derivation of stress exponent by the Mulhearn-Tabor method . . . . . 36

Figure 4.11 Derivation of stress exponent by the Sargent-Ashby method. . . . . . . 37

Figure 4.12 Derivation of stress exponent by the Sargent-Ashby method. . . . . . . . 38

Figure 4.13 Derivation of stress exponent by the Sargent-Ashby method. . . . . . . . 39

Figure 4.14 Variation of Indentation Length with Time . . . . . . . . . . . . 41

Figure 4.15 Front Panel for Constant Load-Hold . . . . . . . . . . . . . . . . . . . . 43

Figure 4.16 Parameter Control Panel . . . . . . . . . . . . . . . . . . . . . 44

Figure 4.17 Displacement Vs Time graph $\ldots \ldots \ldots \ldots \ldots \ldots \ldots \ldots \ldots \ldots \ldots \ldots$

Figure 4.18 Change in Load graph $\ldots \ldots \ldots \ldots \ldots \ldots \ldots \ldots \ldots \ldots \ldots \ldots \ldots$

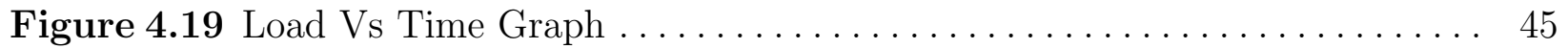

Figure 4.20 Block Diagram $\ldots \ldots \ldots \ldots \ldots \ldots \ldots \ldots \ldots \ldots \ldots \ldots \ldots \ldots \ldots \ldots \ldots \ldots \ldots \ldots$

Figure 4.21 Write to Measurement block diagram $\ldots \ldots \ldots \ldots \ldots \ldots \ldots \ldots \ldots \ldots$

Figure 4.22 Load Control Block diagram False condition . . . . . . . . . . . . . . . . . 49

Figure 4.23 Load Control Block diagram True condition $\ldots \ldots \ldots \ldots \ldots \ldots \ldots \ldots$

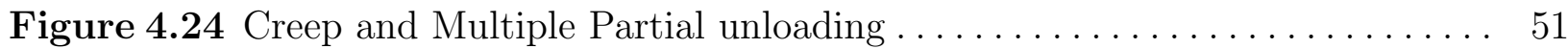

Figure 5.1 Indentation Load Versus Time $\ldots \ldots \ldots \ldots \ldots \ldots \ldots \ldots \ldots \ldots \ldots \ldots$

Figure $5.2 \quad \mathrm{Sn} 37 \mathrm{~Pb}$ Displacement time curve $\ldots \ldots \ldots \ldots \ldots \ldots \ldots \ldots \ldots \ldots$

Figure 5.3 Sn3.5Ag Displacement time curve $\ldots \ldots \ldots \ldots \ldots \ldots \ldots \ldots \ldots \ldots$

Figure $5.4 \quad$ Sn5Sb Displacement time curve $\ldots \ldots \ldots \ldots \ldots \ldots \ldots \ldots \ldots \ldots$

Figure 5.5 Time to Rupture $\operatorname{Sn} 3.5 \mathrm{Ag} \ldots \ldots \ldots \ldots \ldots \ldots \ldots \ldots \ldots \ldots \ldots \ldots \ldots \ldots \ldots \ldots$

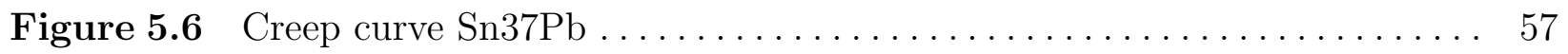

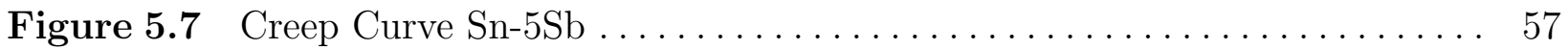


Figure 5.8 Derivation of Stress Exponent fo $\mathrm{Sn} 37 \mathrm{~Pb} \ldots \ldots \ldots \ldots \ldots \ldots \ldots \ldots$

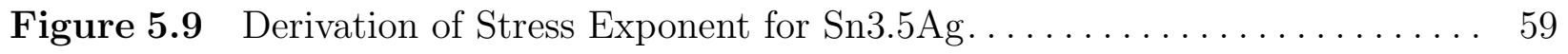

Figure 5.10 Derivation of Stress Exponent for $\mathrm{Sn} 5 \mathrm{Sb} \ldots \ldots \ldots \ldots \ldots \ldots$

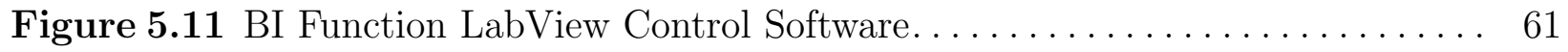

Figure 5.12 Stiffness Response During Indentation Creep . . . . . . . . . . . . 62

Figure 5.13 Creep Contact Stiffness Response Low depth Sensing . . . . . . . . 63

Figure 5.14 Creep Contact Stiffness Response High depth Sensing . . . . . . . . . 63

Figure 5.15 $\mathrm{Sn} 37 \mathrm{~Pb}$ with Low Strain Hardening showing low variation in stiffness response from Low and High depth sensing . . . . . . . . . . . . 64

Figure 5.16 Sn3.5Ag with high strain hardening showing large variation in stiffness response from Low and High depth sensing ............... 65 


\section{CHAPTER 1}

\section{INTRODUCTION}

\section{$1.1 \quad$ Background}

Solder alloys are widely used in the microelectronics industry. They are intended to provide electrical, thermal and mechanical continuity to silicon packages and hence a crucial factor in reliability prediction modelling of silicon packages. These alloys are normally used at room high homologous temperatures, being at $0.65 \mathrm{Tm}$ at room temperature (Where Tm represents the material melting point). Solder alloys operation time, temperature and stress dependent response make constitutive modelling a difficult task. Indentation on the other

hand has gained popularity as an experimental tool to determine the material properties of specimens available in small volumes.

Solder Joint Fatigue is a key cause of product failure in many environments. Solder joint fatigue failures are becoming more prevalent due to continued shrinkage of solder joint size and pitch that comes with more advanced packages. Thermo-mechanical fatigue of solder joints is one of the primary wear out mechanisms in electronic products and is true in products used outside of consumer environments due to longer required lifetimes and more severe operating conditions. Measurement techniques are constantly being improved through intensive research in order to accurately obtain mechanical properties of materials. Indentation is one of the more mature techniques being developed. Indentation tests have for a long time been a standard method for material characterization, which consists of loading an indenter made of diamond or any other hard material and pressing it into the surface of a softer material to be examined. The load-depth relation and unloading characteristics are then studied extensively experimentally or numerically to determine the relevant mechanical behavior or properties. The use of the initial unloading stiffness of the load-depth 
curve to determine a materials Young's Modulus[2, 3, 4, 5] is well accepted. Sneddon's [2] classical elastic indentation solutions which describe the general relationship among the load, displacement and contact area for any punch was the backbone for indentation, since methods of determining Young's modulus, creep and case depth of materials have been established.Utilizing instrumented indentations, Doerner and Nix [5] further investigated the unloading characteristics. In 1992 Oliver and Pharr [4] showed that Bulychev's technique can be applied to any indenter that can be described as a body of revolution of a smooth function. The results showed that the load-displacement relationships for many simple punch geometries can conveniently be written as:

$$
P=\alpha h^{m}
$$

where $\mathrm{P}$ is the indenter load, $\mathrm{h}$ is the elastic displacement of the indenter, and $\alpha$ and $m$ are constants. Values of the exponent $\mathrm{m}$ for some common punch geometries are $m=1$ for flat cylinders, $m=2$ for cones, $m=1.5$ for spheres in the limit of small displacements, and $m=1.5$ for paraboloids of revolution.

Creep is a mechanical property seen in numerous applications. Electronic equipment manufacturers are concerned about the contribution of creep to the failure of solder-joint interconnects which operate at elevated temperatures for extended periods. Indentation is used for measuring the constitutive properties of creep, including the stress exponent and activation energy. These materials have multiple mechanisms of creep which can be detected using instrumented indentation creep.

One of the driving forces in the gas turbine industry is the increased efficiency resulting in less fuel consumption and environmental pollution. Thermal Barrier Coating (TBC) systems however, coated on hot section components (combustion chamber tiles and rotating blades) of land-based gas turbines increases structural potentials in the resistance against hot corrosive and oxidative environments. Micro-indentation stiffness response is one of the techniques used to characterize failure modes for this complex TBC systems [6]. 
In the automotive industry, efficient quality control of parts production is a major issue. Particularly inspection of case hardened materials involve the destruction of produced parts to verify quality of carbonization during heat treatment in the manufacturing process. This reduces the frequency of quality inspections within auto motive manufacturing companies. Most automotive companies will inspect 5 out of 500 parts produced in a day for quality control assurance. This is attributed to the destructive nature of current evaluation techniques present and high costs of the non-destructive evaluation technologies.

During indentation the contact area and initial unloading stiffness are the key parameters to be identified. Direct measurement of the contact area is not feasible, so unloading stiffness is typically used to estimate the contact area through some iterative algorithm. High precision sensors are needed to accurately obtain the load-depth curve and unloading stiffness data.

Recently a Transparent Indenter Measurement (TIM) technique has been developed $[7,8]$, by integrating a Twyman-Green type interferometer into the spherical transparent indenter head. This system measures the indentation-induced out of plane deformation as well as the indented surface which evaluates the young's modulus without unloading stiffness.

A second generation TIM technique developed at West Virginia University is capable of measuring multiple partial unloading utilizing micro-indentation to evaluate Young's modulus without the use of high precision depth sensors. This second generation TIM multiple partial unloading technique was further developed to evaluate Young's modulus at elevated temperatures and controlled environment without the use of depth precision sensors $[9,6]$.

\subsection{Research Objective}

In this research, we present a load-based micro-indentation technique for material property measurement, creep degradation evaluation of solder alloys at homologous temperatures. Solder alloys $\mathrm{Sn} 3.5 \mathrm{Ag}, \mathrm{Sn} 37 \mathrm{~Pb}$ and $\mathrm{Sn} 5 \mathrm{Sb}$ were tested at homologous temperatures. The time-dependent evaluation of the stiffness response during the creep reveals the test 
materials microstructural changes over time as a function of creep. Test results show a correlation to creep damage of the test materials not normally detectable through regular creep indentation methodologies

It is extremely difficult in reality to characterize creep damage of solders utilizing methods such as tensile test, scanning electron microscopy and X-ray system due to the sample size required to perform such tests. The objective of our research is to contribute a method for utilizing depth-sensing indentation techniques to measure the time dependent mechanical properties of materials, such as creep and stiffness response of materials during creep. Understanding the response of a material to an applied force deals with elastic deformation where the strains are nearly instantaneous, elastic deformation where the strains are not instantaneous but rather dependent on time and plastic deformation where the material undergoes non-recoverable strain.

Time dependent phenomena involves creep techniques where load, stress or strainrate is held constant for a period of time ranging from seconds to hours while the response of the material is monitored. The other time dependent phenomena utilizes frequency specific dynamic techniques where the load or stress is varied at a single frequency during which the response of the material is measured. It is possible to perform these tests utilizing bulk testing techniques such as tensile tests, but in many instances due to advanced design concepts requiring smaller volumes of materials, these bulk testing techniques are rendered impractical. This is seen in thin film devices found in the microelectronics industry where solders are used in LED modules used for headlamp illumination, individual cell walls in stress or even the diseased arterial tissue found within the human body. It is possible for specimens mentioned in these cases to be prepared in a form that allows for testing with standard uniaxial techniques. These sample preparation techniques can be tedious and may alter the properties of the area of interest. Growing technology has made it necessary to find an alternate means for mechanical characterization. Depth-sensing indentation has been proven to be a reliable technique for measuring mechanical properties of such small volumes 
of materials such as Young's modulus and Hardness values.

In this study, a second generation TIM micro-indentation package will be created and utilized to measure both time dependent plasticity Creep and Stiffness response during indentation creep.

\subsection{Contribution}

In this research, I will be contributing a new indentation methodology that will bridge the gap in non-destructive evaluation of time dependent mechanical properties of materials, specifically creep and creep stiffness response.

I will propose new indentation methodology capable of characterizing load depth response of solder materials during creep. Traditional creep methods are only capable of determining stress exponents, proposed indentation methodology will be capable of characterizing material stiffness response during creep, which will then be correlated to creep damage of materials. 


\section{CHAPTER 2}

\section{CONTACT MECHANICS}

\subsection{Hertzian contact}

The stresses and deflections arising from the contact between two elastic solids have practical applications in hardness testing, wear and impact damage of engineering materials. In many cases the contact between a rigid indenter and a flat extensive specimen is off particular interest. The most well-known scenario is the contact between a rigid sphere and flat surface, where Hertz [10] found that the radius of a circle of contact a is related to the indenter load $P$ the indenter radius $R$ and the elastic properties of the materials by:

$$
a^{3}=\frac{3 P R}{4 E_{R}}
$$

Where $E_{R}$ is the combined modulus of the indenter and the specimen defined by the elastic modulus and Poisson's ratio of two bodies. Thus the reduced modulus is expressed by Equation 2.1. $\mathrm{R}$ is the relative radius and defined as shown in Equation 2.3.

$$
\begin{gathered}
\frac{1}{E_{R}}=\frac{1-v^{2}}{E_{1}}+\frac{1-v^{\prime 2}}{E_{2}} \\
\frac{1}{R}=\frac{1}{R_{1}}+\frac{1}{R_{2}}
\end{gathered}
$$

The mean contact pressure, $p_{m}$ is given by the indenter load divided by the projected contact area shown in Equation 2.4. Equation 2.5 is derived by substituting Equation 2.4 into Equation 2.1

$$
p_{m}=\frac{P}{\pi a^{2}}
$$




$$
p_{m}=\frac{P}{\pi a^{2}}=\left[\frac{4 E_{R}}{3 \pi}\right] \frac{a}{R}
$$

Indentation tests offer load-depth data, Figure 2.2 shows a schematic of indentation of this relationship. Indentation processes are complex and related not to only elastic, but elasticplastic material behavior as well. Hertz governing contact mechanics equations have since been applied in various indentation research initiatives. For elastic deformation, the total indentation depth is employed and the rigid body motion is reformulated as Equation 2.6, where $h_{e}$ is elastic indentation depth. This Equation 2.6 presents a clear relationship between applied load and elastic indentation depth, therefore this is used as a basic equation for elastic indentation[11].

$$
P=\frac{4}{3} E_{R} R^{\frac{1}{2}} h_{e}^{\frac{3}{2}}
$$

\section{$2.2 \quad$ Field and Swain method}

Indentation may be wholly elastic, elastic/plastic, or wholly plastic, and the mix of these responses is subtly reflected in the loading and unloading process. Many early models included only elastic behavior under the assumption that unloading is a purely elastic process. Field and Swain [12] suggested an indentation method using single partial unloading. Hertz showed the contact area, Equation 2.1 and substituted into Equation 2.6. The relationship between contact radius and elastic indentation depth can be defined as Equation 2.7. Equation 2.7 is translated in terms of contact radius, thus Hertz's elastic contact solution is defined as shown in Equation 2.8. The relationship between total depth and contact depth is shown in Figure 2.1

$$
\begin{gathered}
a^{2}=R h_{e} \\
P=\frac{4}{3} E_{R} a h_{e}
\end{gathered}
$$

Since the contact depth is arranged by the "total depth $h_{t}$ and elastic depth $h_{e}$ ", it 


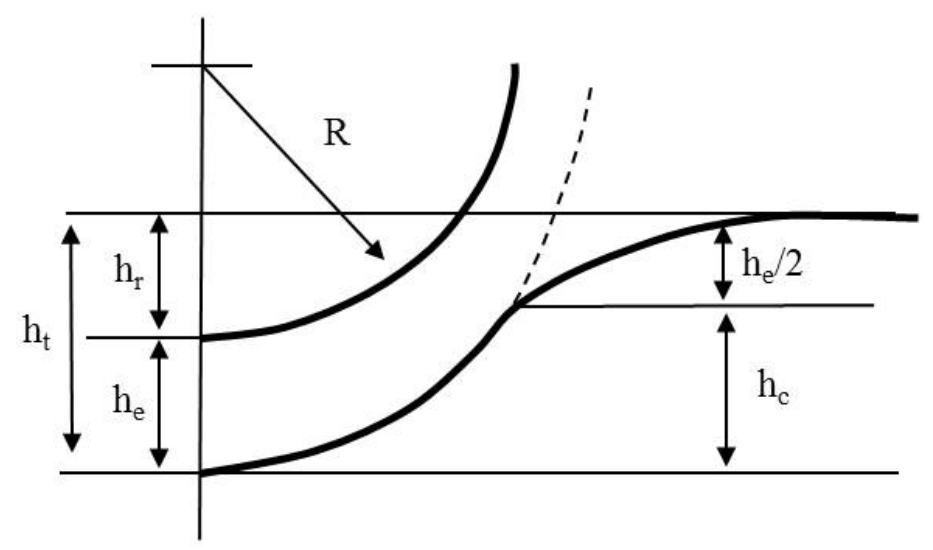

Figure 2.1 Geometry of impression by indentation

is calculated by the total depth and residual depth, Equation 2.9 and Equation 2.10

$$
\begin{gathered}
h_{e}=h_{t}-h_{r} \\
h_{c}=h_{t}-\frac{e}{2}
\end{gathered}
$$

\subsection{Doerner and Nix method}

Doerner and Nix [5] figured out that during the unloading procedure contact radius remains constant until a plastic regime is reached. Due to this, initial unloading slopes within the load-depth curve were found to be linear. Utilizing this phenomenon, a relationship between elastic indentation depth, maximum load, unloading slope and indenter geometry was established by Sneddon [2].It has already been observed in cylindrical punch indentation that the unloading slope is linear until full unloading and the contact radius is the same. Thus Doerner and Nix used cylindrical punch method to determine the contact depth and contact area. Since an easy way to determine contact depth is developed, the contact depth has been determined by extrapolation from initial unloading slope to zero load as shown in Figure 2.2. The contact area is rearranged to give Equation 2.11 and the unloading slope is 


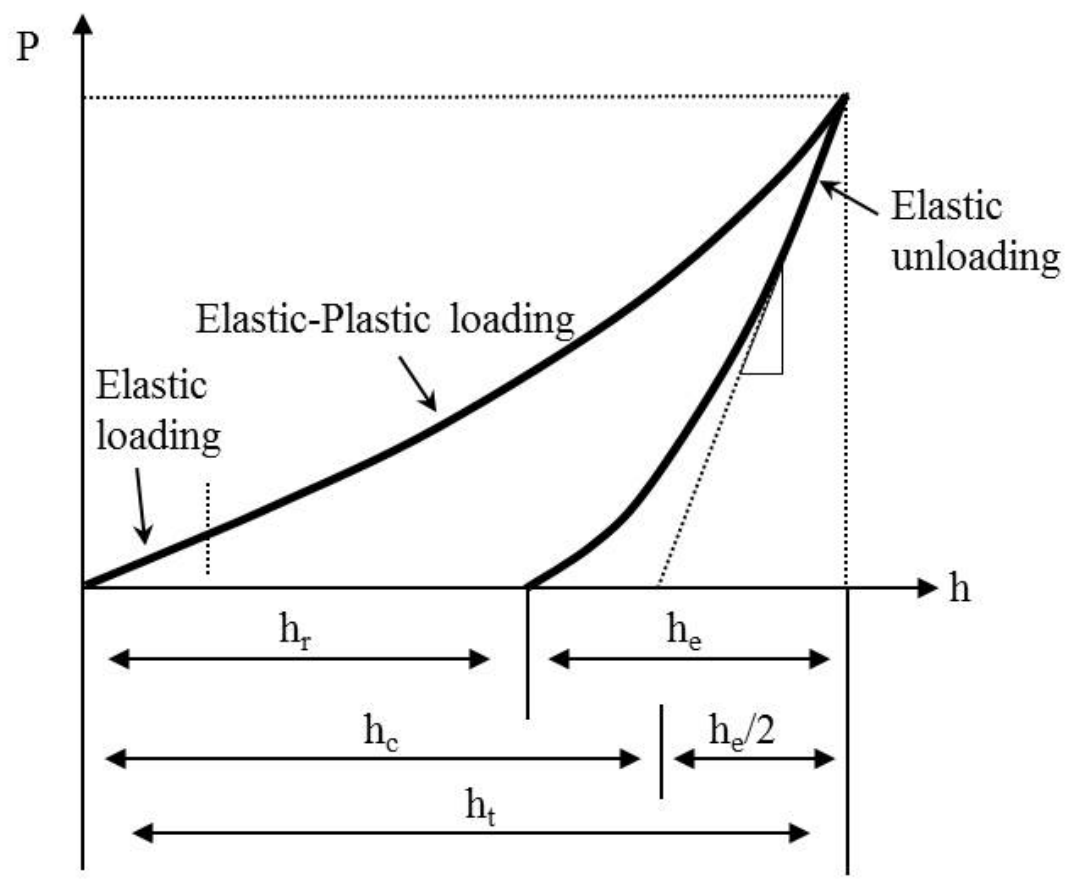

Figure 2.2 Load-depth curve by spherical indentation

given by Equation 2.12

$$
\begin{gathered}
A=24.5 h_{c}^{2} \\
\frac{d P}{d h}=2 h_{c} E_{R} \sqrt{\frac{24.5}{\pi}}
\end{gathered}
$$

\subsection{Oliver and Pharr method}

Contact radius can be related to contact depth and indentation radius utilizing Equation 2.13. Where $h_{c}$ is contact depth caused by plastic deformation. The Hertzian loading technique has been adapted to measure the strength and flaw density distribution for transparent brittle materials. Replacing the steel or tungsten carbide spherical indenter, normally used in Hertzian strength measurements, by a sapphire hemisphere enables direct observa- 


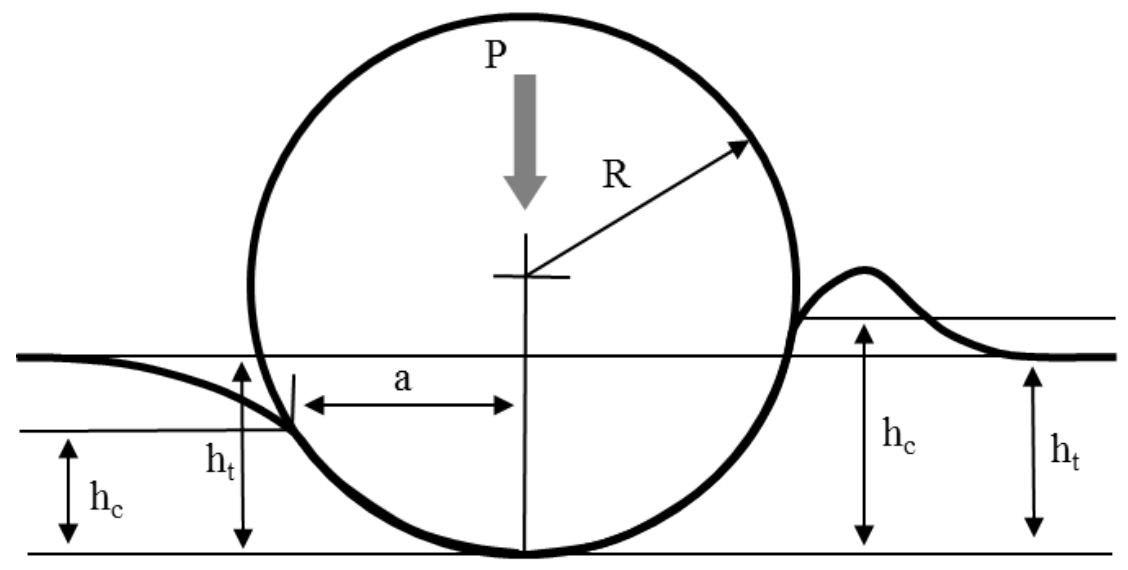

Figure 2.3 Schematic of contact behavior

tion of the formation of cracks in opaque brittle materials [13]. Figure 2.3 shows sink in and pile up behavior during contact deformation which is experimentally observed during spherical indentation.

$$
a=\sqrt{2 h_{c} R-h_{c}^{2}} \approx \sqrt{2 h_{c} R}
$$

Previous models were expanded to incorporate elastic-plastic deformation around the indented region which established a relationship between total indentation depth and indenter contact area [14]. Sneddon suggested elastic depth for an elastic indentation solution, Equation 2.14.

$$
h_{e}=\epsilon \frac{P_{\max }}{\left(\frac{d P}{d h}\right)}
$$

Oliver and Pharr used Sneddon's elastic solution in order to represent contact depth with total indentation depth. $\epsilon$ is a coefficient for indenter shape found from experimental results and is related to material behavior, Equation 2.15 


$$
h_{c}=h_{t}-\epsilon \frac{P_{\max }}{\left(\frac{d P}{d h}\right)}
$$

Oliver and Pharr showed that the contact stiffness can be evaluated by power law equation with fitting the unloading data. $C, m$ and $h_{r}$ are determined by least-square fitting, Equation 2.16

$$
P=C\left(h-h_{r}\right)^{m}
$$

Doerner and Nix also defined contact area as a function of contact depth. Oliver and Pharr rearranged the contact area Equation 2.17

$$
A=\pi a^{2}=2 \pi h_{c} R
$$

This contact area has high accuracy when determining elastic modulus and other indentation measurements. Also in the case of adhesive contact, the reduced modulus can be calculated using unloading slope and contact area Equation 2.18. Where $\beta$ depends on indenter geometry and is 1 for a conical indenter.

$$
E_{R}=\frac{\sqrt{\pi} d P}{2 \beta \sqrt{A} d h}
$$

Sneddon's solution was implemented for the Oliver-Pharr method, the effects of the indenter angle and the Poisson's ratio were examined [15]. Elastic-plastic behavior has been considered, but these analytical models are derived under the basic assumption that the unloading process is purely elastic and tested against homogeneous isotropic material.

\subsection{Elastic-plastic regime in indentation}

During indentation, the elastic-plastic material behavior in indentation is very complex to describe exactly. Finite element methods have been widely employed in the study 
of elastic-plastic material behavior during indentation. D.J. Strange et al. conducted finite element analysis with two separate work hardeneing models and verified their accuracy by comparing experimental data [16]. I.S. Choi et al. conducted parametric finite element analysis studies of indentation for non-linear plastic materials by building a methodology for interpretations of depth sensing techniques [17]. Pile-up/sink-in behavior during indentation is known to be a function of strain hardening exponent and ratio of yield stress to elastic modulus [18]. Relationships between material properties and indentation parameters have been developed for which elastic-plastic properties were found without the use of contact radius measurements [19]. 


\section{CHAPTER 3}

\section{INSTRUMENTED INDENTATION}

Indentation is a mechanical testing process that has been used for hardness testing since the 1800's. A specific load for a specific time is applied to a given test material by using hard geometrical materials. Mechanical properties of the materials can then be evaluated using the material's response to the applied load. The materials reactions such as depth and area have been measured using various optical techniques. Indentation testing has quickly become helpful to all industrial sectors, including lumber, ceramics, and glass production. Indentation quickly became very popular in the nanotechnology industry due to its nondestructive evaluation ability to get mechanical properties of small volumes of materials.

Indentation is the primary technique used for the examination of thin films and coating materials due to their geometry and configuration. The similarity between instrumented indentation and hardness testing is that they both push a rigid indenter into the surface of an unknown sample using a specific load. The instrumented indentation then uses high resolution displacement or optical sensors to monitor the indentation size and depth throughout the evaluation procedure. Also the load-indentation depth plots obtained from these methods can be used to determine the materials mechanical property information. Brief reviews of these techniques are discussed below [9]

\subsection{Spherical Indentation}

Hertz during his time as a post doctorate realized that although much was known about the optical aspect of two lenses being placed together, no good understanding of the deflection occurring at the point of contact had been established [10]. Hertz became particularly concerned by the nature in which localized deformation and pressure between 


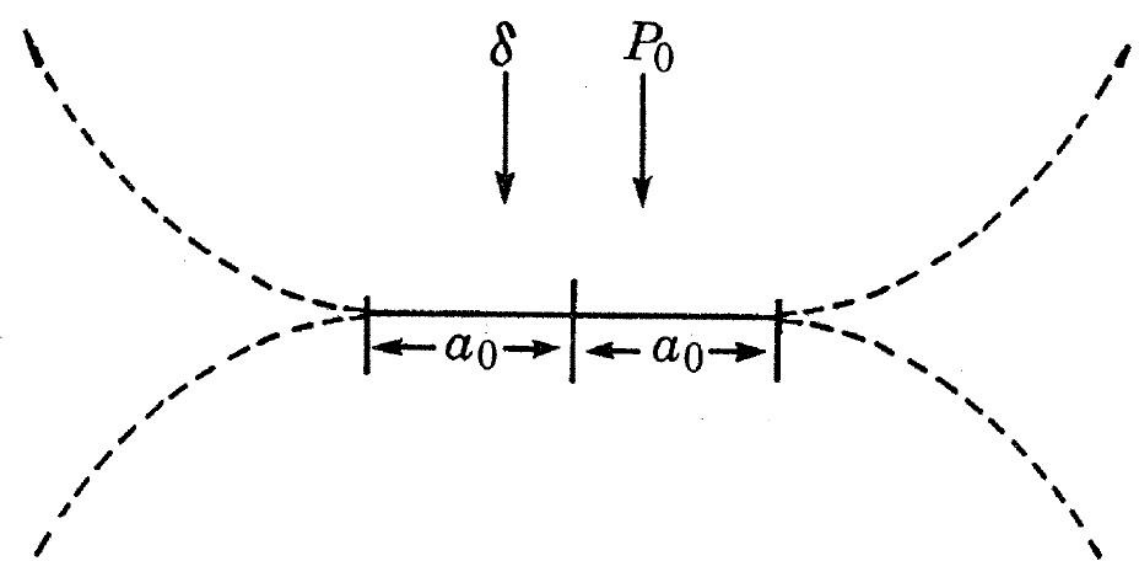

Figure 3.1 Contact deformation between two spheres

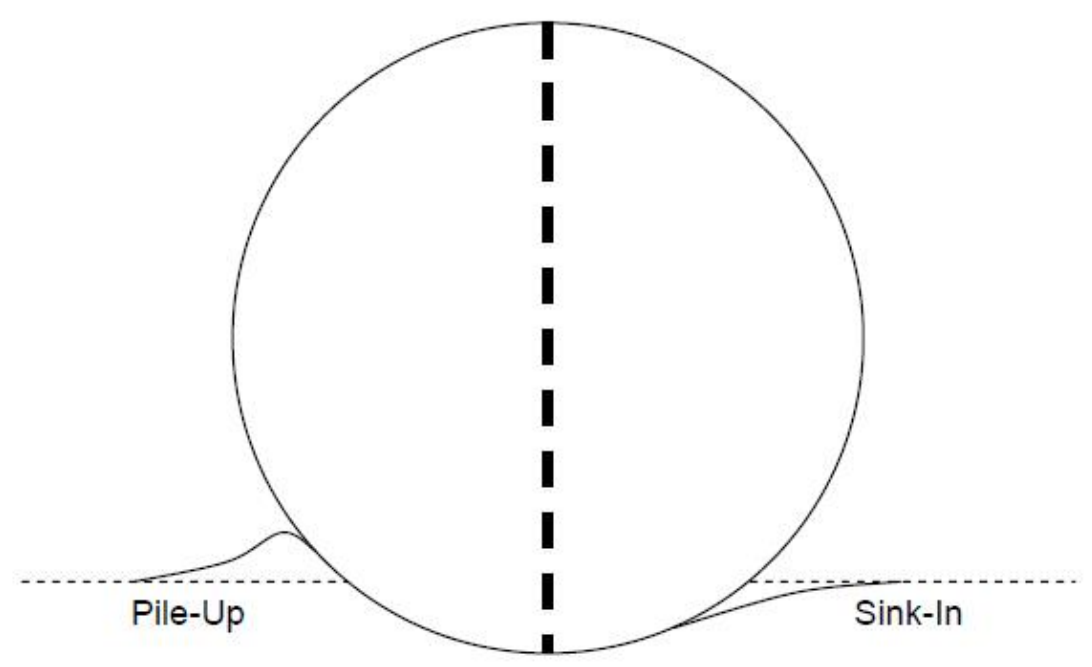

Figure 3.2 Pile-up and sink-in (not simultaneously) occurring during spherical indentation

the two spherical surfaces could be quantified Figure 3.1 [20].

Hertz's established the relationship between contact area and material properties from which all modern day contact mechanics theories are derived. During spherical indentation of an elastic material, the specimen's surface is typically drawn in and downwards toward the indenter, as a result, a sink in effect around the indenter is observed Figure 3.2. 


\subsection{Instrumented Indentation Data Analysis}

Hardness test involves the measurement of the indentation impression size directly, while instrumented indentation calculates this value with knowledge of the indenter's geometry and indentation depth. Due to this, instrumented indentation is often referred to as depth sensing indentation testing. Load and depth curves are recorded as load is applied to the indenter and specimen, which ultimately leads to the extraction of elastic modulus and hardness information from the test material. This applied load creates plastic deformation within the specimen directly beneath the indenter tip, causing a residual impression to remain following removal of the load. The depth of penetration together with the known indenter geometry provides an indirect measurement of contact area, from which an estimate of hardness is made. However elastic modulus calculation requires the acquisition of additional parameters, which are discussed below [6].

\subsubsection{Single Point Unloading}

Single point unloading uses only one slope within the load displacement curve to calculate the reduced modulus as shown in Figure 3.3. This provides an accurate measurement of the materials elastic response. Using Equation 3.1, elastic modulus is calculated, where contact area is calculated using a known indenter geometry and indentation depth $A=\pi a^{2}$ [4].

This technique is particularly popular in the material research community for its shallow penetration depth requirement. The shallow depths required, classify the technique to be relatively non-destructive, which permits samples composed of multiple layers, such as thin films, to be evaluated without interference from the substrate's material properties.

$$
E_{R}=\frac{1}{2} \frac{d P}{d h} \sqrt{\frac{\pi}{A}}
$$




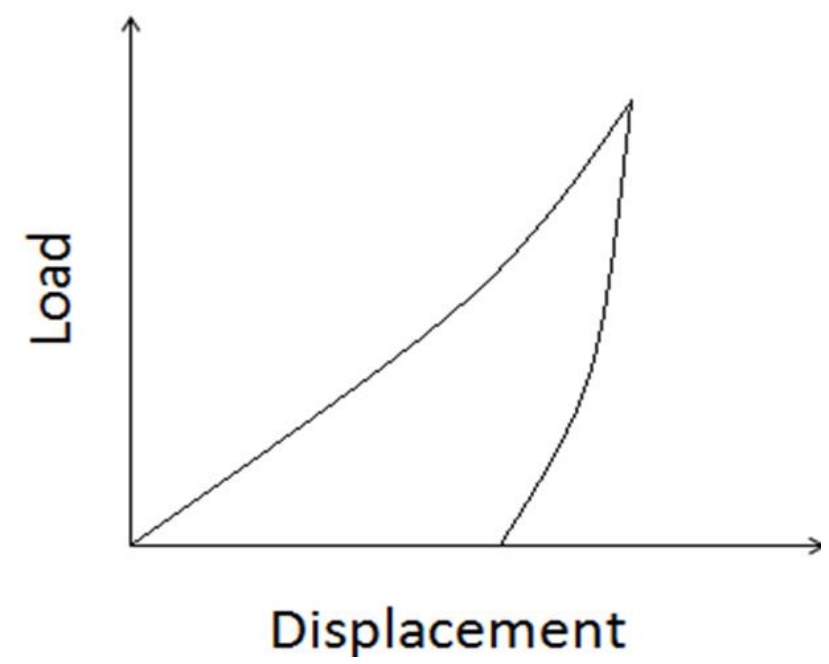

Figure 3.3 Load displacement curve for single point unloading algorithm.

\subsubsection{Multiple Partial Unloading}

Developed at West Virginia University, the first generation of instrumented indentation analysis data reduction techniques required the use of transparent sapphire spherical indenter. This transparent indenter measurement (TIM) system, with phase shifting Twyman-Green and Moir interferometer techniques directly measures the out-of-plane deformation and contact radius throughout the indentation process [21]. This technique requires the use of sophisticated optical systems to continuously measure the contact radii, which provides the platform for elastic modulus and true stress strain relationship. A second generation TIM data reduction technique was developed wherein a partial unloading procedure was employed to bypass the optical requirement Figure 3.4.

This principle operates under the assumption that the total displacement $h_{\text {total }}$ is the summation of total indentation depth $h$ and the system deflection $h_{s}$ Equation 3.2. Assuming the indentation unloading response is solely elastic, the elastic compliance $\frac{d h_{e}}{d P}$ is equal to the indentation compliance $\frac{d h}{d P}$ Equation 3.3 is gotten from the derivative of this function with respect to indentation load and replacing elastic compliance with indentation compliance. 


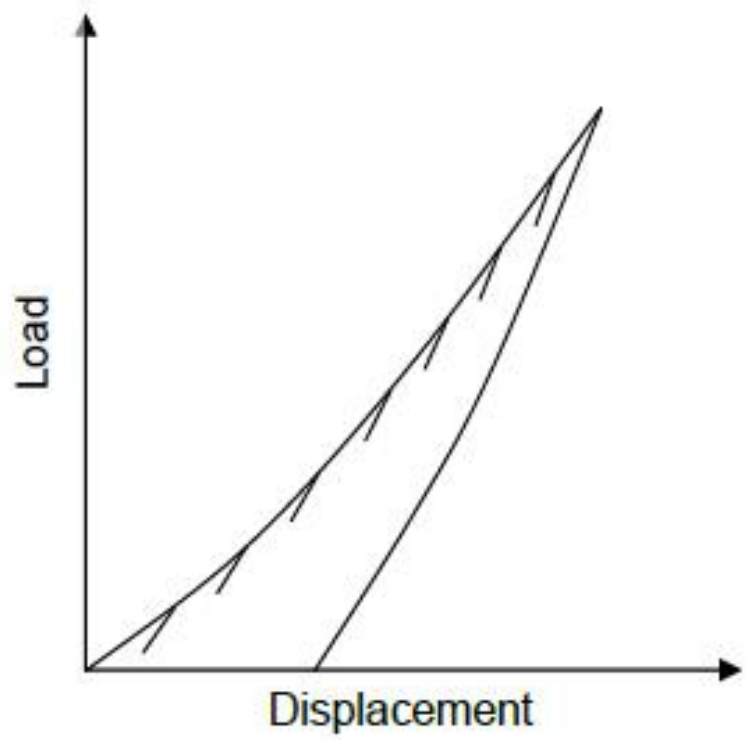

Figure 3.4 Load displacement curve for multiple partial unloading algorithm

$$
\begin{gathered}
h_{\text {total }}=h+h_{s} \\
\frac{d h_{\text {total }}}{d P}=\frac{1}{2 E_{R}} \sqrt{\frac{\pi}{A}}+\frac{d h_{s}}{d P}
\end{gathered}
$$

Assuming the system compliance $\frac{d h_{s}}{d P}$ remains constant throughout a given indentation test, a function containing only differences in contact area and slope between partial unloadings is developed Equation 3.4. Contact area and total displacement are the only nonconstant variables, therefore a function that requires only contact area and displacement is developed for the extraction of reduced modulus.

$$
E_{R}=\frac{1}{2} \sqrt{\pi}\left(\frac{1}{\sqrt{A}_{2}}-\frac{1}{\sqrt{A}_{1}}\right)\left({\frac{d h_{\text {total }}}{d P_{2}}}_{2}-\frac{d h_{\text {total }}}{d P_{1}}\right)^{-1}
$$

Multiple partial unloading technique does not require any optical contact area measurement. Therefore rewriting the Equation 2.6 in the form $P=\alpha h_{e}^{m}$, solving for $h_{e}$ and tak- 
ing the derivative of both sides with respect to $P$ yields Equation 3.5, where $\alpha=\left(\frac{4}{3}\right) E_{R} R^{-\frac{1}{2}}$, $m=\frac{3}{2}$ and $C=\left(\frac{1}{m}\right) \alpha^{\frac{1}{m}}$

As can be seen from Equation 3.5, the total displacement compliance $\left(\frac{d h_{\text {total }}}{d P}\right)$ and $p^{-\frac{1}{3}}$ maintain a linear relationship if and only if the system compliance $\left(C_{s}\right)$ remains constant throughout the multiple partial unloading steps. The slope $(C)$ can then be used in the determination of the reduced modulus Equation 3.6.

$$
\begin{gathered}
\frac{d h_{\text {total }}}{d P}=C P^{(1 / m)^{-1}}+\frac{d h_{s}}{d P} \\
E_{R}=\left(6 m^{3} R\right)^{-\frac{1}{2}}
\end{gathered}
$$

It is important to note that the single point unloading are incapable of obtaining this slope, thus require contact area or indentation depth measurements. Also the multiple partial unloading method on the other hand eliminates error due to high load application. Specifically, if a large load is applied, the resulting elastic modulus will be too large, same goes for if the load is too small, there would be an underestimation of the materials true elastic modulus.

\subsection{Instrumented Indentation Systems}

This complex method with a simplistic design and set up requires a vibration free environment for testing, due to the indentation chain components being extremely sensitive. This is accomplished by the use of an optical table as a steady platform, and the use of a rigid loading frame. The rigidity of the loading frame is essential in attaining the boundary conditions under which the equations for ideal contact mechanics are derived, unfortunately some level of system deflection exists. The system compliance is unavoidable, yet greater accuracy is achieved when the value is minimized. Figure 3.5 shows the current indentation system which comprises of a load cell, indenter, piezoelectric actuator and loading frame. 


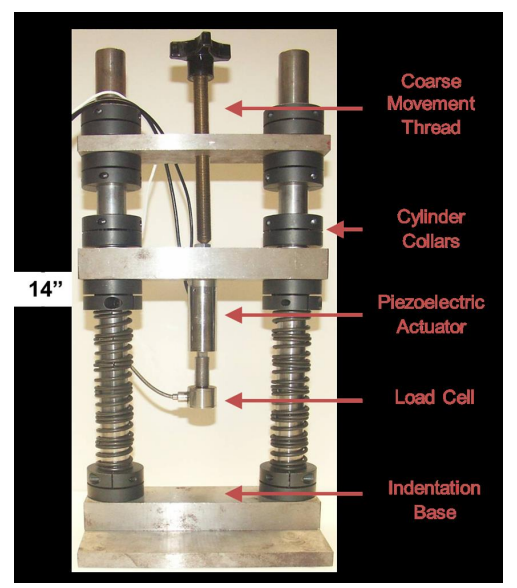

Figure 3.5 Instrumented indentation system loading chain schematic

The indentation chains components must meet the standard practices for instrumented indentation testing developed by ASTM International [22]

\subsubsection{Load Cell}

The load cell in an indentation system converts a load response to an electrical signal in the indentation system. Stress analysis is often performed by measuring strains on the surface of deformed elements. The electrical strain gauge is the most common choice for measurements of this strain [22]. Known for its accuracy and size the strain gauge load cells are extremely reliable. The electrical strain gauge can be used to determine the load when applied to a known material with known geometry. It is by this principle which the strain gauge load cell operates. It also requires a Wheatstone bridge configuration to amplify the source of electrical load signals to be acquired throughout the indentation test [23]

\subsubsection{Actuator}

The piezoelectric actuator consists of multiple piezoelectric discs and is a function of the applied electric field. Mechanical strain is produced when a voltage is applied to 
these materials. The piezoelectric actuator is typically used for depth sensing indentation applications due to its high resolution. Mechanical strain (displacement) similar to that of thermal expansion is produced when a voltage is applied to these materials. The active material of the positioning element is composed of piezoelectric disks. Separated by thin metallic electrodes, these elements provide a great deal of stiffness at high pressures, which provide stability through the indentation test [23].

\subsubsection{Indenter}

The choice of indenter used in the indentation system is of utmost importance and should depend on the choice of material being tested. Sharp indenters such as Vickers, Bekovich and Knoop induce plasticity earlier in the indentation process; hence they are used for determination of modulus of top coats of thin films. A Spherical indenter has a gradual transition from elastic to elastic-plastic response. This is good for determining strain hardening characteristics of test materials. The indenter material must be quite rigid and strain resistant. Common materials used for indenters are, sapphire, tungsten carbide and diamond. Sapphire indenters, although brittle are often the desirable choice for experiments due to their optical properties and cost [6].

\subsubsection{Loading Frame}

The loading frame, probably the most important aspect of an indentation system, usually made of steel, must be of heavy construction. The system compliance depends on the rigidity of the loading frame, which affect the accuracy of indentation results directly. The loading frame should be designed with specimen size and geometry in mind. In order to minimize system compliance, a rigid stabilizing or clamping element must be utilized at each joint [6]. 


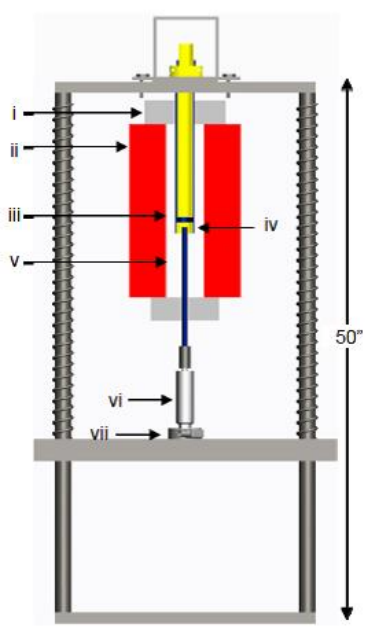

(a)

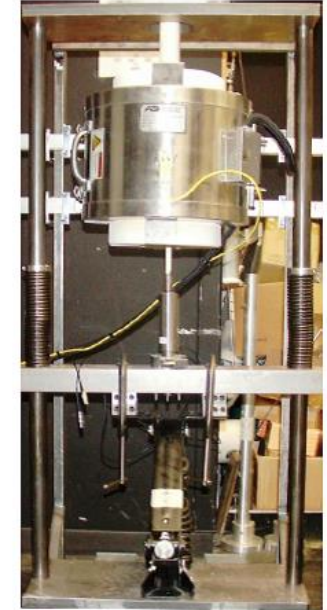

(b)

Figure 3.6 High temperature indentation system loading frame design; a) i: glass fiber insulation, ii: furnace heating element, iii: sample, iv: spherical sapphire $750 \mu \mathrm{m}$ radius indenter, v: alumina indenter rod, vi: $0.8 \mathrm{~nm}$ resolution Physik Instrumente P-246.7S $120 \mu \mathrm{m}$ piezoelectric actuator, vii: 0.1\% accuracy Honeywell Model $75100 \mathrm{lb}$. load cell and b) optical image

\subsection{High Temperature Indentation}

Instrumented indentation techniques are generally used for room temperature results. Mechanical property evaluation and characterization at elevated temperatures require an extension of this instrumented indentation system. Micro-indentation hardness tests performed on jadeite and diopside at temperatures between $300^{\circ} \mathrm{C}$ and $750^{\circ} \mathrm{C}$ have been conducted with high levels of accuracy [24]. A high temperature system developed at West Virginia University capable of utilizing the previously detailed multiple partial loading and unloading procedure for mechanical property evaluation will be discussed in detail below.

\subsubsection{System Description}

A high temperature system using multiple partial unloading micro indentation procedure was used to evaluate elastic modulus at elevated temperatures [9] Verification tests 
of this multiple partial unloading procedure at elevated temperatures have been discussed elsewhere [6]. This high temperature system consists of a low compliant frame structure with guide rails and boundary constraints as seen in Figure 3.6. The high temperature system is very rigid and allows for little system compliance. A custom indenter consisting of alumina rod with a semi-spherical lens linked to the center of the rod is used.This custom indenter is necessary to protect the highly delicate temperature sensitive components of the indentation chain from extremely high temperatures.An inverted indentation system is implemented in this high temperature indentation system, which allows heat lost to radiate in the direction opposite to that of the indentation chain. A sample constraint composed of both inner and outer ceramic tube is utilized for creating the boundary conditions required for idealized indentation throughout testing. The sample is clamped between the base of the inner tube, and the shelf of the outer tube.

This system is designed to perform instrumented indentation tests on samples at elevated temperatures and controlled environments. Details of elastic modulus tests performed using multiple partial unloading technique at elevated temperatures and controlled environment are detailed elsewhere [9]. 


\section{CHAPTER 4}

\section{CREEP}

Creep effects in metals are of a major concern amongst engineers, firstly because creep is observed in steam turbine components including pipework, discs and blading operating at high temperatures. Discs and blades are stressed by centrifugal forces which cannot be reduced by increasing the thickness; the working stress can only be reduced by designing the disc to have optimum profile. Therefore there is a direct need to asses the ability of materials to resist creep, and this is the major reason creep tests are performed [33].

The time-dependent behavior of creep is a process of plastic deformation under applied stress less than the yield stress. This phenomenon occurs in homologous temperatures (actual temperature divided by melting temperature)greater than $0.4\left(T>0.4 T_{M}\right)$

The aim of creep theory is to describe strains responding to various stress states, magnitude of stresses and temperatures. The basic results of a creep test are the strain versus time curve shown in Figure 4.1. Initially, the strain rate $\frac{d \epsilon}{d t}=\dot{\epsilon}$ decreases as a result of creep resistance of the material deformation with increasing strain (I). This is known as primary (unsteady) creep. The strain rate, eventually reaches a minimum and becomes near-constant $\left(\epsilon_{\min }^{\cdot}=\dot{\epsilon_{s s}}\right)$. This is known as secondary or steady-state creep (II). In tertiary creep (III), the strain-rate increases with strain. The steady-state region of the curve is the most important section of the creep deformation curve because it indicates how long the material can be used safely.

Ideally the creep deformation should be linked to an applied stress. Thus, as the specimen elongates, the cross sectional area decreases and the load needs to be decreased to maintain constant stress. The effect of a change in stress is only considered for large deformations, and only comes into play in the tertiary region. 


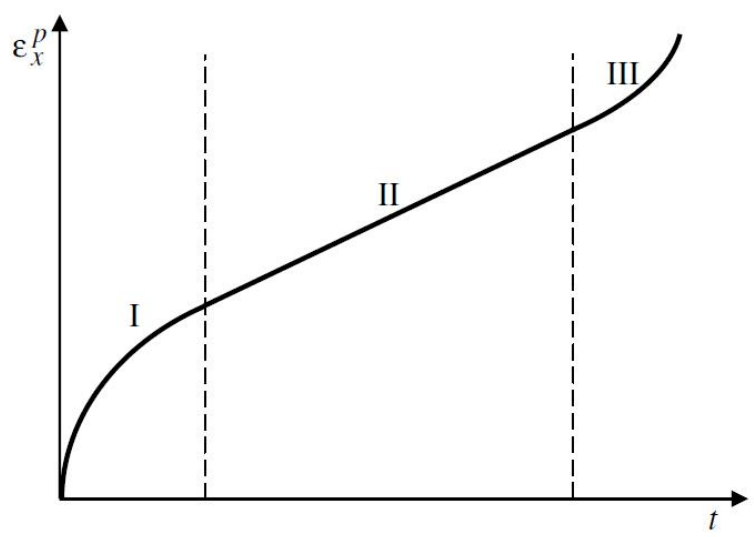

Figure 4.1 Creep diagram in uniaxial tension: primary (unsteady) creep (I), steady-state creep (II) and tertiary creep (III)

Creep mechanisms can be visualized by using superposition of various strain-time curves. Equation 4.1 describes the strain-time relation. Where $\beta$ is a constant for transient creep, and $k$ is related to the constant strain rate.

$$
\epsilon=\epsilon_{i}\left(1+\beta t^{\frac{1}{3}}\right) \exp (k t)
$$

A better fit is obtained from Equation 4.2, where $\mathrm{r}$ is a constant, $\epsilon_{t}$ is the strain at the transition from primary to secondary creep and $\dot{\epsilon}_{s s}$ is the steady-state strain rate.

$$
\epsilon=\epsilon_{i}+\epsilon_{t}(1-\operatorname{expt}(r t))+t \epsilon_{s s}^{.}
$$

There are no generally accepted forms of nonlinear strain-time relations, but Equation 4.3 is one form, where B, m, D, a and b are empirical constants. Equation 4.4 results if $t>t_{\text {transient }}$, which results in the strain rate being the steady-state or minimum strain rate as shown in Equation 4.5

$$
\epsilon=\epsilon_{i}+B \sigma^{m} t+D \sigma^{\alpha}(1-\exp (\beta t))
$$




$$
\begin{gathered}
\epsilon=\epsilon_{i}+B \sigma^{m} t+D \sigma^{\alpha} \\
\frac{d \epsilon}{d t}=B \sigma^{m}=\dot{\epsilon_{s s}}
\end{gathered}
$$

To consider the temperature effect, the model of Equation 4.5 can be written as an Artheniustype model:

$$
\frac{d \epsilon}{d t}=B \sigma^{m}=\dot{\epsilon_{s s}}=A \sigma^{n} \exp \left(\frac{-Q}{R T}\right)
$$

where $\mathrm{n}$ is the stress exponent, $\mathrm{Q}$ is the activation energy for creep, $\mathrm{R}$ is the universal gas constant and $\mathrm{T}$ is the absolute temperature. During an isothermal test, the exponential function of Equation 4.6 becomes a constant resulting in:

$$
\dot{\epsilon_{s s}}=\dot{\epsilon_{\text {min }}}=B \sigma^{n}
$$

Equation 4.7 can be linearized by taking logarithms of both sides as shown in Equation 4.8. Log-log plots of $\epsilon_{\min }^{\dot{ }}=\dot{\epsilon_{s s}}$ versus $\sigma$ often results in a bilinear relation in which the slope $\mathrm{n}$ (power law or diffusion creep) can be determined

$$
\log \dot{\epsilon}_{s s}=\log \dot{\min }^{\cdot}=\log B+n \log \sigma
$$

\subsection{Power-Law Creep}

The central idea of power law creep is that the creep rate, $\dot{\epsilon}$, at a given temperature depends both upon the applied stress, $\sigma$, and at least one strength factor, $\tau$

$$
\epsilon_{s s}=f(\sigma, \tau)
$$

During creep of a material under constant stress, the creep rate depends on how the strength parameter changes in the course of creep. Strain hardening and recovery increase 
and decrease the strength respectively and at steady state the rate of hardening equal to the rate of recovery [34]. By taking into account the appropriate expressions for hardening and recovery, it is possible to arrive at the Dorn equation that expresses the correlation of creep rates among various metals as a function of stress and temperature [35], which is expressed as:

$$
\dot{\epsilon_{s}}=A\left[\frac{\sigma}{G}\right]^{n} f(T)
$$

Where $f(T)$ is the temperature dependence which will be considered in the following section, $G$ is the shear modulus, $\mathrm{n}$ being the stress exponent which is defined as $d \ln \epsilon / d \ln \sigma$ at a constant temperature and $\mathrm{A}$ is a parameter which accounts for any effects of structure not included in the Dorn equation.

During indentation creep, the elastic modulus is one of the principal factors influencing the creep rate at a given level of stress. This is important because the speed of dislocation glide and climb are strongly influenced by the elastic stress fields of dislocations obstructing the path of moving dislocations.

\subsection{Creep Steady State Microstructure}

The formation of subgrains dominates the microstructural changes that occur during the creep flow in most annealed polycrystalline metals at temperatures above 0.5TM, where $T M$ is the homologous temperature which is actual temperature divided by the melting temperature of the alloy. The subgrain development is due to accumulation of edge dislocations by climb(polygonization) leading to the development of low-angle boundaries which are now universally called "subgrains". The subgrain structures that are associated with creep do not form instantaneously, they form gradually throughout the course of primary creep. In the initial stages of deformation, dislocations move through a well annealed crystal at speeds

approaching the speed of sound in the material [36].During which the dislocation density 
increases abruptly and dislocations are distributed in a homogeneous fashion [37]. This deformation happens until the inter dislocation stresses approach the applied stress, due to elevated temperatures, thermal activation allows continued dislocation motion past obstacles and deformation can continue. Steady state creep coincides with the development of a steady state substructure which is characterized by the condition that the average dislocation density and the subgrain size remain constant with further creep strain[38].

\subsection{Room Temperature Indentation Creep Literature Review}

\subsubsection{Indentation Creep from Vickers Hardness}

It is generally accepted that the mechanical behaviour of metallic materials at homologous temperatures higher than 0.5 can be fairly expressed by the power-law creep in a wide range of strain rates. Thus, for steady- state creep, the relationship between the strain rate, state, and the tensile stress, $r$, at a constant temperature can be expressed by:

$$
\dot{\epsilon}=A \sigma^{n}
$$

where $\mathrm{n}$ is the steady-state stress exponent, defined as $n=\frac{d l n \dot{\epsilon}}{d l n \sigma}$, and A is a constant.

Mulhearn and Tabor used the expression shown below to acquire the stress exponent for pure lead at temperatures above $0.6 T_{m}$.

$$
-\left(n+\frac{1}{2}\right) \log H_{v}=\log t+B
$$

where $\mathrm{Hv}$ is the Vickers number, $\mathrm{t}$ is the indentation dwell time and $\mathrm{B}$ is a constant. Hardness against time on a log-log scale, a straight line with slope $\left(n+\frac{1}{2}\right)^{-1}$ is obtained.

Juhasz et al. [100] used vickers tests and obtained the stress exponent $n$ of superplastic lead-tin alloy in steady-state creep of the following form:

$$
n=\left[\frac{\partial \ln \dot{d}}{\partial \ln H_{v}}\right]_{d}
$$


where $H_{v}$ is the Vickers hardness number and $\dot{d}$ is the variation in indentation depth and $\mathrm{d}$ is the indentation diagonal length. Therefore plotting $\dot{d}$ against $H_{v}$ on a double logarithimic scale, a straight line would be obtained, which the slope is the stress exponent, n.

Sargent and Ashby [101] performed hot hardness tests on a wide range of materials and proposed a dimensional analysis for indentation creep. According to their model, the displacement rate of an indenter has been derived as:

$$
\frac{d u}{d t}=\left[\frac{\dot{\epsilon_{0}}}{C_{2}}\right]\left[\left(\frac{C_{1}}{\sigma_{0}}\right)\left(\frac{P}{A}\right)\right]^{n}
$$

where $\mathrm{A}$ is the projected area of indentation, $C_{2}$ is a constant and $\dot{\epsilon}$ is the rate at a reference stress $\sigma_{o}, \mathrm{n}$ is the stress exponent and $\mathrm{P}$ is the applied load. For a pyramid indenter the penetration is proportional to $\sqrt{A}$, i.e.,

$$
u=C_{3} \sqrt{A}
$$

Differentiating Equation 4.15 with respect to time and substituting into Equation 4.14 gives:

$$
\frac{d A}{d t}=C_{4} \dot{\epsilon}_{0} A\left(\frac{P}{A} \sigma_{0}\right)^{n}
$$

where $C_{3}$ and $C_{4}$ are constants. When $\mathrm{P}$ is held constant, Equation 4.16 can be written as:

$$
\frac{1}{H_{v}} \frac{d H_{v}}{d t}=-C_{4} \dot{\epsilon}_{0}\left(\frac{H_{v}}{\sigma_{0}}\right)^{n}
$$

Sargent and Ashby then derived the following relationship between indentation hardness and dwell time: 


$$
H_{v}(t)=\frac{\sigma_{0}}{\left(n C_{4} \dot{\epsilon_{0}} t^{\frac{1}{n}}\right)}
$$

where $H_{v}(t)$ is the time dependent hardness. Using Equation 4.18 the slope of a plot of $\ln \left(H_{v}\right)$ against $\ln (t)$ at a constant temperature is $-\frac{1}{n}$. Also from Equation 4.17 a plot of $\ln \left(H_{v}\right)$ versus $\ln \left[-\frac{1}{H V} \frac{d H_{v}}{d t}\right]$ at a constant temperature has slope of $n$. Using Sargent-Ashby analysis, we can convert the term $\frac{1}{H_{v}} \frac{d H_{v}}{d t}$ in Equation 4.17 to a measurable quantity.

Vickers hardness is given by $H_{v}=0.1854 \frac{F}{d^{2}}$ where $F$ is the applied load in $N$ and $d$ is the average diagonal length in $\mathrm{mm}$. Therefore the relationship between Vickers hardness and applied load can be expresses as:

$$
0.1854 F=d^{2} H_{v}
$$

During indentation test, the applied load is constant, so differentiating Equation 4.18 gives:

$$
\frac{d H_{v}}{d t} \cdot d^{2}=-2 d \frac{d(d(t))}{d t} \cdot H_{v}
$$

Further on, this equation can be simplified to the following form:

$$
\frac{d H_{v}}{d t} \frac{1}{H_{v}}=\frac{2 \dot{d}}{d}
$$

Substituting Equation 4.17 and 4.18 gives:

$$
n \log H_{v}=\log \left(\frac{2 \dot{d}}{d}\right)+C
$$

Therefore plotting a log of $H_{v}$ versus $\log \left(\frac{2 \dot{d}}{d}\right)$ has a slope of $\frac{1}{n}$ and the stress exponent can be obtained. It has therefore been proven that indentation creep behavior of cast $\mathrm{Pb}-\mathrm{Sb}$ alloys at room temperature $\left(T>0.5 T_{m}\right)$ by measuring the stress exponents of these alloys 
using above mentioned methods of analysis.

Roumina et al [42] analyzed creep behavior of cast $P b-20 S b$ alloys by above mentioned indentation methods at room temperature. Multiple samples were tested using Vickers hardness tester where applied load and testing time were the only variables. Indentation hardness measurements were made on each sample using loads of 50, 100 and $150 N$ for dwell times up to $120 \mathrm{~min}$. Each reading was an average of at least five separate measurements taken at random places on the surface of the specimens. All of the indentations were taken a minimum of $5 \mathrm{~mm}$ away from the edges and $10 \mathrm{~mm}$ from other indentations. Variation in indentation diagonal length with time under constant loads of 50, 100 and $10 N$ shows indentation length increases with loading time and the applied load. As can be seen in Figures 4.2, 4.3 and 4.4, the curves have two stages similar to an ordinary creep curve. The initial stage of the curve shows an increase in the concerned variable with time, with decreasing rate, followed by a steady-state region where indentation sizes increase linearly with time. Hardness test being a compression test, fracture of the specimen cannot occur, reason being the third stage does not exist as an ordinary creep test. As can be seen in Figures 4.2, 4.3 and 4.4, the PbSb alloys exhibit different indentation creep behavior.

According to Mulhearn-Tabor the rate of diagonal variation can be obtained by differentiating the curves in Figures 4.2, 4.3 and 4.4. Using Mulhearn-Tabor relationship, Equation 4.12 and plotting time against hardness on a double logarithimic scale, a straight line with slope $-\left(n+\frac{1}{2}\right)$ is obtained.

Utilizing methods of Juhasz et al, Sargent-Ashby and Mulhearn-Tabor mentioned before have been applied to the indentation data of the materials to obtain the steady-state creep exponents. Plotting Vickers hardness number on a double logarithmic scale gives a slope of $\mathrm{n}$ (stress exponent) as can be seen in Figures 4.2, 4.3 and 4.4.

Utilizing the Sargent-Ashby model, the stress exponent acn be obtained from a plot of $\log H_{v}$ versus $\log \frac{2 \dot{d}}{d}$ having a slope of $\frac{1}{n}$. This can be seen in Figures 4.11, 4.12 and 4.13. It can be noticed for all three methods that each materials fitted lines are almost parallel, 


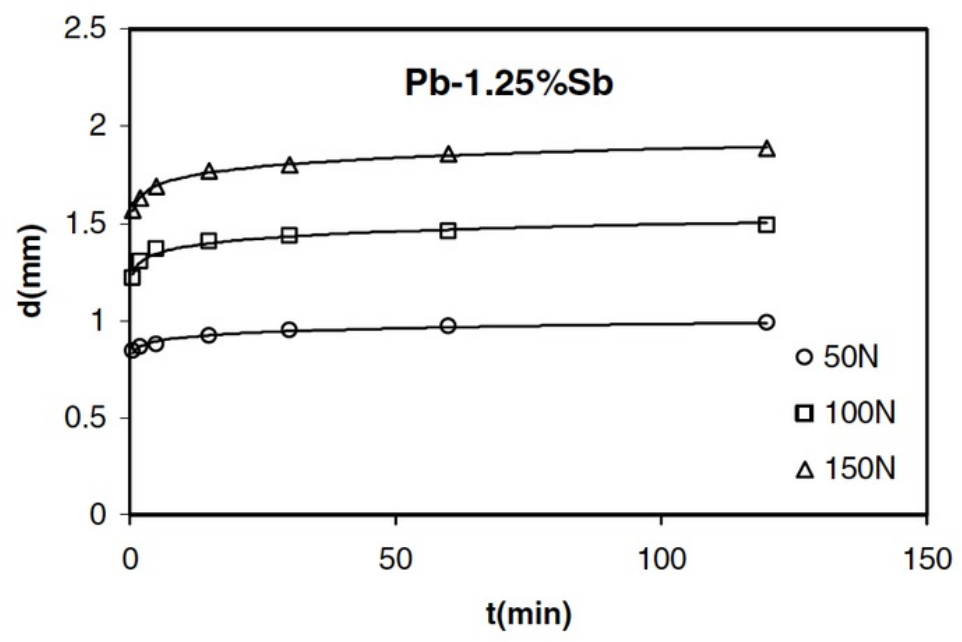

Figure 4.2 Indentation creep curves at different temperatures

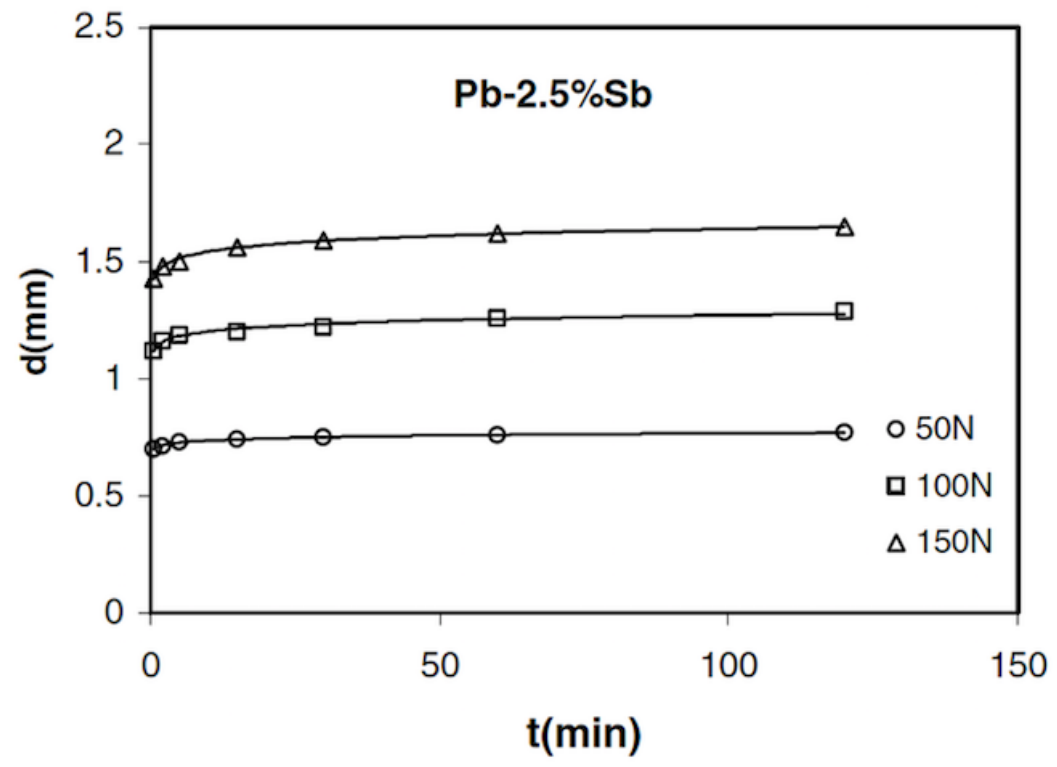

Figure 4.3 Indentation creep curves at different temperatures

implying that the stress exponent is independent of the applied load. These dfifferent stress exponents are shown in Table 4.1. 


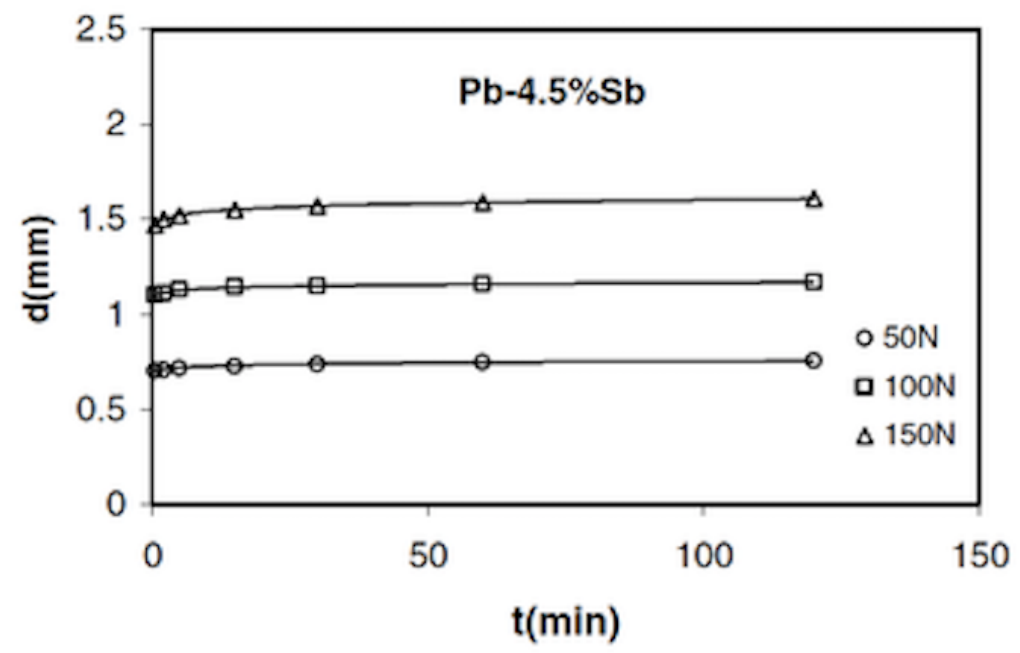

Figure 4.4 Indentation creep curves at different temperatures

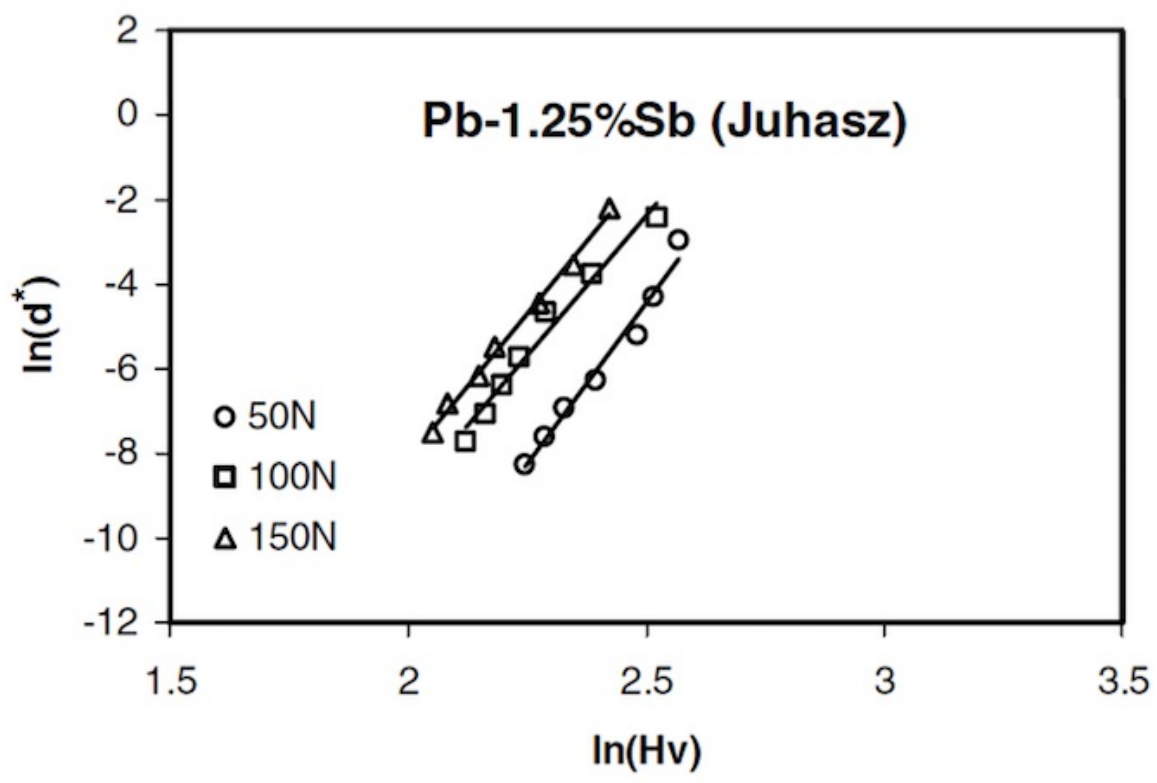

Figure 4.5 Derivation of stress exponent by the Juhasz et al. method

The indentation creep test has been demonstrated to be capable of evaluating creep behavior of materials using small specimens. The stress exponents calculated from these different methods of analysis are in good agreement with each other. These exponents can 


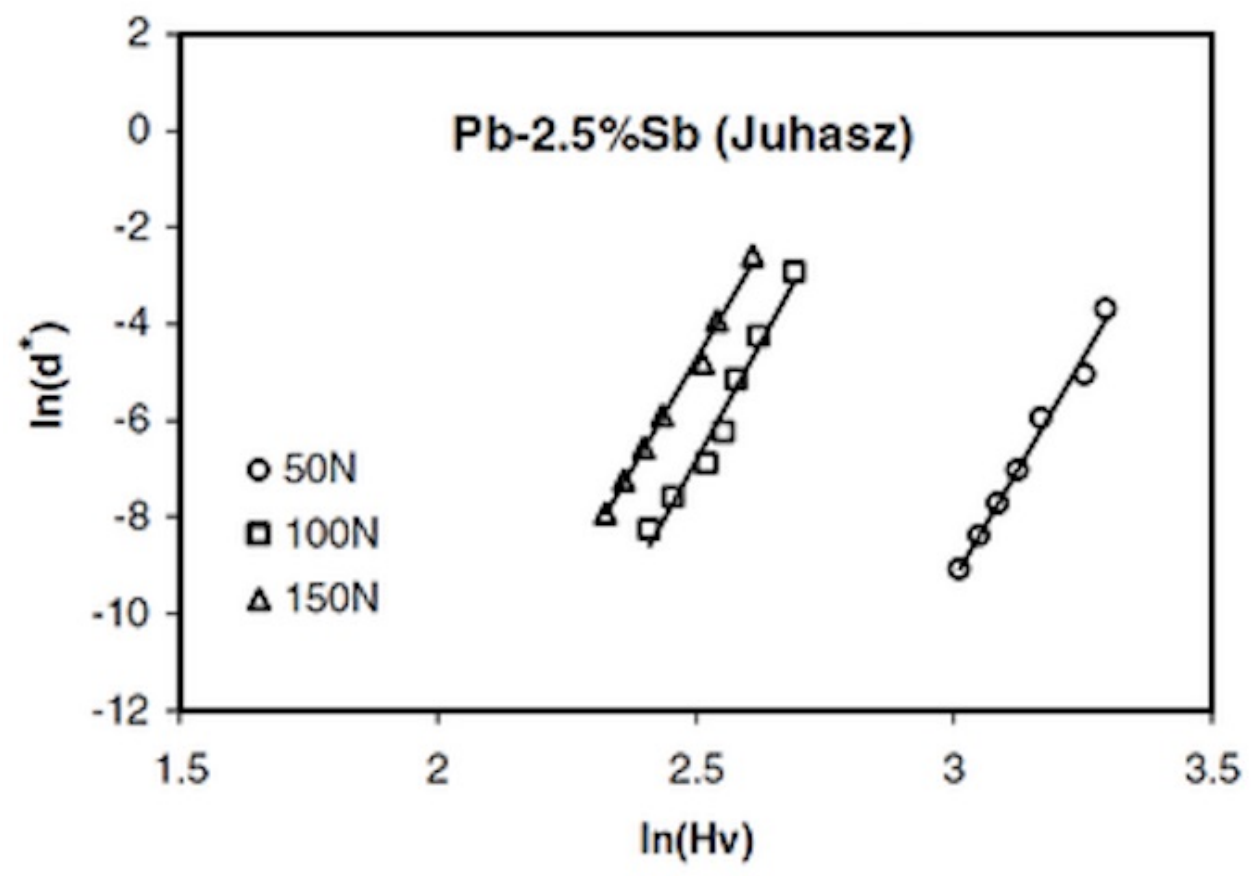

Figure 4.6 Derivation of stress exponent by the Juhasz et al. method

be used to determine the mechanisms of creep deformation.

All these methods involve measuring vickers hardness of the sample over a period of time, which involves taking these measurements at different locations over a period of time. This requires the use of multiple samples or multiple test conditions which removes the possibility of analyzing the material response during creep. This research proposes a method of acquiring the creep from one location over a period of time and can monitor the material stiffness response during creep.

\subsection{Indentation Creep}

An indentation test is a convenient method for measuring the mechanical properties of a material. Its most common application is to measure hardness. The traditional hardness test involves applying a load $L$ into the surface of a material and the penetration depth $h_{c}$ or 


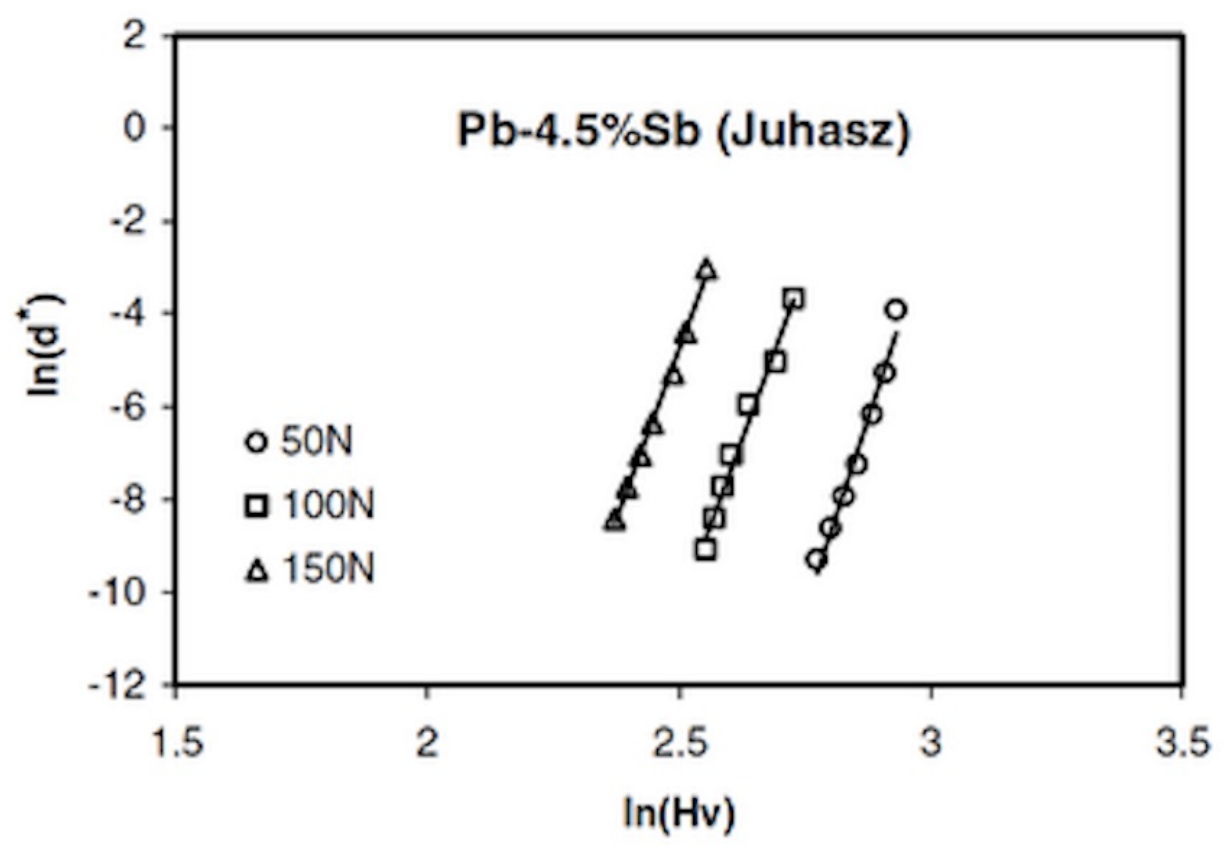

Figure 4.7 Derivation of stress exponent by the Juhasz et al. method

Table 4.1 The stress exponents (n-values) derived from different indentation methods

\begin{tabular}{|c|c|c|c|c|c|}
\hline Material & Load $(\mathrm{N})$ & Juhasz et al. & $\begin{array}{l}\text { Mulhearn- } \\
\text { Tabor }\end{array}$ & $\begin{array}{l}\text { Sargent- } \\
\text { Ashby }\end{array}$ & $\begin{array}{ll}\text { Grain } & \text { size } \\
(\mathrm{mm}) & \end{array}$ \\
\hline \multirow[t]{3}{*}{$\mathrm{Pb}-1.25 \% \mathrm{Sb}$} & 50 & 15.2 & 15.2 & 15.5 & 0.33 \\
\hline & 100 & 13.2 & 13.2 & 13.7 & \\
\hline & 150 & 13.6 & 13.8 & 14.1 & \\
\hline \multirow{3}{*}{$\mathrm{Pb}-2.5 \% \mathrm{Sb}$} & 50 & 18.1 & 18 & 18.4 & 0.28 \\
\hline & 100 & 19.5 & 19.5 & 20 & \\
\hline & 150 & 18.2 & 13.8 & 14.1 & \\
\hline \multirow{3}{*}{$\mathrm{Pb}-4.5 \% \mathrm{Sb}$} & 50 & 15.2 & 15.2 & 15.5 & 0.21 \\
\hline & 100 & 13.2 & 13.2 & 13.7 & \\
\hline & 150 & 13.6 & 13.8 & 14.1 & \\
\hline
\end{tabular}

contact of radius $a_{c}$ is measured. Conventional hardness test is one of the oldest and simplest methods of material evaluation. Tabor [39], showed that elasto-plastic material response in tensile testing can be correlated to the response in spherical or pyramidal indentation. The 


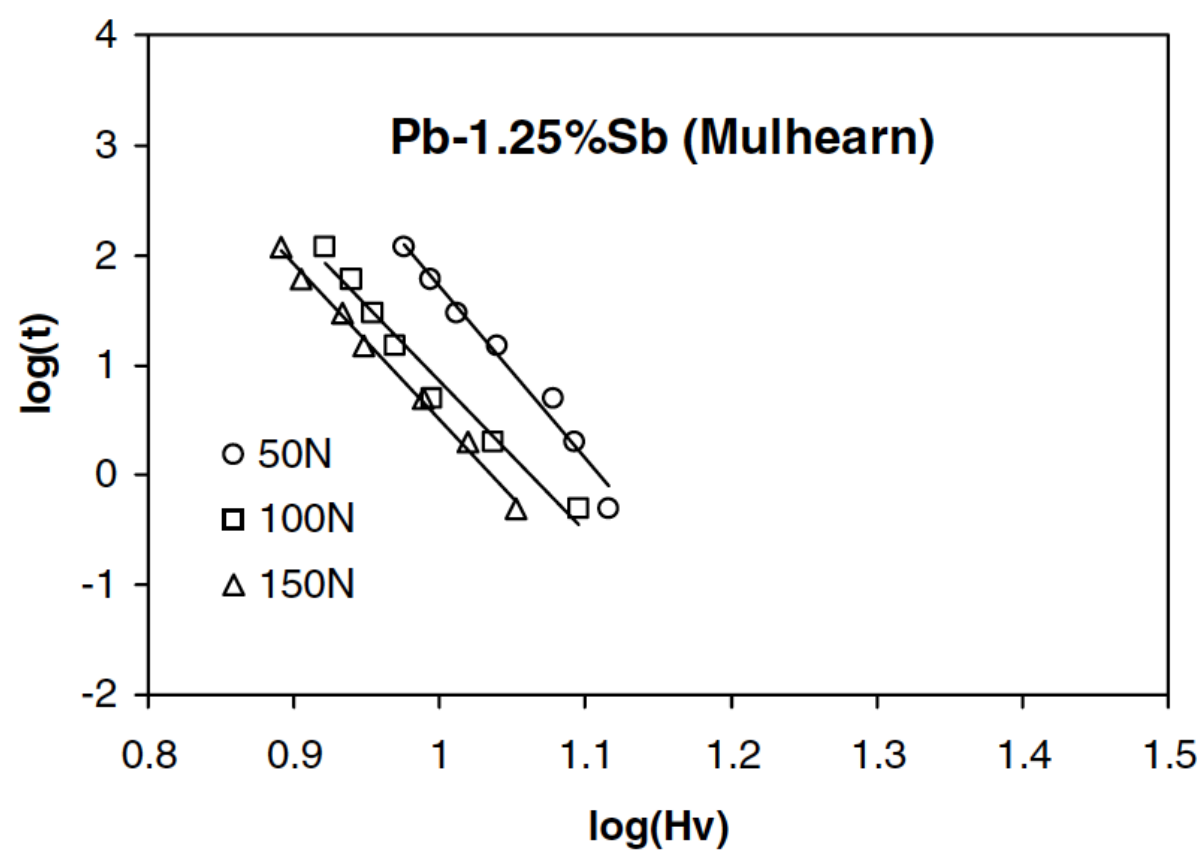

Figure 4.8 Derivation of stress exponent by the Mulhearn-Tabor method

indentation creep process can be defined as the time dependent penetration of a hard indenter into the material under constant load and temperature. The variation in the indentation size is monitored with dwell time. This can be particularly advantageous when the material is only available as small test pieces or there are some difficulties with machining of some samples made of very soft materials. This makes indentation creep a quick, simple and non-destructive procedure to extract information on the mechanical behavior of materials, and also reduces the effort for sample preparation. The fundamental process parameters for spherical indentation are: indentation force $P$, mean contact pressure $p_{a v}=\frac{P}{\pi a^{2}}$, contact radius $a$, permanent penetration depth $h$, and the sphere Diameter $D$.

It was concluded that the relationship between mean pressure and penetration depth follows a power law. Tabor used this to map the pressure-contact radius curve $p_{a} v=$ $p_{a} v(a / D)$ to the $\sigma-\epsilon_{p}$ curve as shown in Equation 4.23, where $\epsilon_{p}$ denotes plastic strain 


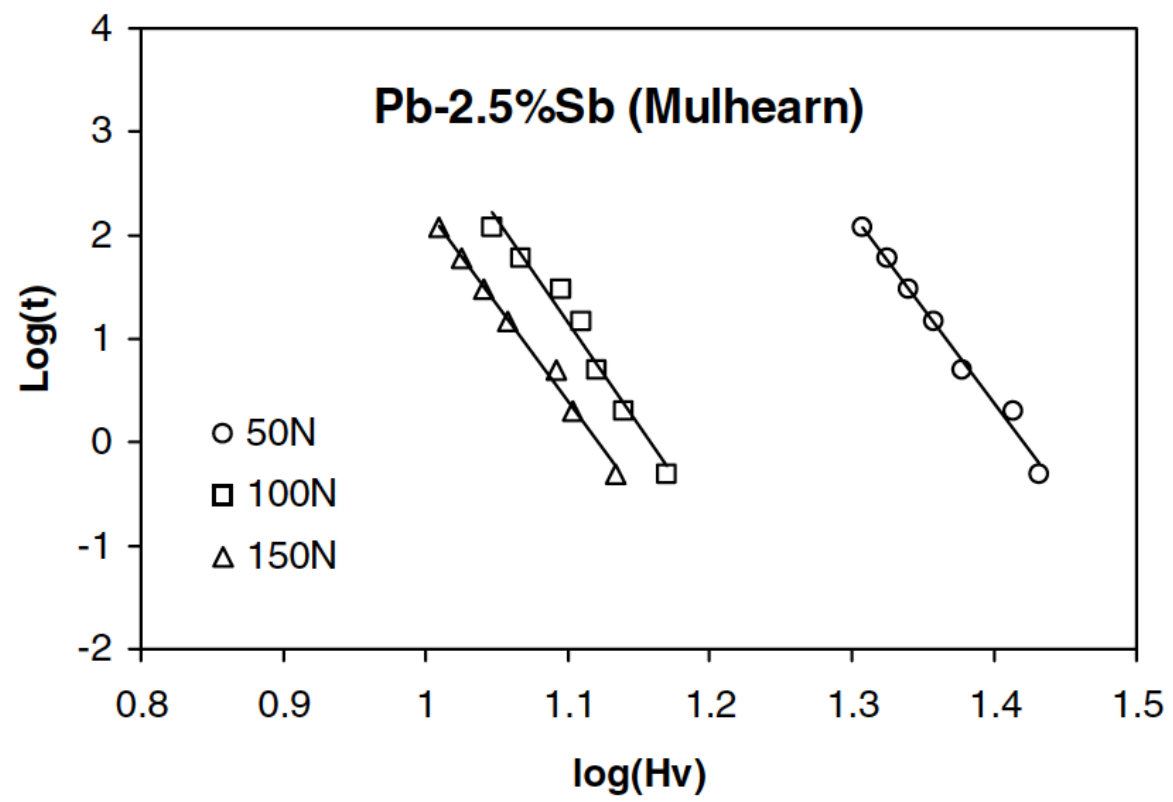

Figure 4.9 Derivation of stress exponent by the Mulhearn-Tabor method

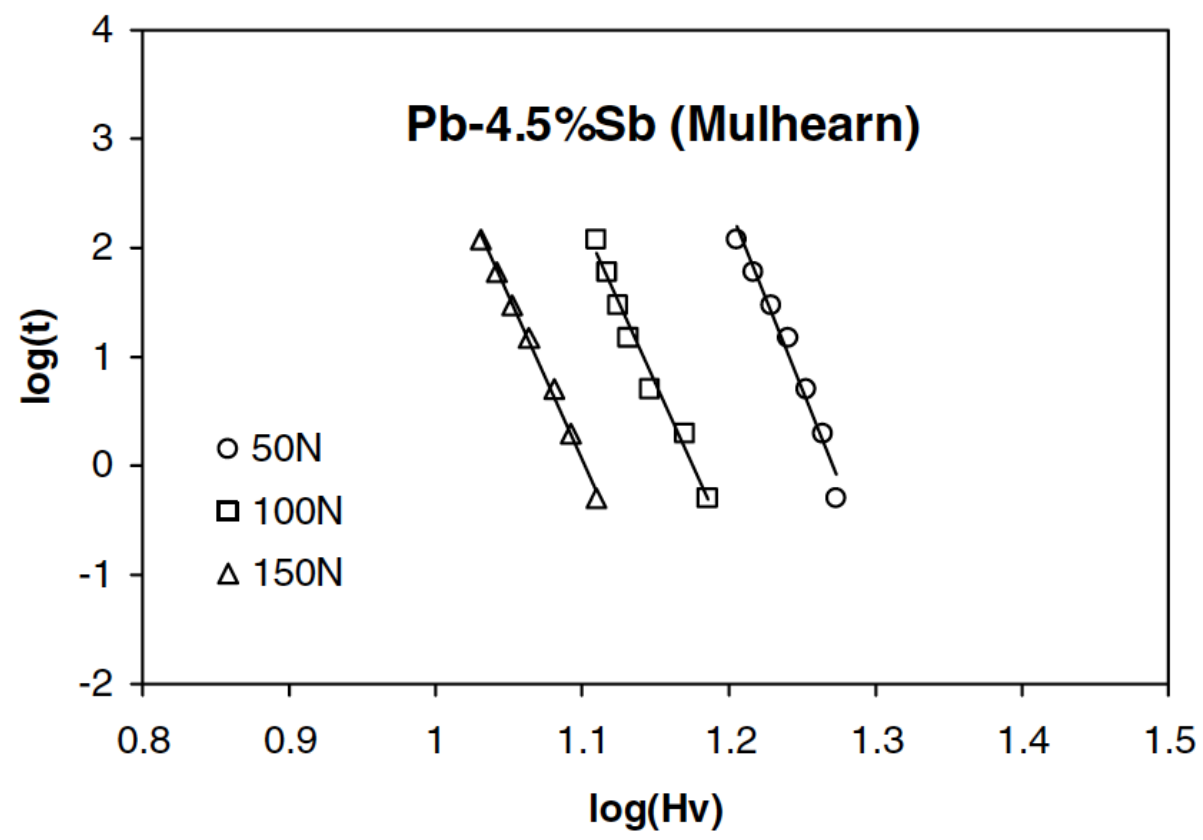

Figure 4.10 Derivation of stress exponent by the Mulhearn-Tabor method 


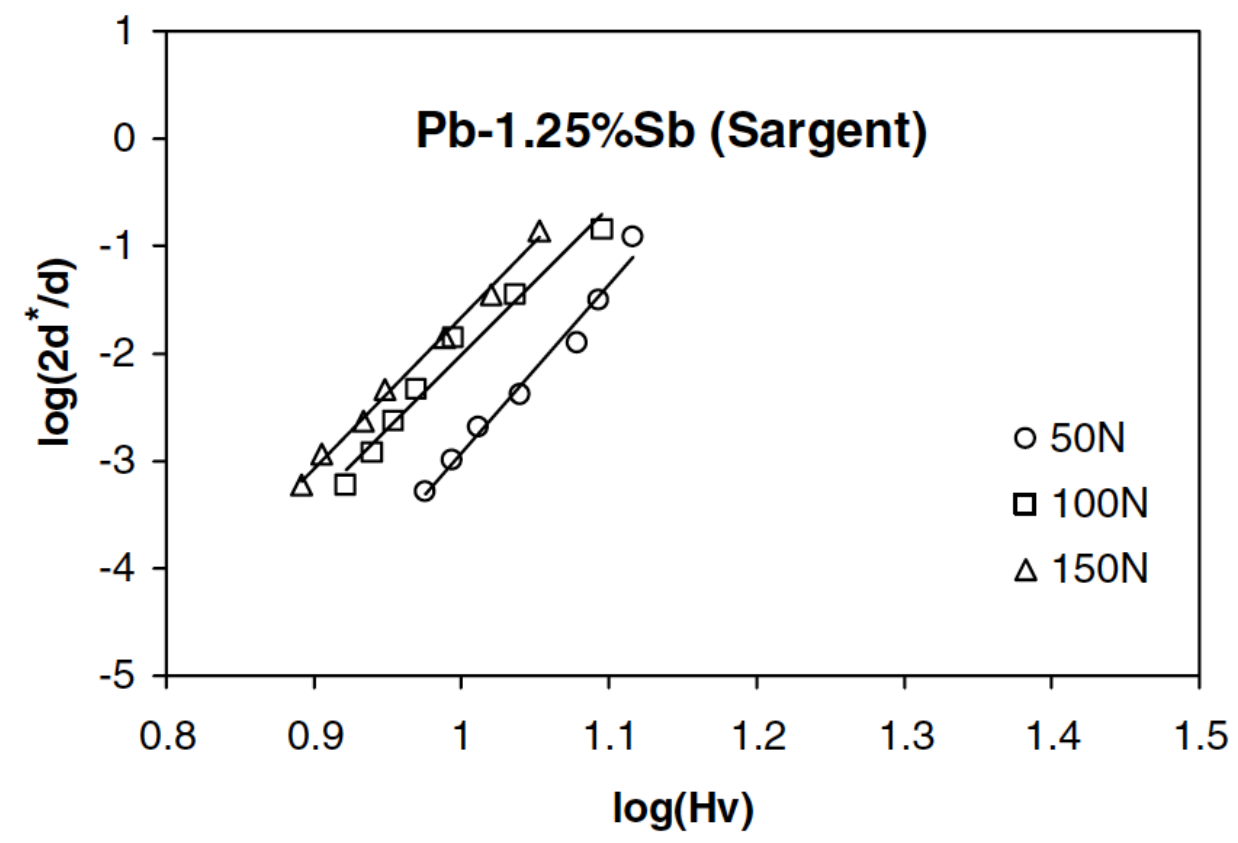

Figure 4.11 Derivation of stress exponent by the Sargent-Ashby method

[39].

$$
\epsilon_{p}=0.4 a / D
$$

Various models have been developed for the analysis of indentation creep data discussed below.

\subsubsection{Indentation Load Relaxation (ILR)}

The idea of using ILR techniques was first presented by Hannula et al [40]. This experiment involves pushing the indenter into the sample, until the desired load is achieved, then the indenter position is fixed. The elastic strain in the machine is converted to the plastic strain in the specimen. This technique is used to study time dependent deformation in small volumes. Using a Vickers indenter with $1 \mu^{2}$ flat area on the apex, an effective stress was defined as 


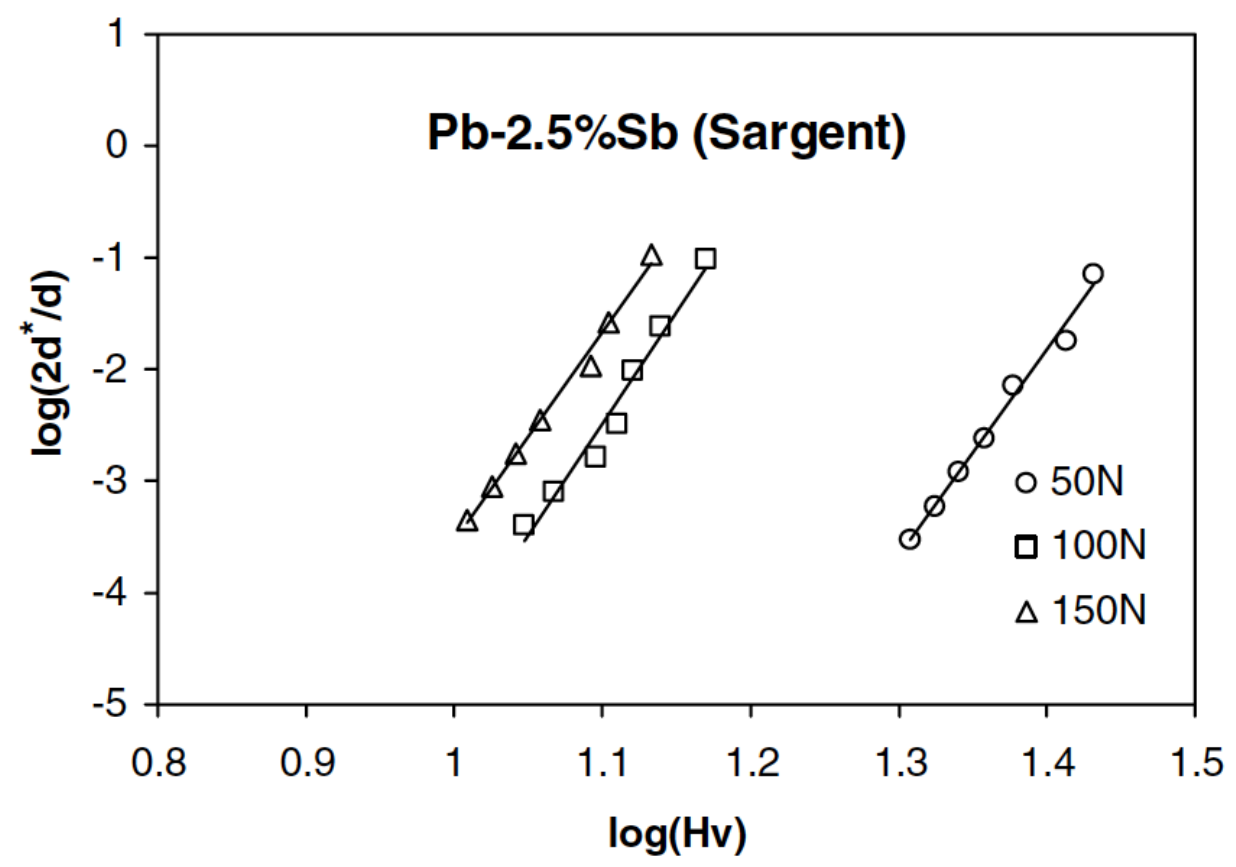

Figure 4.12 Derivation of stress exponent by the Sargent-Ashby method

$$
\sigma_{e f f}=P / A
$$

where $\mathrm{P}$ is the load on the indenter and $\mathrm{A}$ is the projected area of contact. An effective strain rate was defined as

$$
\dot{\epsilon}=c \frac{\dot{h}}{h}
$$

where $\mathrm{c}$ is a constant, $\dot{h}$ is the instantaneous descent rate of the indenter and $h$ is the indenter depth (total depth or plastic depth). The stress exponent for creep is then defined as $\frac{d \ln \dot{\epsilon}}{d \ln H}$ at constant temperature.

\subsubsection{Constant Rate of Loading (CRL)}

The (CRL) test is a multi-indentation test that was developed for determining stress exponents using depth sensing indentation systems [41]. This test applies load incrementally 


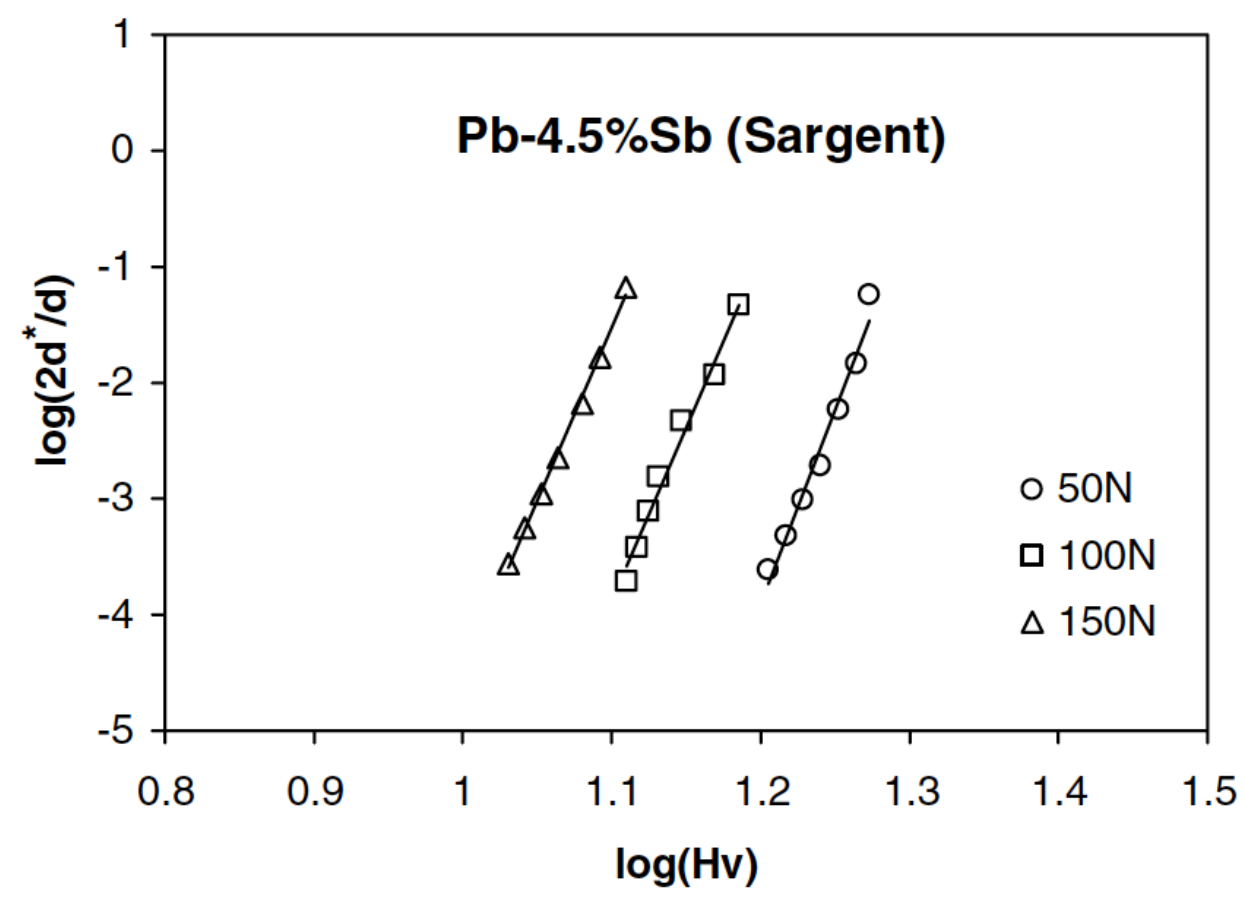

Figure 4.13 Derivation of stress exponent by the Sargent-Ashby method

in the indenter at rates specified by the experimenter. In a CRL test, the indenter is loaded at a constant loading rate until the indenter has reached a prescribed depth in the material. An effective stress is then calculated based on a series of experiments at different loading rates for each indentation mode. The stress exponent for creep is then identified from the applied load and achieved depth as $\frac{d \ln \dot{\epsilon}}{d \ln H}$

The only problem found with the CRL method is the continuous change of the indentation strain rate through out the loading segment. Although the changes in stress and strain rate may seem minimal, it is still considered to be a far more dynamic test than others.

\subsubsection{Step Constant Indentation Strain Rate}

Stemming from the equation of hardness of a material, 


$$
H=\frac{P}{A}=\frac{P}{c h^{2}}
$$

where $\mathrm{H}$ is the hardness, $\mathrm{P}$ is the load, $\mathrm{A}$ the projected contact area, $\mathrm{h}$ is the contact depth, and $\mathrm{c}$ is a constant that depends upon the geometry of the indenter. Hardness equation can be re-written as

$$
c h^{2} H=P
$$

Differentiating equation 4.27 with respect to time leads to

$$
2 \operatorname{ch} \dot{h} H+\operatorname{ch}^{2} \dot{H}=\dot{P}
$$

Simplified to

$$
\begin{aligned}
& \dot{h}=\frac{\dot{P}}{2 c h H}-\frac{c h^{2} \dot{H}}{2 c h H} \\
& \frac{\dot{h}}{h}=\frac{\dot{P}}{2 c h H}-\frac{c h^{2} \dot{H}}{2 c h^{2} H} \\
& \frac{\dot{h}}{h}=\frac{1}{2}\left(\frac{\dot{P}}{P}-\frac{\dot{H}}{H}\right)=\dot{\epsilon}_{i}
\end{aligned}
$$

where $\epsilon_{i}$ is the indentation strain rate. Equation 4.31. Controlling the loading rate in such a manner as to maintain $\dot{P} / P$ constant would result in a constant indentation strain rate. This methodology requires the use of a perfect Berkovich geometry indenter, given by

$$
A=24.56 h_{c}^{2}
$$

where $h_{c}$ is the contact depth of the indentation. The Berkovich geometry is typically chosen over a Vickers indenter as it is much easier to produce near perfect tips due to the 
natural intersection of three planes at a point.

The variation of the indentation diagonal length with time under constant loads of 50, 100 and $150 \mathrm{~N}$ was studied by [42]. It was seen that indentation length increases with the loading time and the applied load as seen in figure 4.14

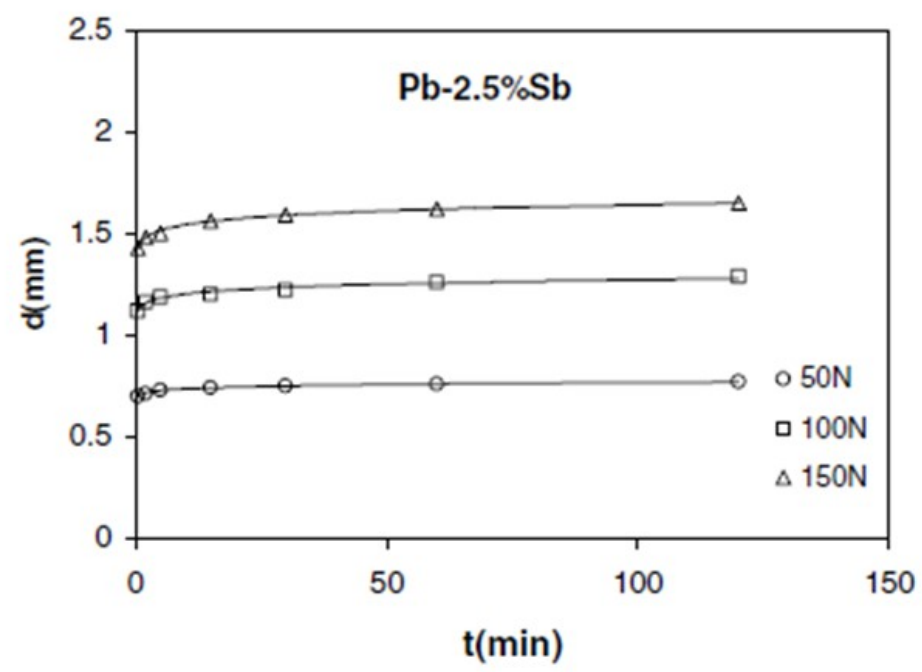

Figure 4.14 Variation of Indentation Length with Time

\subsubsection{Constant Load- Hold}

The idea of measuring creep properties with depth-sensing indentation systems under constant load was introduced by Pollock et al [44]. Pollock makes the approximation that the strain rate $\dot{\epsilon}$ should scale to

$$
\dot{\epsilon}=k_{2} \frac{\dot{h}}{h}
$$

where $\dot{h}$ is the instantaneous descent rate of the indenter, $h$ is the instantaneous displacement and $\mathrm{k}$ is a geometric constant. Using this analysis Pollock investigated the time dependent response of Ni films on $\mathrm{Si}$ at room temperature. 
This experimental procedure involves loading the indenter at a high loading rate and then holding the load on the indenter constant and monitoring the displacement of the indenter as a function of time. The contact area changes as the indenter penetrates the material, while the load is held constant, in other words the effective stress changes as the test proceeds. One can then obtain several effective stress strain rate pairs from one indentation experiment. The creep exponent is found from the slope of a plot of log hardness versus log indentation strain rate.

\subsection{Development of Constant Load-Hold}

In this research I have created a LABVIEW based software by modifying preexisting multiple partial unloading software, capable of controlling the preexisting instrumented indentation system described in Section 3.3. To use this software one must first click the find contact button, which moves the indenter until a predetermined load is identified by the load cell. The input parameters such as Load, $p i$ velocity and file location must be identified, before performing the constant load control by clicking the creep test button.

\subsubsection{Development of Constant Load-Hold Lab View Software IV}

Every LABVIEW IV has a front panel and a block diagram. When the LABVIEW program is opened, the main front panel is shown on the screen. This front panel consists of parameter controls and graphical output displays. The front panel for this constant loadhold is shown in Figure 4.15. The different components of the front panel will be discussed in detail below. To run the program, the creep test button can be clicked; likewise the stop creep button terminates the execution of the program.

The parameter control section of the front panel is shown in Figure 4.16. This is where the user can enter values for each parameter in the program. The parameters setup here are the user load $[N]$ and pi velocity $[\mu m / s]$. The other outputs on the parameter 


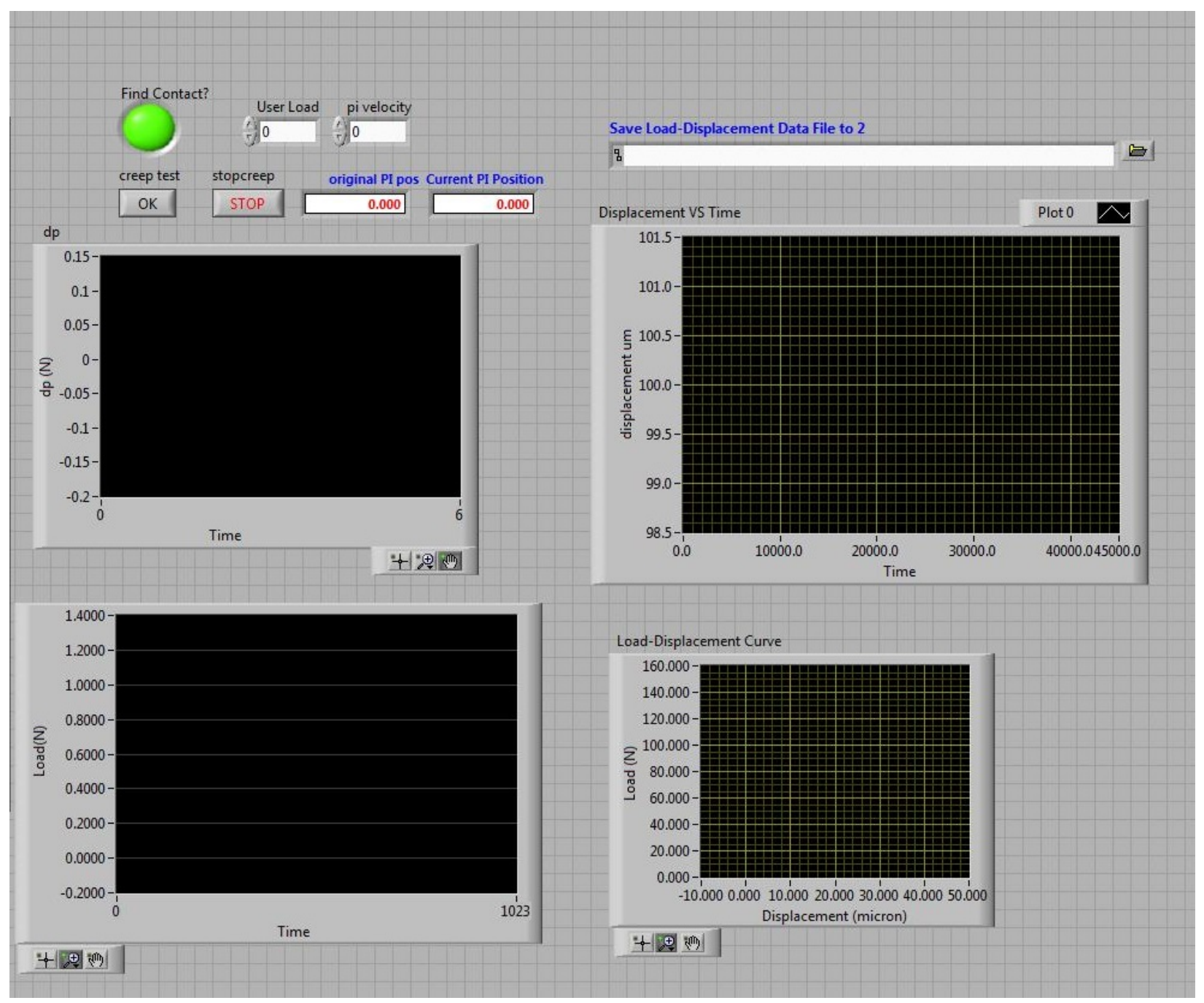

Figure 4.15 Front Panel for Constant Load-Hold

control panel are the original $p i$ position and the current $p i$ position, which tracks the travel range of the PZT actuator described in subsection 3.3.2.

Figure 4.17 shows the displacement vs time graph which allows the user observe the displacement over time during the duration of the experiment. Note that this displacement is the total indentation displacement $h_{\text {total }}$ as discussed in section 3.2.2.

The user can monitor the change in load using the graph output seen in Figure 4.18. The change in load for this experiment can then later be exported and calculated as a percentage to validate the constant load-hold experiment. The load vs time seen in Figure 4.19 


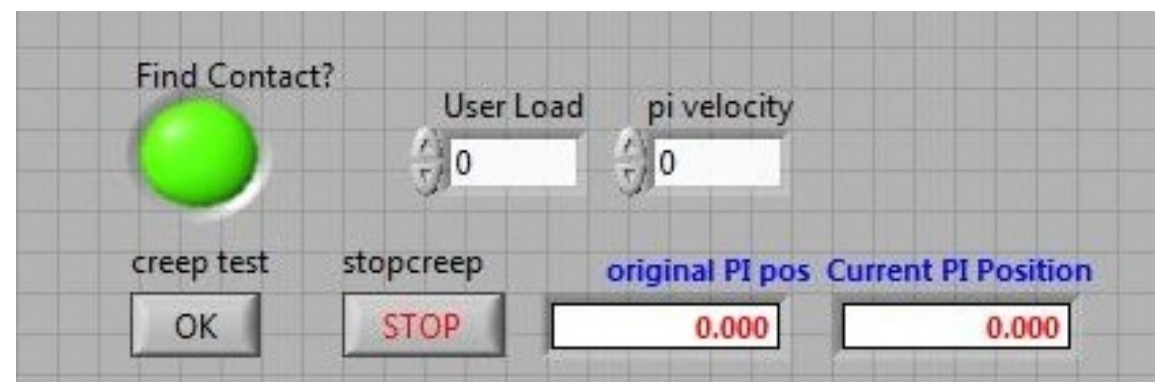

Figure 4.16 Parameter Control Panel

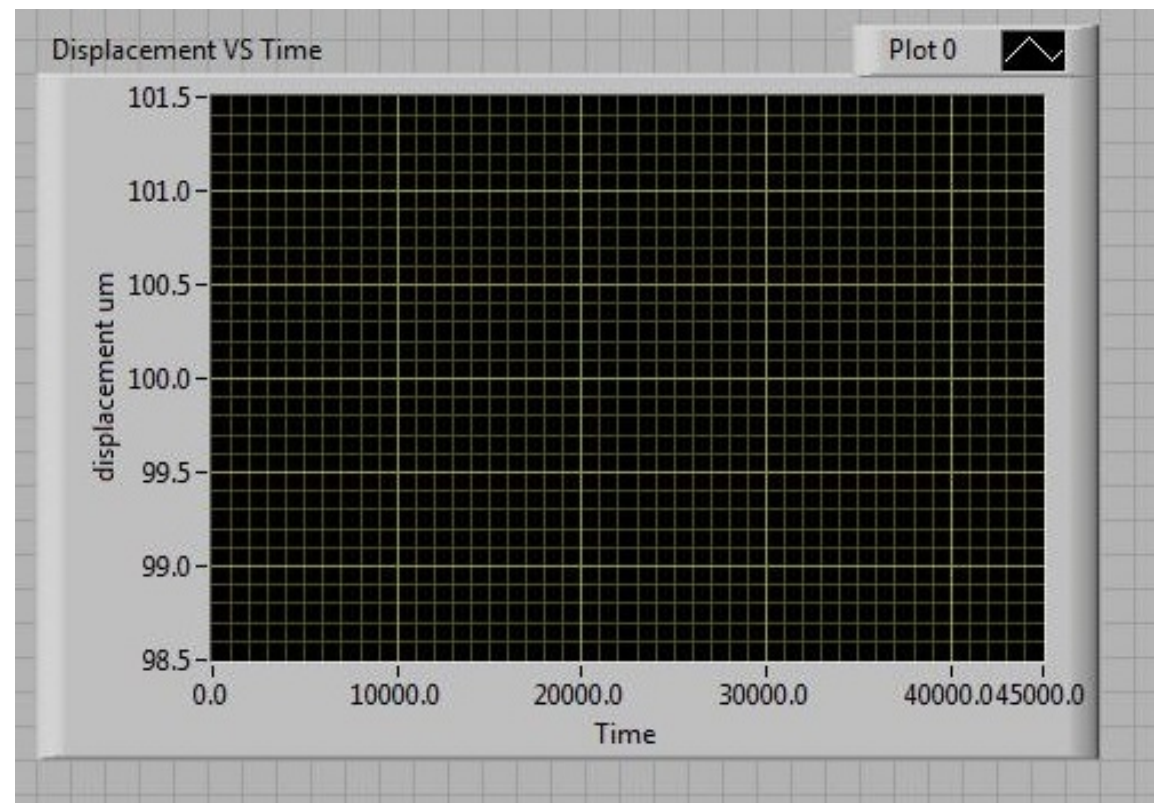

Figure 4.17 Displacement Vs Time graph

graph gives the user an idea of the load over the duration of the experiment.

\subsubsection{Development of Constant Load-Hold Lab View Software IV Block Dia- gram}

The overall view of the system which controls the inputs entered to give you the system outputs is shown in Figure 4.20. It consists of various functions blocks which contains controls to manipulate the instrumented indentation system described in Chapter 3 to generate the 


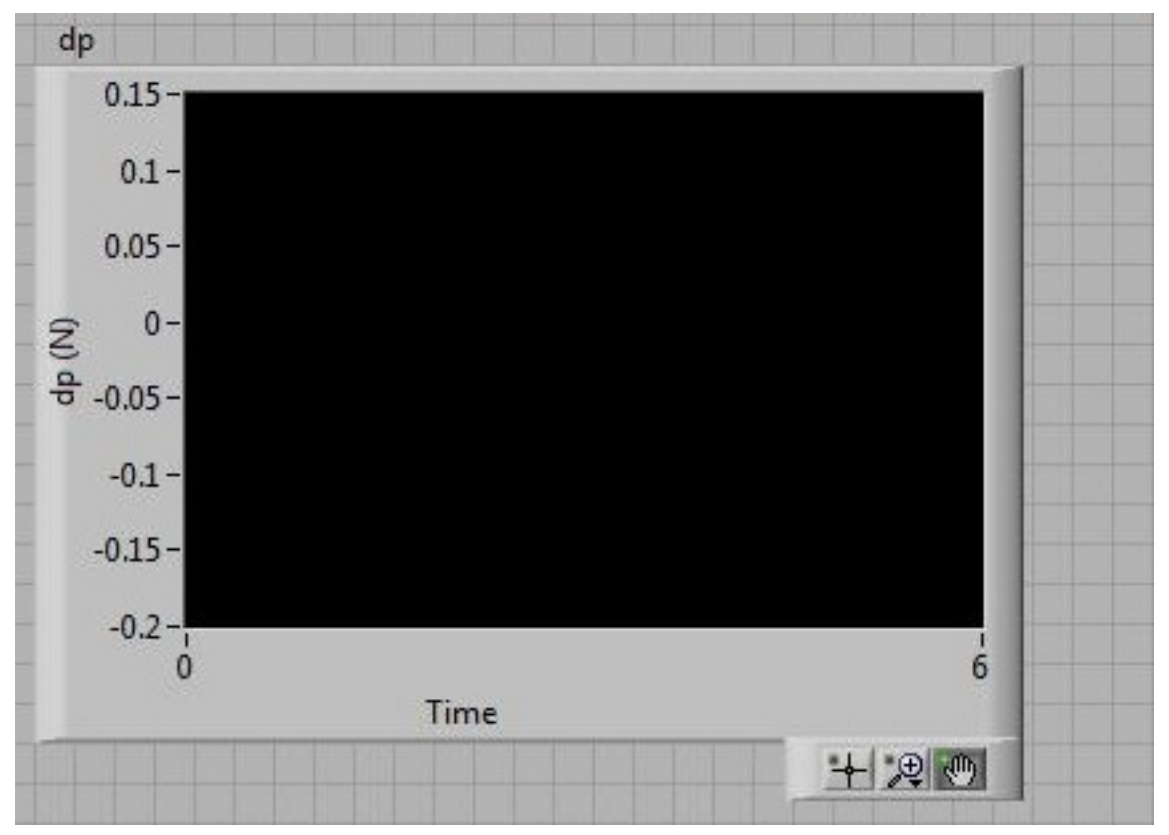

Figure 4.18 Change in Load graph

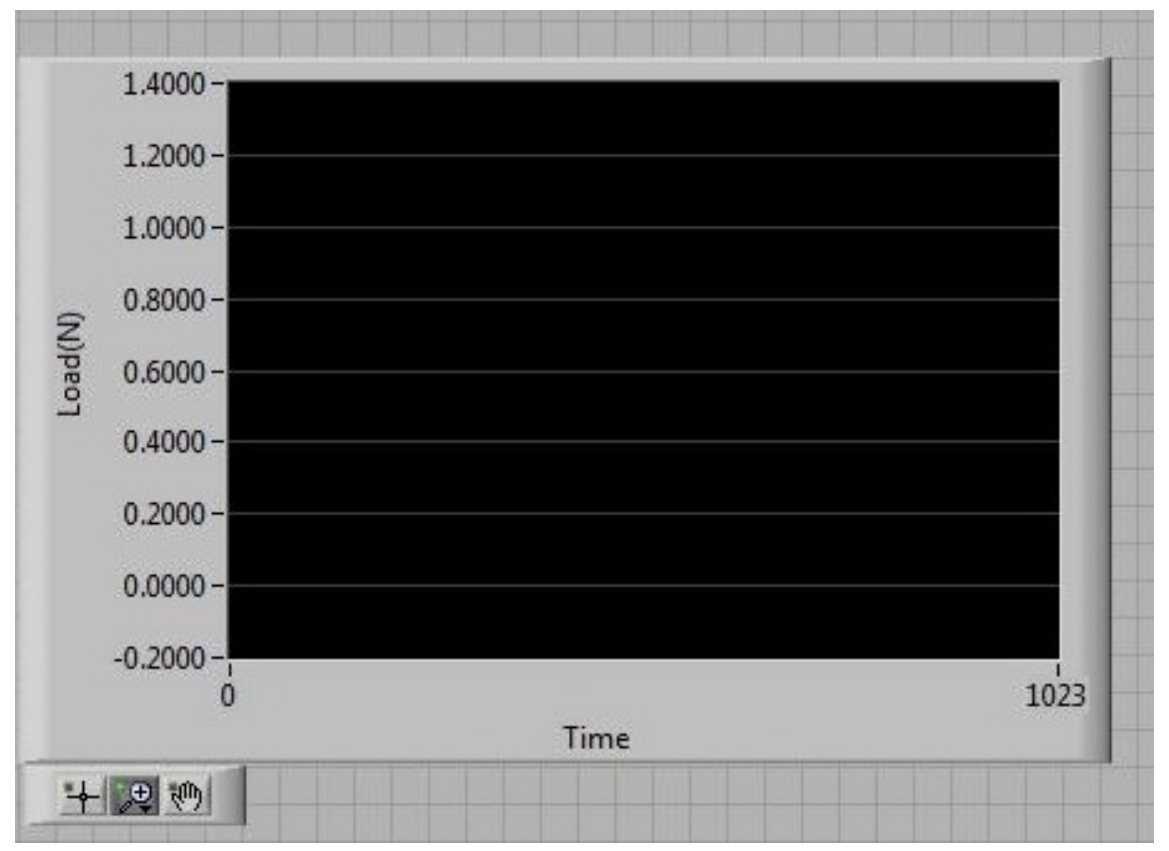

Figure 4.19 Load Vs Time Graph 
outputs. This allows the different function blocks to be easily viewed and edited if needed.

The various parts of the block diagram will be further explained below.

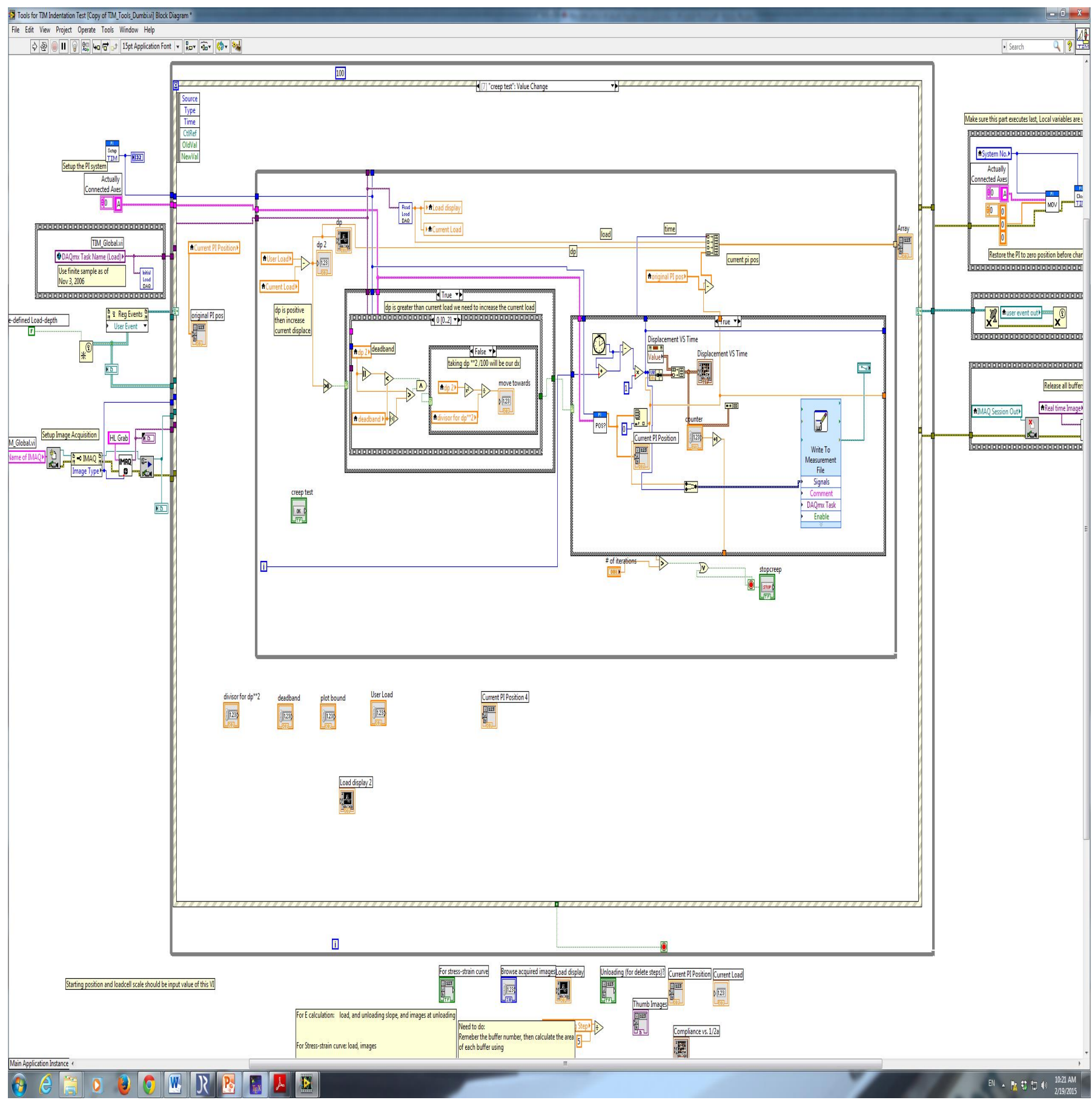

Figure 4.20 Block Diagram 


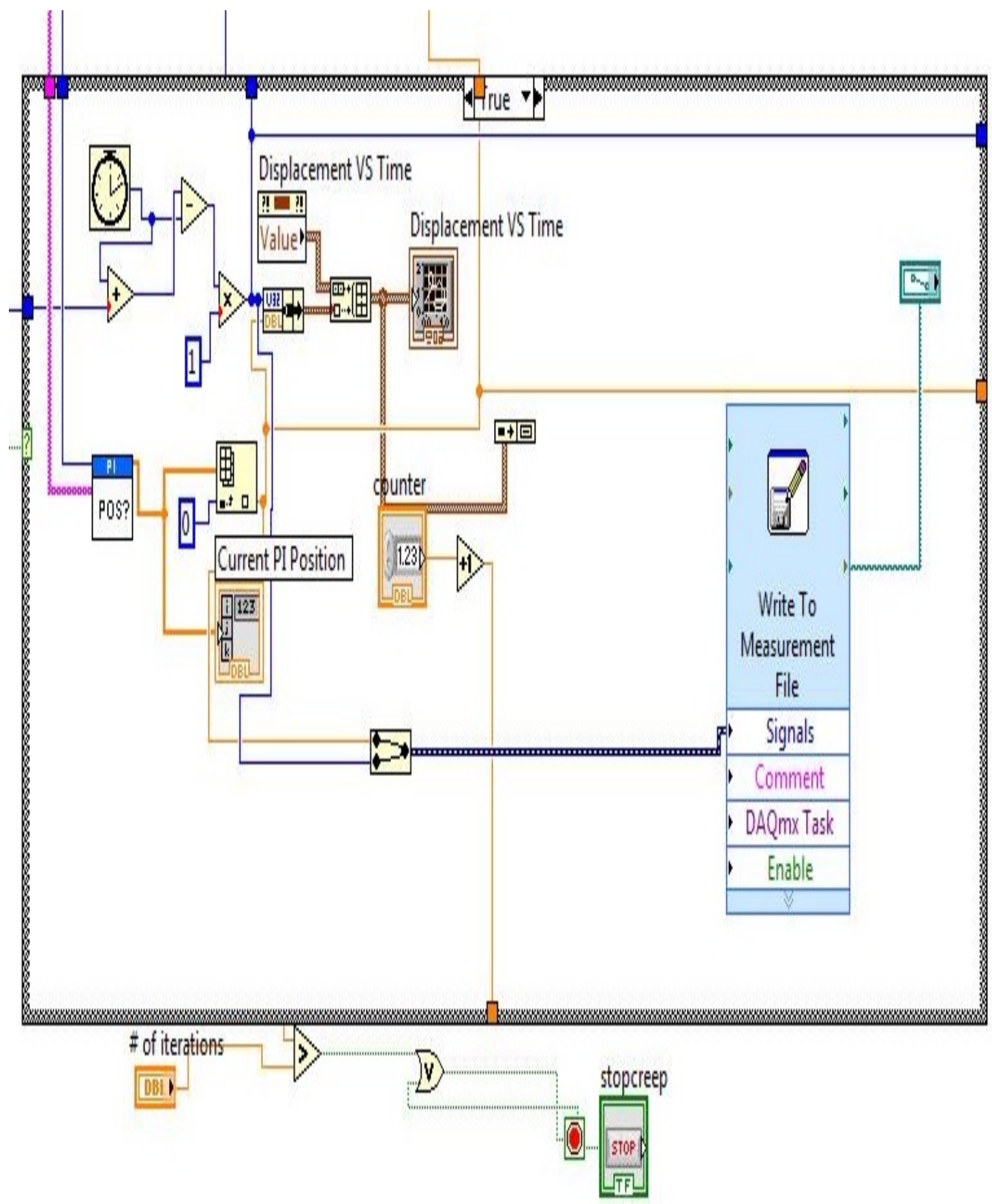

Figure 4.21 Write to Measurement block diagram

Figures 4.22 and 4.23 contains the function blocks necessary for controlling the PZT actuator based on user load by monitoring if the current load is greater than the user specified 
load. If this operating condition for this case structure is false, the event described in Figure 4.22 takes place. Otherwise if the operating condition is true, the event specified in Figure 4.23 takes place.

Figure 4.21 contains functions for monitoring time, displaying graphs described in the front panel, and most importantly saving data to a user specified file and location. The functions in the block diagrams are controlled by a while loop function which is activated when you push the creep test button. The while loop function will continue to run until the condition described by the user has been reached or you push the stop creep button. The data is automatically stored to the user described location during the test.

\subsection{Development of Constant Load-Hold with multiple partial unloading}

Another goal of this research is to combine the multiple partial unloading technique described in Section 3.2.2 which utilizes closed loop displacement control, together with the constant load-hold technique described in Section 4.5 which utilizes closed loop load control, to create a new bi-function control system which will have a great potential for creep stiffness response analysis at room and elevated temperature.

This would involve executing both closed loop displacement control and closed loop load control at separate interfaces to produce plots similar to Figure 4.24 


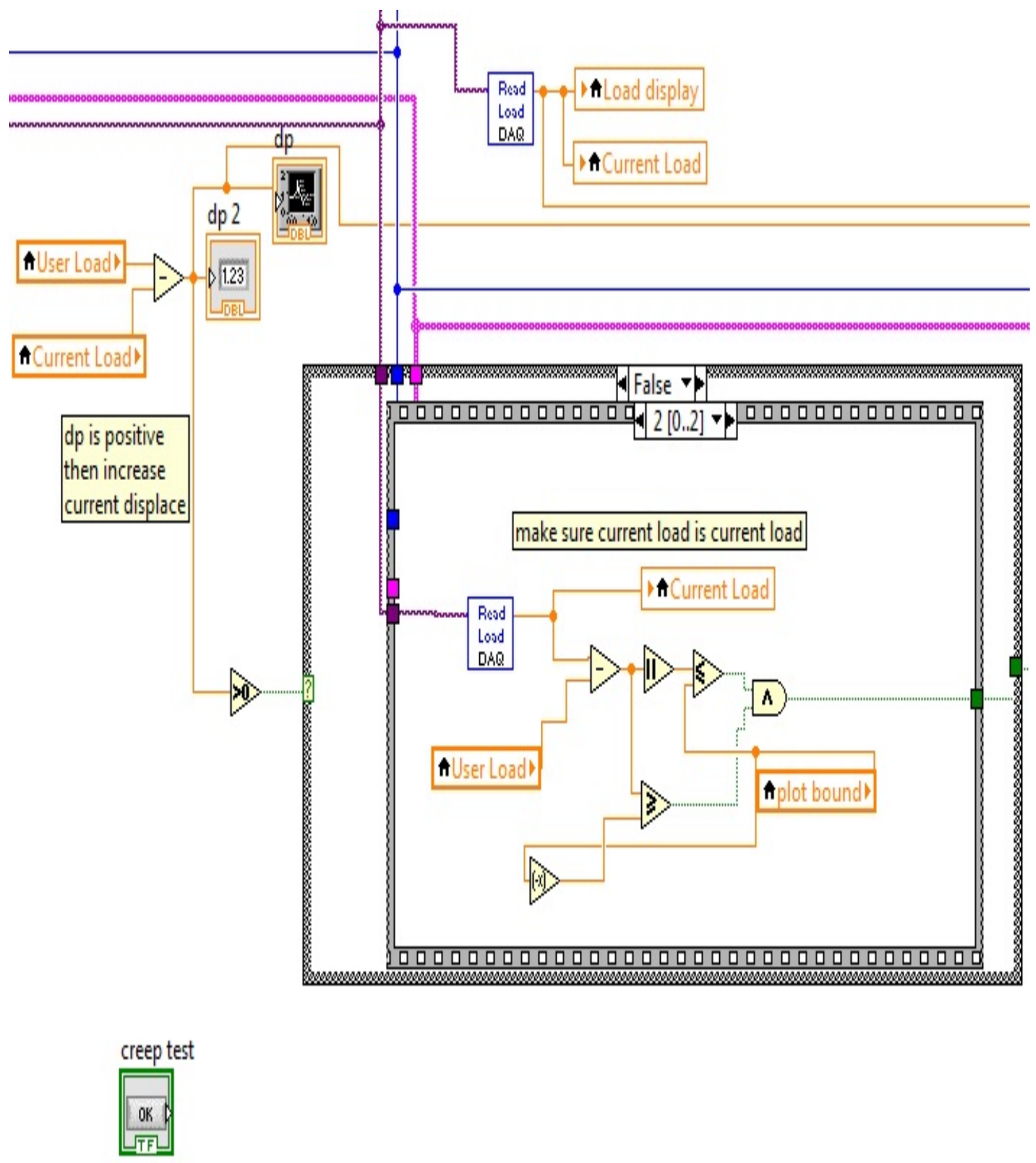

Figure 4.22 Load Control Block diagram False condition 


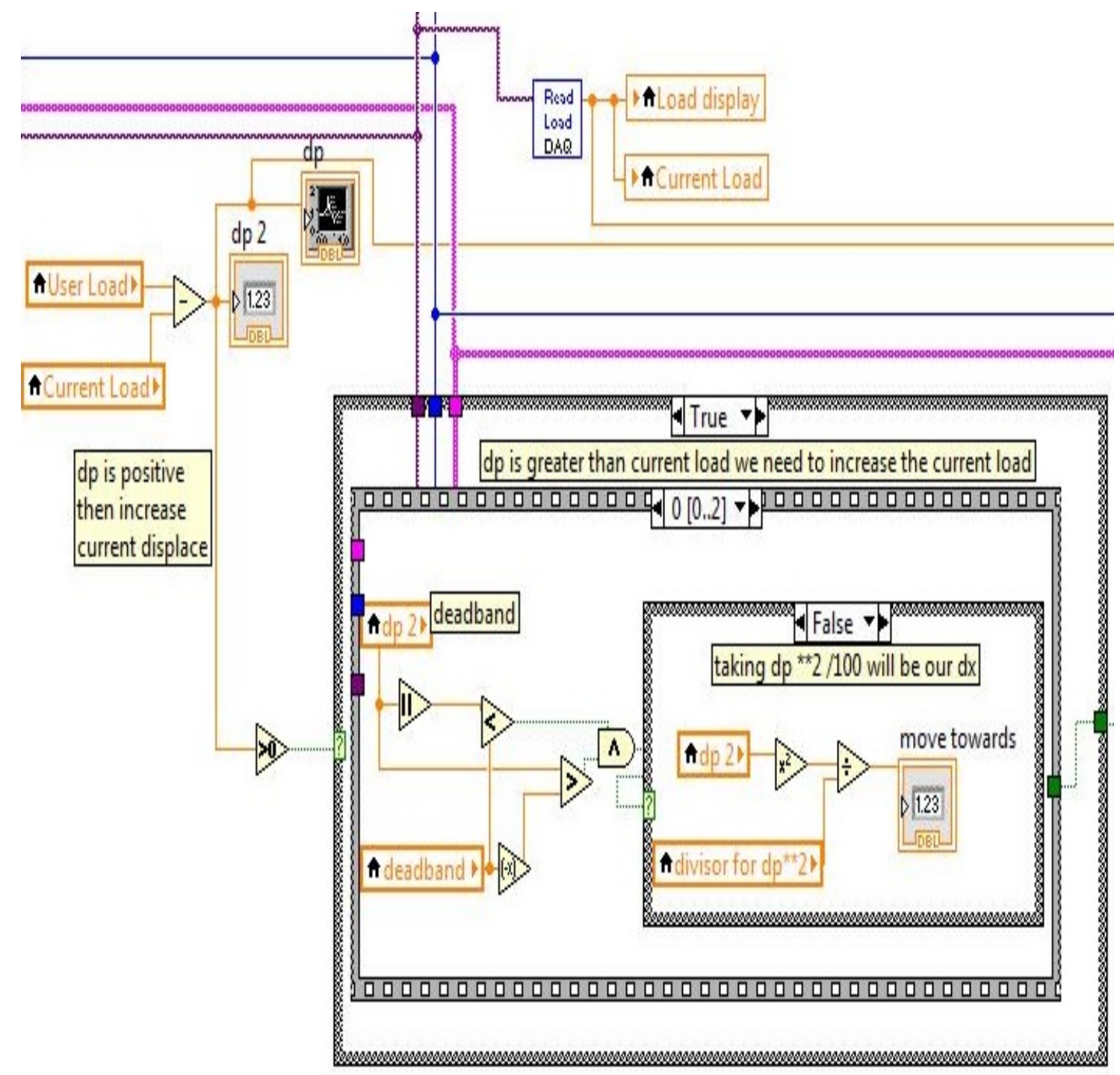

creep test

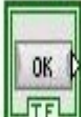

Figure 4.23 Load Control Block diagram True condition 


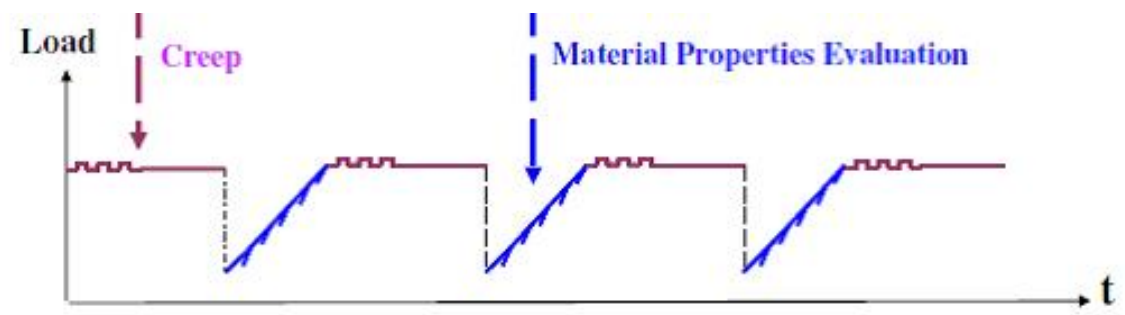

Figure 4.24 Creep and Multiple Partial unloading 


\section{CHAPTER 5}

\section{RESULTS AND CONCLUSIONS}

\subsection{Close-Loop Load Control}

The most important aspect of this creep test is the capability of achieving and keeping constant load precisely during the creep test. Figure 5.1 shows load being held at $5 \mathrm{~N}$ over a period of time.

Solder materials, like lead-antimony solders are extremely soft and extremely deformable under ambient conditions, because the room temperature represents a high homologous temperature to them. Under uniaxial stress, elastic, viscoelastic and inelastic behavior can be observed. The creep behavior of solder material was observed in this study under room.

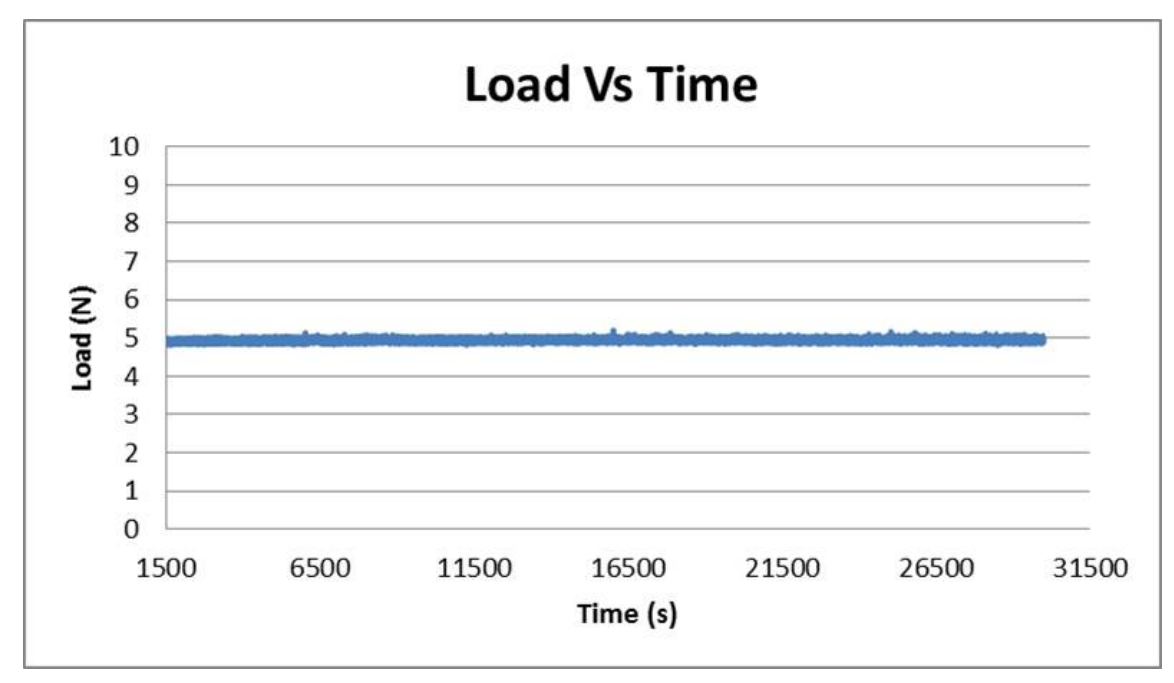

Figure 5.1 Indentation Load Versus Time

$[$ UserInputLoad $=5 \mathrm{~N}]\left[\right.$ ActualLoad $\left.=4.9414 N \pm 5.3724^{-14} \mathrm{~N}\right]$ 


\subsection{Indentation Creep Stress Exponent determination}

The classical approach to compare indentation and uniaxial creep data makes use of conversion factors. The section stress $\sigma_{N}$ which characterizes the load in an indentation creep experiment, is defined as the force $F$ applied on the indenter divided by the cylindrical indenter area A: $\sigma_{N}=F / A$. The conversion factors $c_{o}$ relates the net section stress $\sigma_{N}$ to an appropriate uniaxial reference stress $\sigma$ by

$$
\sigma=c_{o} \sigma_{N}
$$

where $c_{o}$ is a conversion factor which ranges from $0.26-0.36[45]$. The uniaxial reference strain rate $\dot{\epsilon}$ is

$$
\dot{\epsilon}=c_{2} \frac{\dot{d}}{2 r}
$$

where $\dot{d}$ is indentation creep depth rate (indentation rate), $c_{2}$ a conversion factor which is usually $1,[45]$, and $\mathrm{r}$ the indenter radius. Here we use conversion factors $c_{2}=0.865$. Hyde et al. [98] determined the conversion factor to relate creep data from indentation and tensile creep to be $c_{2}=0.755$ determined from finite element calculations.

Following the uniaxial creep behavior of materials, the creep stress exponent is determined from Norton's creep law:

$$
\dot{\epsilon}=c_{m} \sigma^{n_{m}}
$$

In the creep experiment, displacement and time are measured first. From this data Figure 5.4,Figure 5.3 and Figure 5.2 it is possible to extract contact radius utilizing equation 2.1. Where $a$ is contact radius, $h$ is indentation depth, $\mathrm{D}$ is indenter Diameter, and $C=0.943$ (for Hertzian Elastic Case)

$$
a=C * \sqrt{D * h}
$$




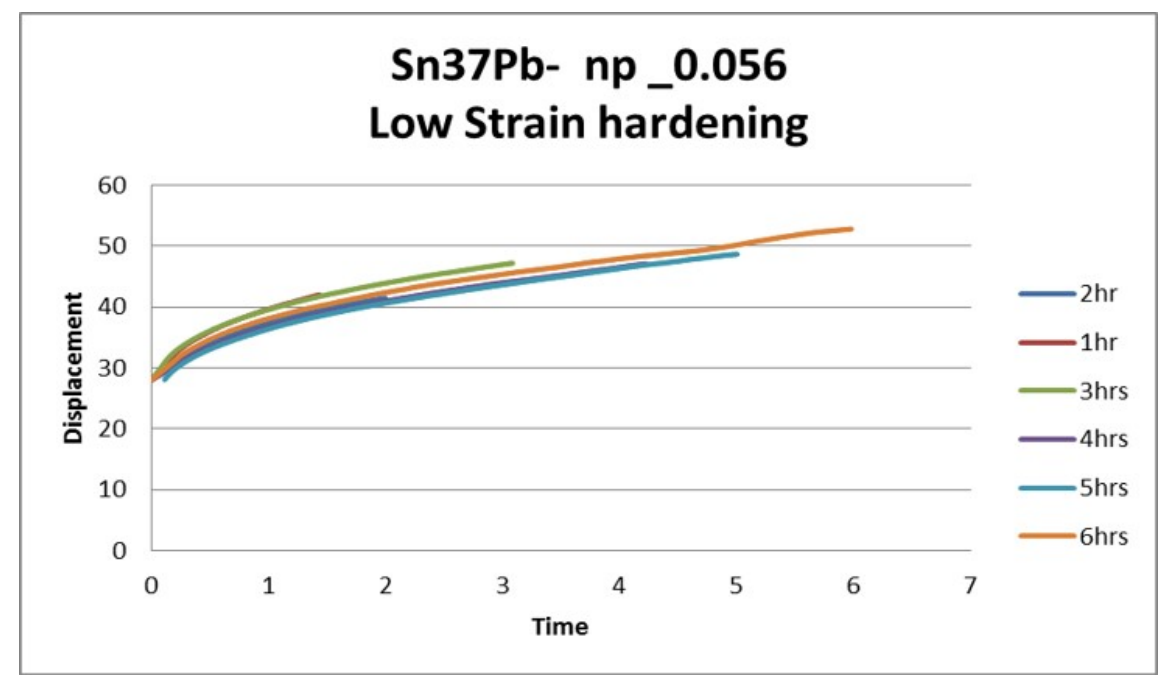

Figure 5.2 $\mathrm{Sn} 37 \mathrm{~Pb}$ Displacement time curve

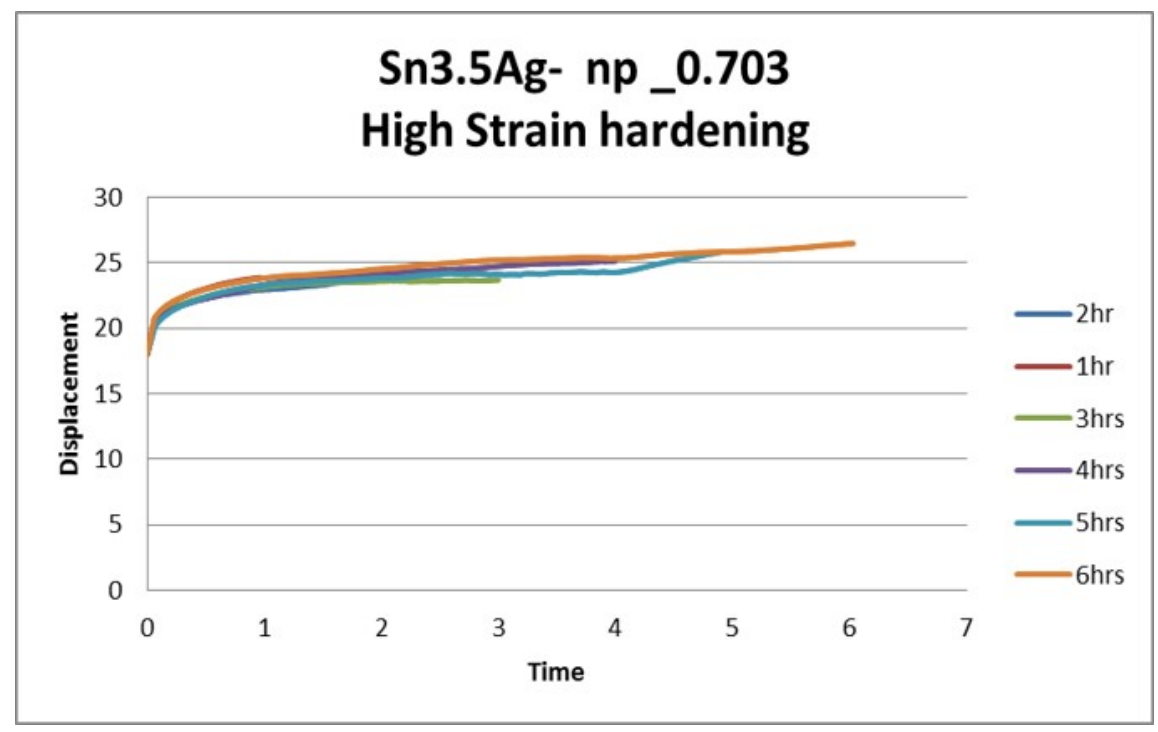

Figure 5.3 Sn3.5Ag Displacement time curve

The net section stress $\sigma_{N}$, which characterizes the load in an indentation creep experiment, is defined as the force $F$ applied on the indenter divided by the cylindrical indenter area $A: \sigma_{N}=\frac{F}{\Pi a^{2}}$. The conversion factors $c_{o}$ relates the net section stress $\sigma_{N}$ to an appropriate uniaxial reference stress $\sigma$ by

$$
\sigma=c_{o} \sigma_{N}
$$




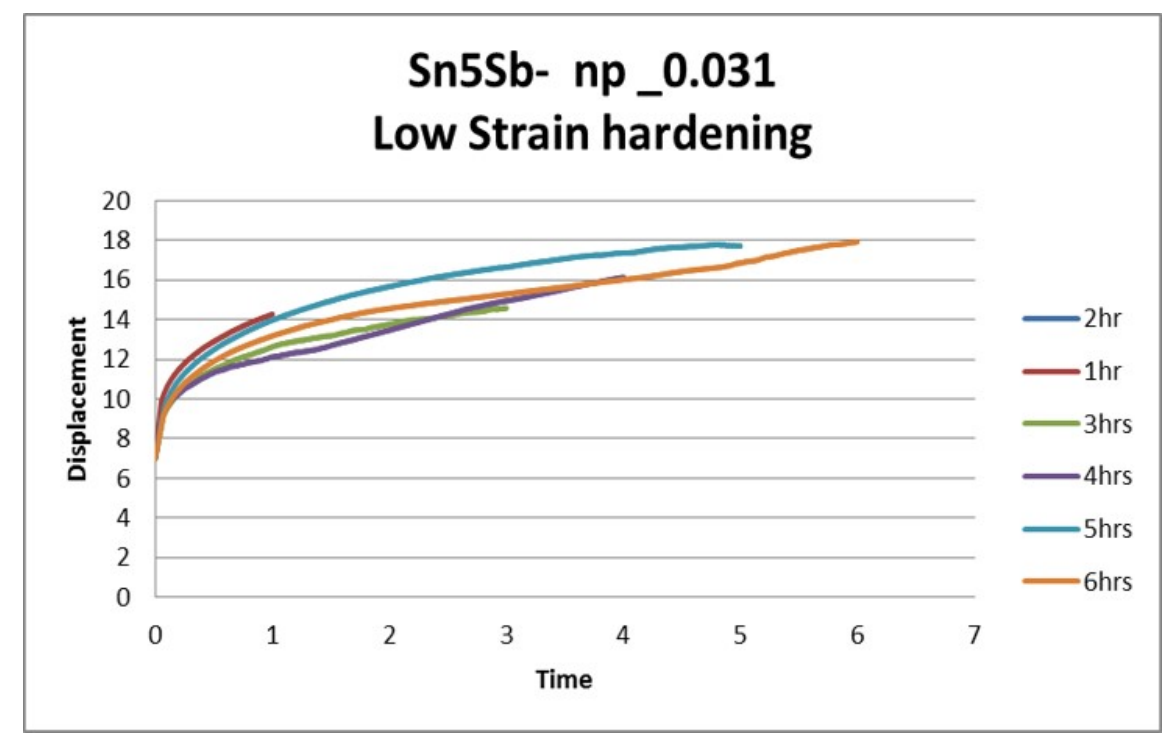

Figure 5.4 Sn5Sb Displacement time curve

where $c_{o}$ is a conversion factor with range $0.26-0.36$. The uniaxial reference strain rate $\dot{\epsilon}$ is

$$
\dot{\epsilon}=C_{2} \frac{\dot{d}}{2 r}
$$

where $\dot{d}$ is indentation creep depth rate (indentation rate), $c_{2}$ a conversion factor, and $\mathrm{r}$ the indenter radius. Here we use $C_{2}=0.865$ determined from iteration calculations performed.[46]

$$
n=\left[\frac{\log (\dot{\epsilon})}{\log (\sigma)]}\right.
$$

\subsection{Traditional Tensile Creep test}

Tensile tests were carried out on $S n 37 \mathrm{~Pb}, S n 3.5 \mathrm{Ag}$ and $S n 5 S b$ solder alloys on a commercial closed-loop servo-hydraulic test machine and conducted as per ASTM E8M-98 under stroke control with a strain rate of $10^{-3} s^{-1}$ at room temperature. Creep tests were conducted at constant loads for these different alloys individually. After the creep rupture tests, specimen cross-sections were analyzed using an optical microscope and the creep rupture 
mechanisms were based on the fractography. The creep tests were performed in accordance with ASTM E139-96 under constant load, and at testing temperatures corresponding to a range of about $0.5-0.74 T_{m}$ (homologous temperature) for the two given lead solders. A direct-load creep testing machine was used to perform the constant-load creep test with application of various load weights as the loading source. Creep curves obtained for these solder alloys are seen in Figures 5.5, 5.6 and 5.7. The Sn3.5Ag solder has the greatest creep strength among the given three alloys, as it shows the highest value of stress exponent, lowest minimum creep rate, and longest rupture time at a given stress and temperature.

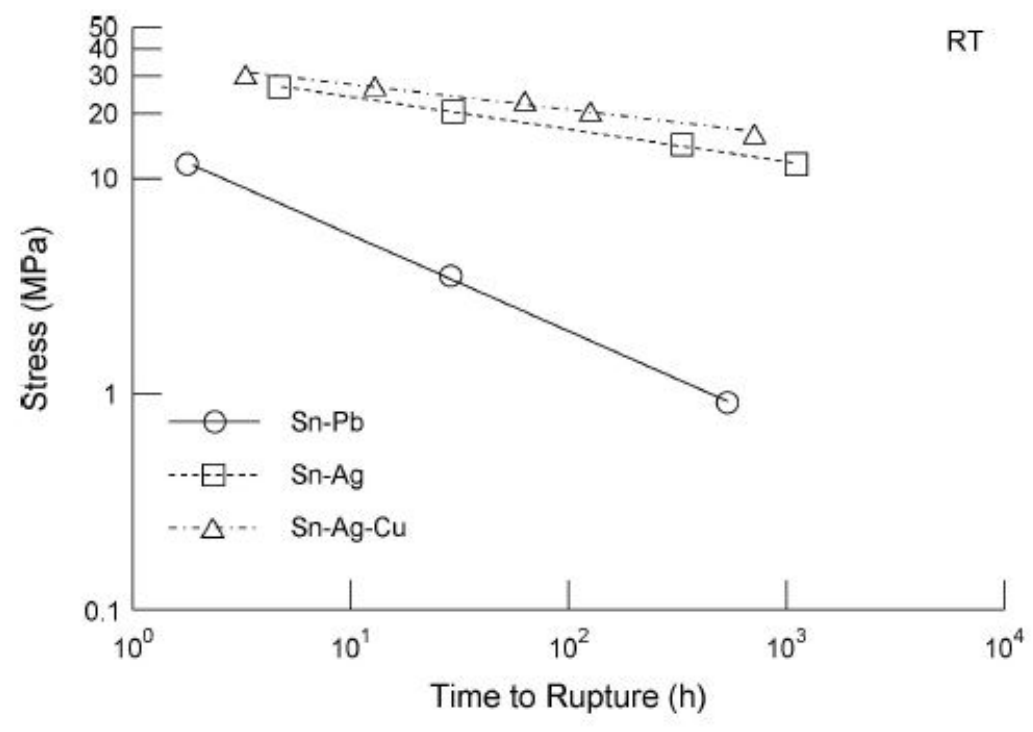

Figure 5.5 Time to Rupture Sn3.5Ag

\subsection{Experimental procedure}

The materials used were three tin alloys, $S n 37 \mathrm{~Pb}, S n 3.5 \mathrm{Ag}$ and $S n 5 S b$. These samples were polished and then tested utilizing the constant load hold multiple partial loading 


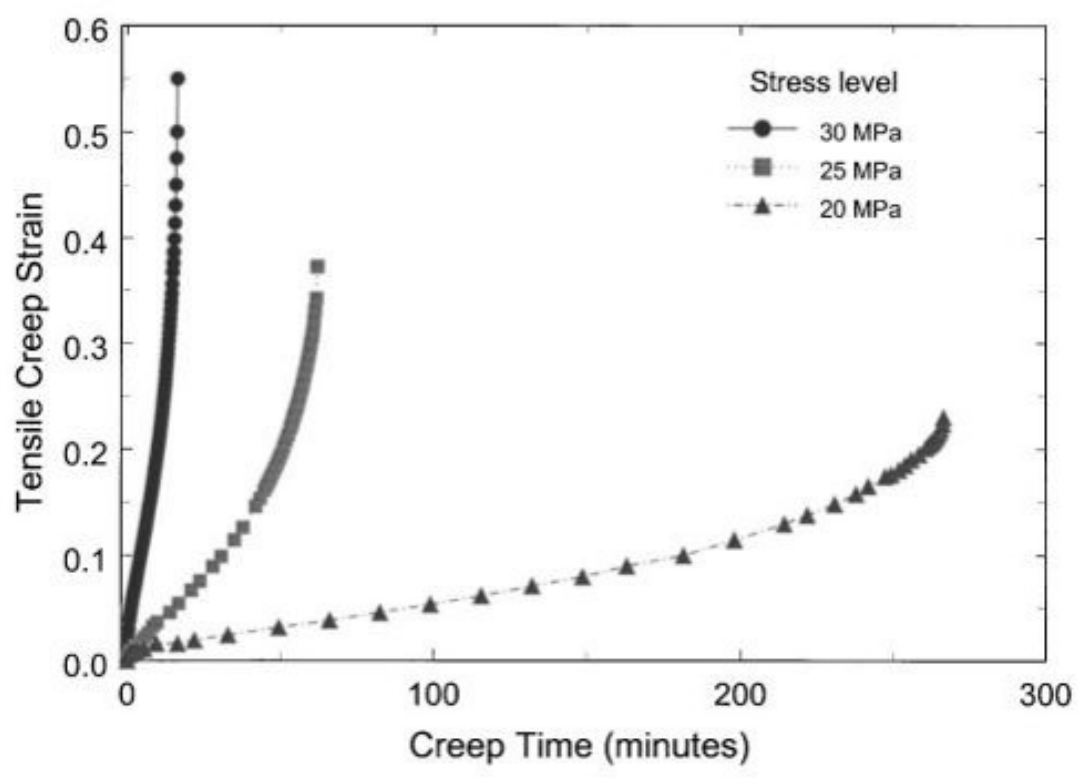

Figure 5.6 Creep curve $\mathrm{Sn} 37 \mathrm{~Pb}$

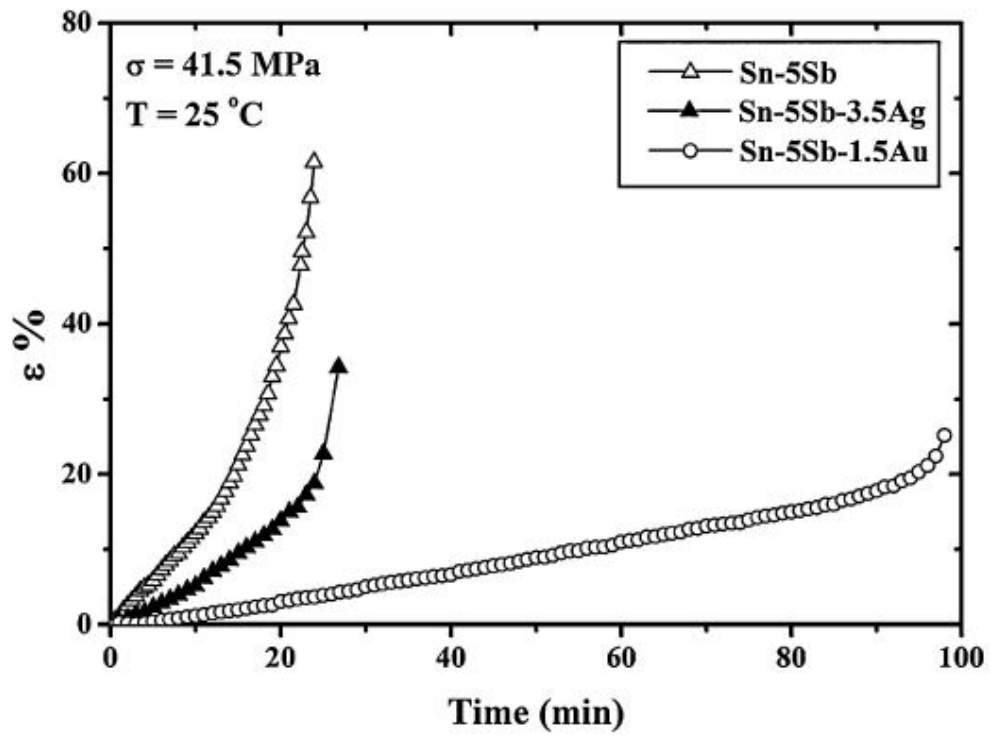

Figure 5.7 Creep Curve Sn-5Sb

and unloading technique, where the applied load and testing time were the only variables. Indentation load of $5 N$ for a dwell time of $6 \mathrm{hrs}$ minimum. The variation of indentation 
depth vs time can be seen in Figures 5.2, 5.4 and 5.5. It can be seen that the indentation length increases with the loading time and the applied load. As can be seen in these figures, the curves consist of two stages similar to an ordinary creep curve. The first stage of the curve records an increase in the concerned variable with time, with a decreasing rate, followed by a steady- state region where indentation sizes increase linearly with time. As the indentation test is actually a compression test, fracture of the specimen does not occur and hence, it is obviously not possible to record the third stage of the curve as opposed to what happens in an ordinary creep tests. The testing methodology proposed in this research will be used to determine the tertiary stage of creep as observed during tensile test utilizing a unique multiple partial loading and unloading technique during creep constant load indentation. Figures 5.2, 5.4 and 5.3 also indicates that $S n 37 \mathrm{~Pb}, S n 3.5 \mathrm{Ag}$ and $S n 5 S b$ alloys exhibit different indentation creep behavior. Useful in design production of solder alloys, this methodology would be used to extract creep damage characteristics at a specified stress and temperature The stress exponent obtained for each alloy via the above mentioned approach, are represented in Table 5.1.

Table 5.1 Stress Exponents

\begin{tabular}{|l|lr|l|l|}
\hline \hline Materials & $\begin{array}{l}\text { Depth } \\
\text { Stress }\end{array}$ & $\begin{array}{r}\text { Sensing } \\
\text { Expo- } \\
\text { nent(n) Method } \\
\text { using PZT }\end{array}$ & $\begin{array}{l}\text { Strain Hardening } \\
\text { Exponent } n_{p}\end{array}$ & Error (\%) \\
\hline $\mathrm{Sn} 37 \mathrm{~Pb}$ & 6.5 & 0.056 & $4.8 \%$ \\
$\mathrm{Sn} 3.5 \mathrm{Ag}$ & 10.2 & 0.703 & $6.4 \%$ \\
$\mathrm{Sn} 5 \mathrm{Sb}$ & 2.6 & 0.031 & $13 \%$ \\
\hline
\end{tabular}

Utilizing equations 5.7, 5.6, 5.5 and 5.4, $\log \dot{\epsilon} / \log \sigma$ plots of the three alloys in this study were made in Figures 5.8, 5.10 and 5.9.

The stress exponents calculated using the depth sensing stress exponent method are 


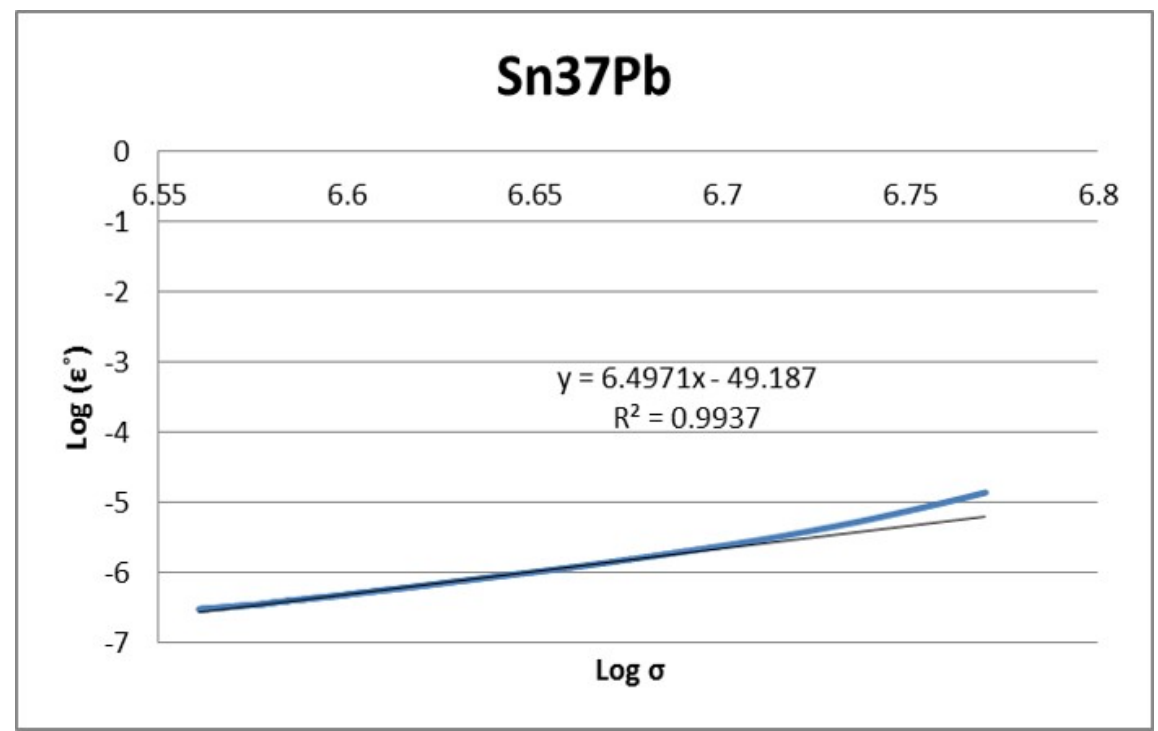

Figure 5.8 Derivation of Stress Exponent fo Sn37Pb

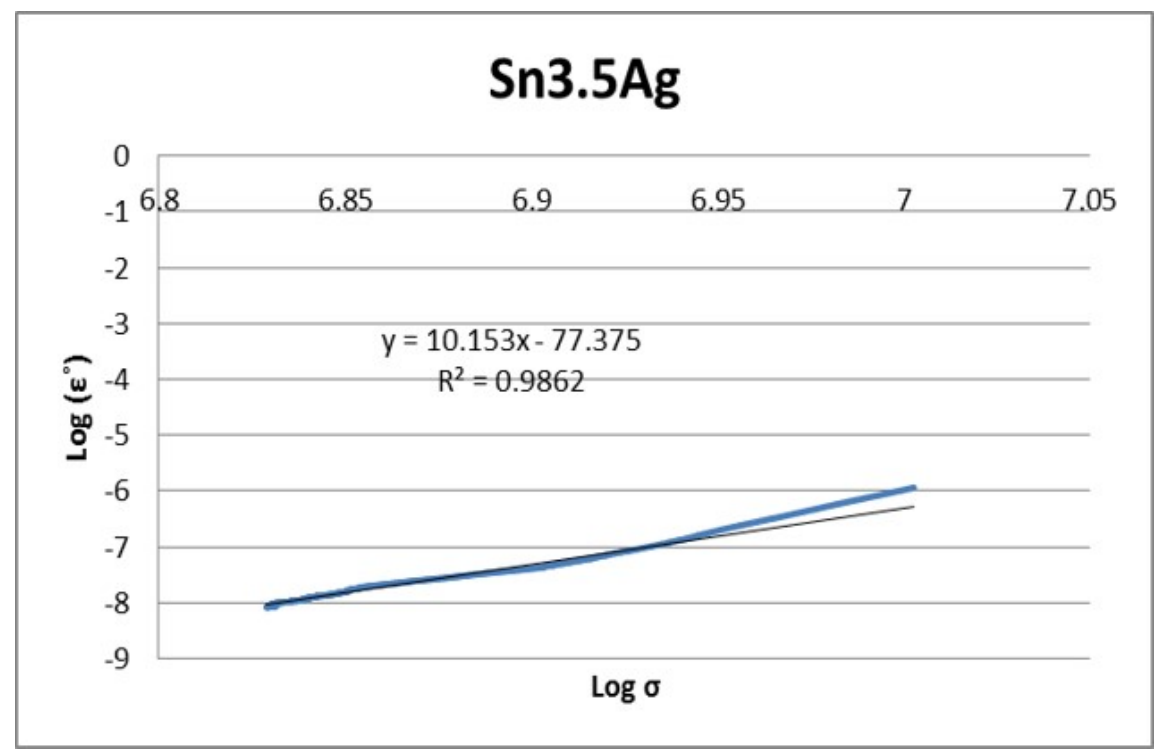

Figure 5.9 Derivation of Stress Exponent for Sn3.5Ag

in good agreement with the stress exponent calculated using traditional tensile test.It should be considered that difference of one or two units in stress exponent values has no real physical significance when dealing with deformation mechanisms. According to the power law creep, a decrease in stress exponent would result in an increase in creep rate due to a decrease 


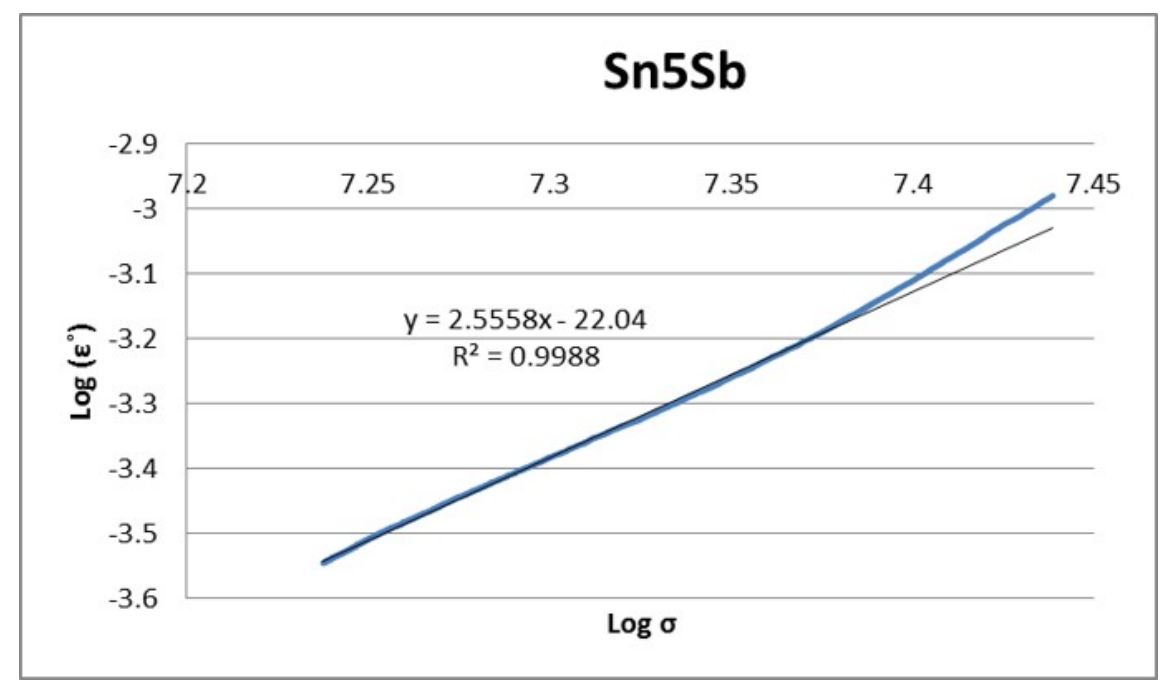

Figure 5.10 Derivation of Stress Exponent for Sn5Sb

in yield strength [42]. Therefore the $S n 3.5 \mathrm{Ag}$ alloy with higher $n$ values is more resistant to indentation creep compared to $S n 37 \mathrm{~Pb}$ and $S n 5 S b$ alloys. The same result can be extracted from the indentation curves shown in Figures 5.3, 5.2 and 5.4. The stress exponent values can be used to identify the mechanisms controlling the deformation process. Diffusional creep is associated with the $\mathrm{n}$ values around 1 , grain boundary sliding leads to $n$ values close to 2 and mechanisms attributed to dislocation movement such as slip creep are linked to $n$ values in the range of $5-7$ which moves up to higher values than 8 when particles reinforcement takes place [42]. The high stress exponents obtained for present materials indicate that creep deformation is related to the dislocation movement and thus, grain size is the controlling parameter of deformation.

\subsection{Creep Continuous Stiffness Response CCSR}

During indentation creep, the stiffness response can be extracted using the unique multiple partial loading and unloading sequence described in Section 3.2.2. The CCSR is accomplished by performing multiple partial loading and unloading during creep indentation utilizing Lab view software created. Compared to a traditional creep test, the CCSR are 
particularly useful as they measure contact stiffness in small indents carried out over a long period of time. The depth sensing indenter used in this study can extract the stiffness response of the material during indentation creep withing seconds utilizing multiple partial loading and unloading discussed in 3.2.2.

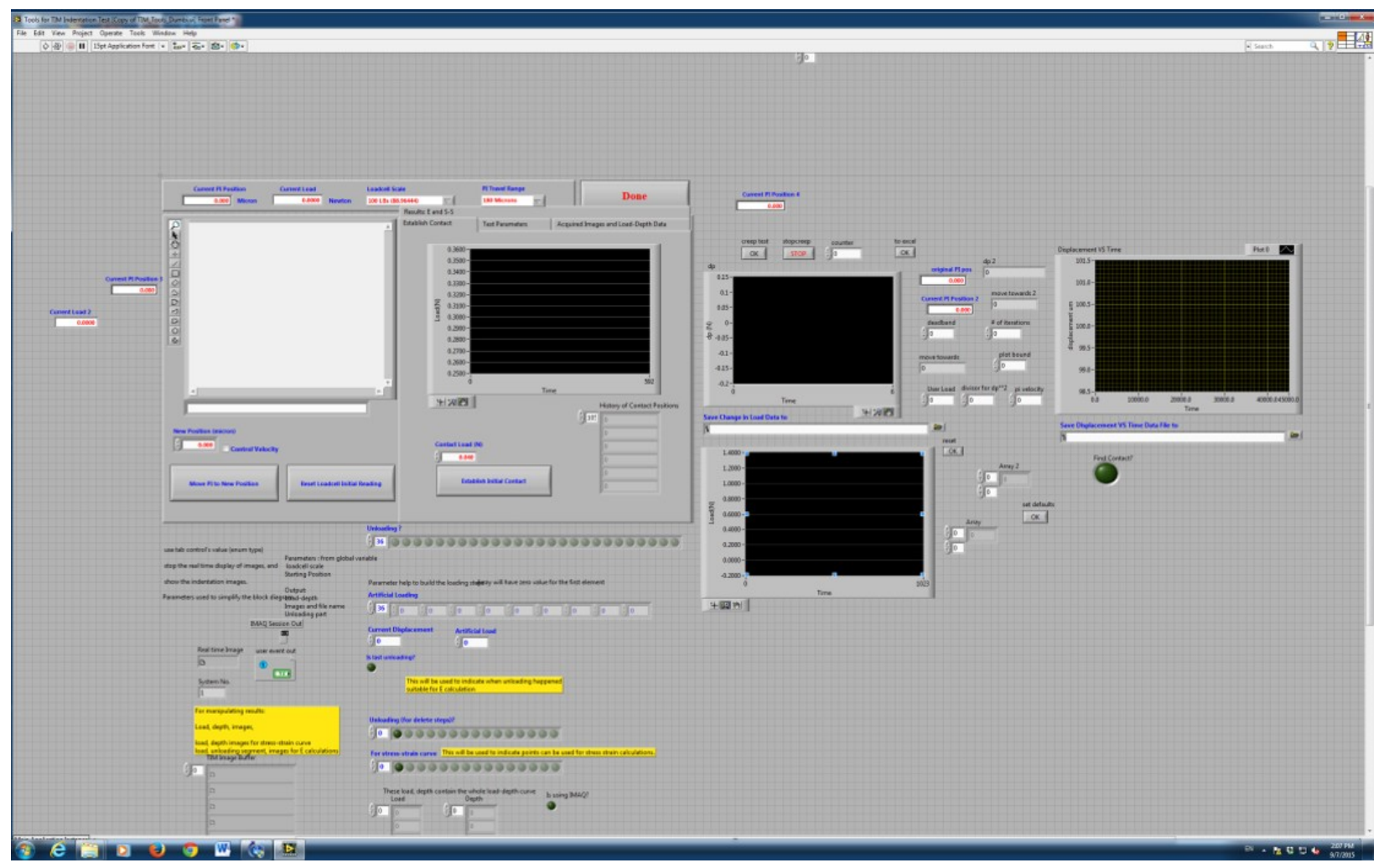

Figure 5.11 BI Function LabView Control Software

To accomplish this, a system capable of controlling the indenter at constant load was developed in section 5.1. Integrating this system into a bi-functional system, the contact stiffness response is measured for approximately 30 seconds utilizing the multiple partial loading and unloading technique every hour during the indentation creep. The solder alloys studied from 5.1, all have different strain hardening exponent, which was later found to contribute to the stiffness response during creep. 


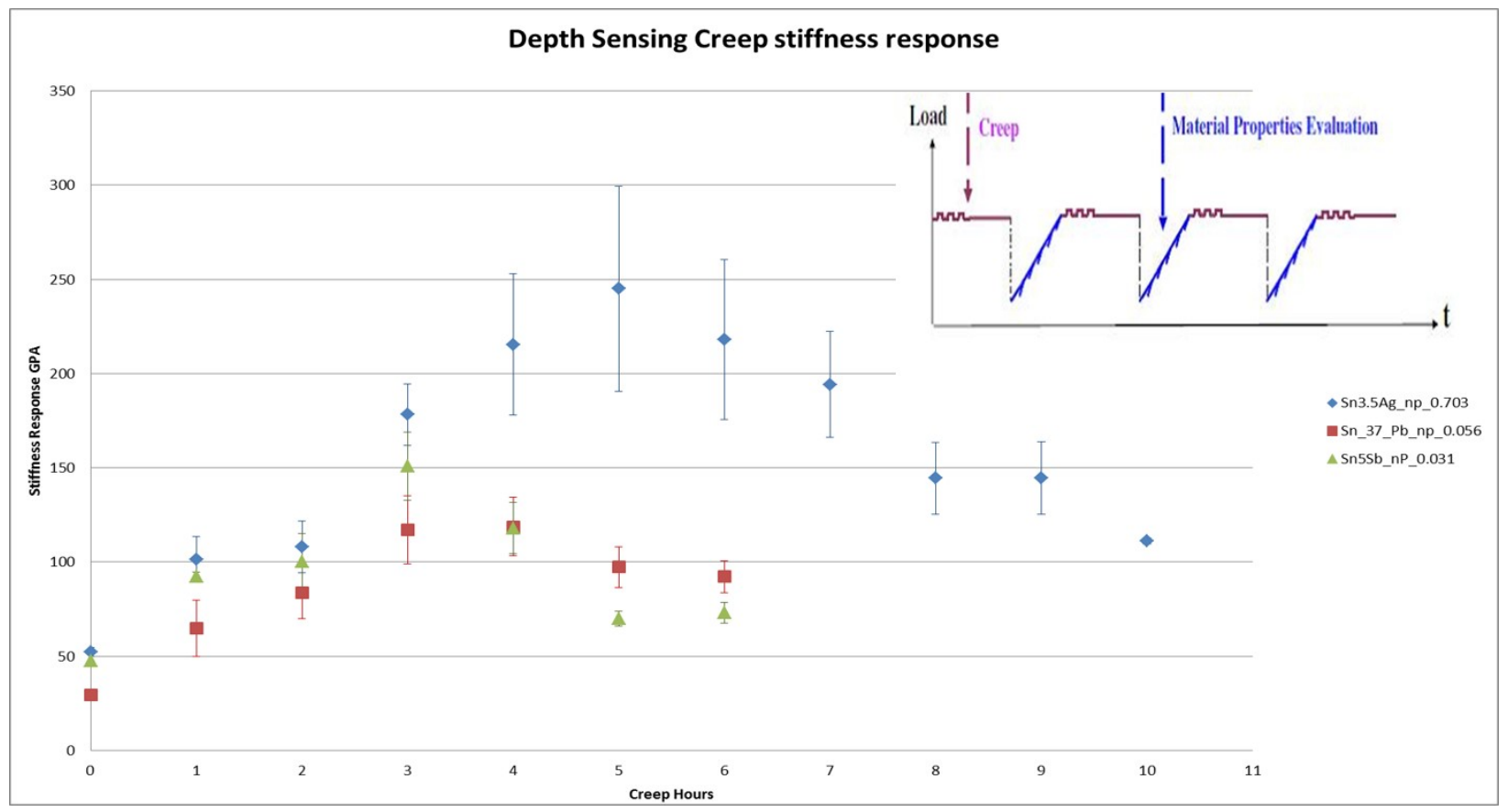

Figure 5.12 Stiffness Response During Indentation Creep

Figure 5.12 shows creep stiffness response of three solder alloys utilizing CCSR method. It can be observed that the contact stiffness response increases with time during the creep indentation method, and eventually drops when creep damage sets in. This can be seen when comparing with creep rupture time experiments performed during traditional tensile tests as discussed in Section 5.3[47, 34]. Sn3.5 Ag exhibits the highest strain hardening exponent, which transcribes to a larger resistance in deformation during indentation creep. As can be seen in Figure 5.12, the strain hardening exponent plays a role in the variation seen in contact stiffness response during indentation creep. Multiple partial loading and unloading utilized in this study can be separated into two methods, Low depth sensing and High depth sensing.

Low depth sensing involves using the multiple partial loading unloading technique up to 5 unloading points, which reduces the response of the material to the top most layer see Figure 5.13.

While high depth sensing utilizes the same technique up to 10 unloading points which 


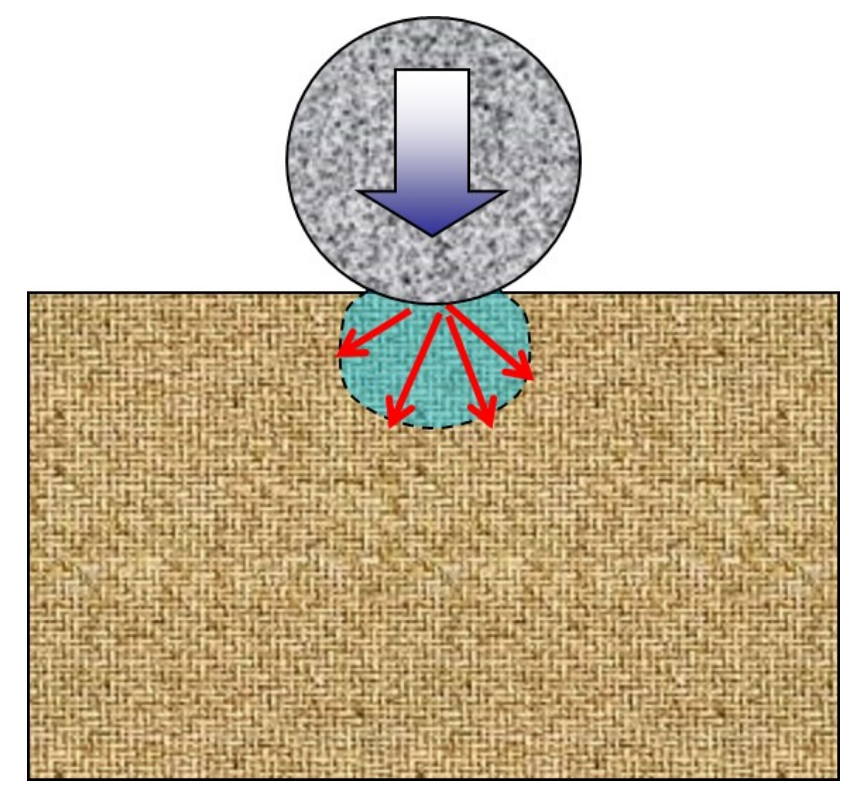

Figure 5.13 Creep Contact Stiffness Response Low depth Sensing

obtains responses from the substrate of the material see Figure 5.14.

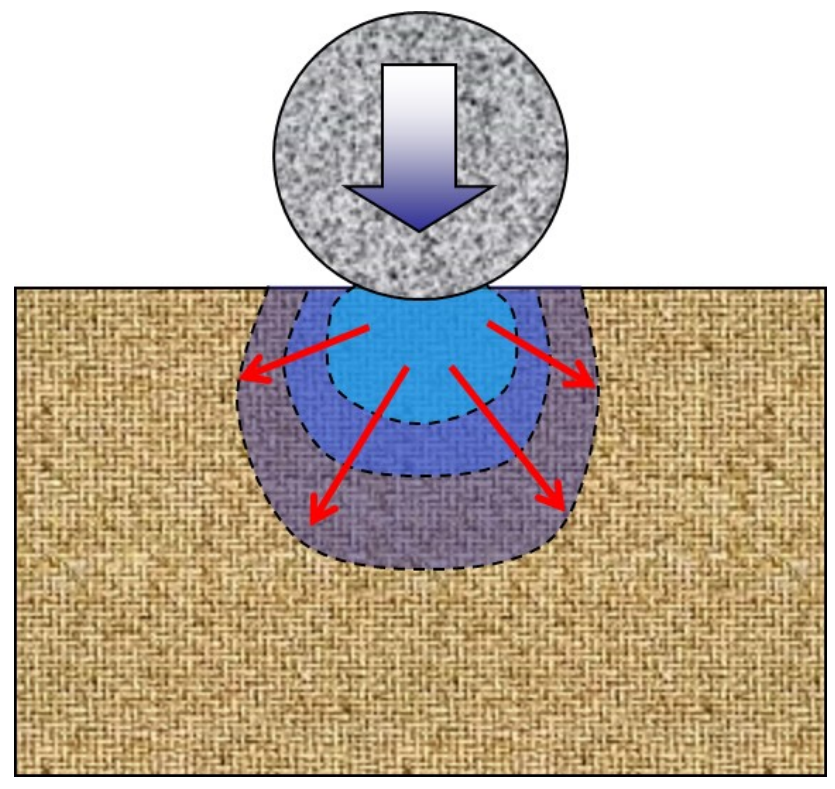

Figure 5.14 Creep Contact Stiffness Response High depth Sensing 
During indentation creep it was observed that solder materials with higher strain hardening exponent exhibited larger differences between 5 unloading and 10 unloading responses over time. The 5 unloading picks up stiffness response from the surface of the material, so during the early stages of indentation creep, stiffness response from the substrate on top layer of the material are similar. During later stages of indentation creep, strain hardening occurs, which is dependent on the strain hardening exponent. At this point, usually before tertiary creep comes in play, 5 unloading picks up a larger stiffness response which is indicative of localized deformation caused by indentation creep. The conclusions from our tests indicate that materials with higher strain hardening exhibit larger differences between low and high depth sensing, due to the strain hardening during indentation.

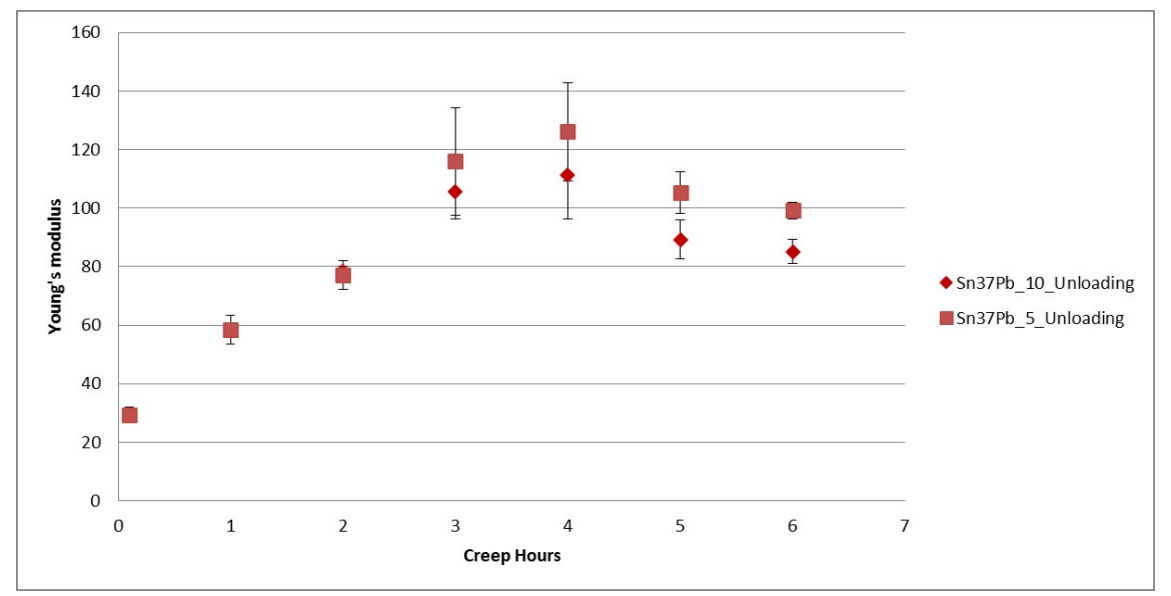

Figure 5.15 $\mathrm{Sn} 37 \mathrm{~Pb}$ with Low Strain Hardening showing low variation in stiffness response from Low and High depth sensing

The 10 unloading picks up stiffness response far from the surface of the material, so during the early stages of indentation creep, stiffness response from the substrate on top layer of the material are similar. During later stages of indentation creep, strain hardening occurs, which is dependent on the strain hardening exponent. Using 10 unloading shows stiffness response further away from the Top layer of the material which is further from the 
region of localized deformation caused by indentation creep.

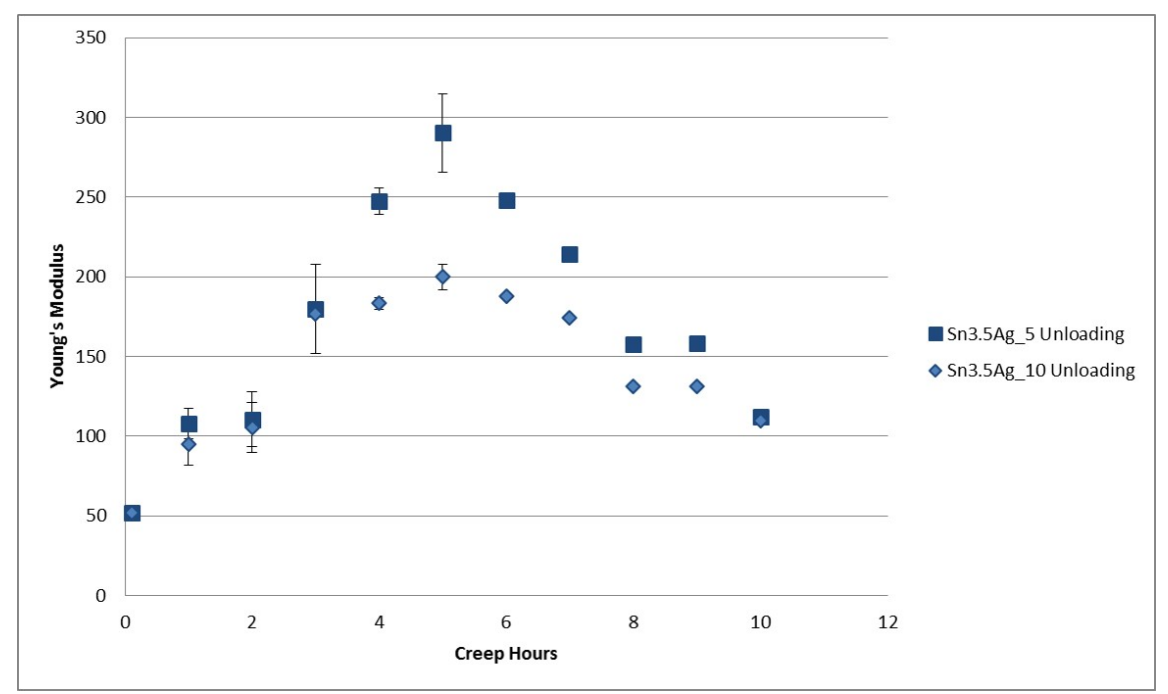

Figure 5.16 Sn3.5Ag with high strain hardening showing large variation in stiffness response from Low and High depth sensing

\subsection{Remaining Life Creep Continuous Stiffness Response CCSR}

For design purposes, it would be ideal to have methods available for correlating and extrapolating creep-rupture data such that the rupture time can be accurately predicted. Monkam-Grant [48] and Larson-Miller [49] relationships, were used in this current study to correlate the rupture time data for the given lead free solders under the given test conditions.

Monkman and Grant [48] observed that the rupture time, $t_{f}$ in long term creep test could be related to the minimum strain rate by a power law function:

$$
\dot{\epsilon}_{m i n} t_{f}^{m}=C_{M G}
$$

where the exponent $\mathrm{m}$ and constant $C_{M G}$ are material dependent. The constant $C_{M G}$ usually depends on temperature. The practical advantage of the Monkman-Grant rule is 
that the minimum strain rate can be measured early in a creep test so as to predict a long life case. As long as the value of $C_{M G}$ can be predicted in short-term tests, the remaining life can then be predicted once the minimum strain rate has been established [47]

Monkman-Grant relationship for each given lead-free solder alloy is approximately independent of temperature over the range of given test conditions. Therefore we can estimate the rupture time from the minimum creep rate or vice versa. This model serves as a useful tool to predict the rupture time for the given two lead-free solders at various combinations of stress and temperature. Rupture time correlates well with minimum creep rate implies cavity formation and growth is basic to the inter granular creep fracture process[48].

Another model used in this study is the Larson-Miller relationship, which is similar in principle but different in its functional form. In 1952, Larson and Miller assumed the following relationship between creep lifetime, applied stress and temperature [49]:

$$
P_{L M}=T\left(C_{L M}+\log t_{f}\right)
$$

Where $P_{L M}$ is the Larson-Miller parameter and is a function of applied stress, $T$ is temperature in Kelvin and $t_{f}$ is creep rupture time in hours. Extracting values of $C_{L M}$ can be gotten from intercept of $\log t_{f}$ versus $1 / T$ discussed in [47]. From equation 5.9, the Larson-Miller Parameter $P_{L M}$ can be determined for different alloys at different stress levels.

In order to estimate the rupture time utilizing CCSR, it is proposed in this work to correlate the stiffness response gotten during indentation creep over a period of time by normalizing the young's modulus with the applied stress. It is assumed an independent relationship of temperature in the creep rupture time prediction model. It means the intrinsic temperature dependence of rupture time is implied in the Young's modulus term.

Utilizing a simple power law $\frac{E}{E_{d}} t_{f}^{z}=L$, where $E$ is the youngs modulus, $E_{d}$ is the stiffness response obtained during indentation creep utilizing CCSR technique, Z and L are constants modified from Larson-Miller parameters for these specific solder alloys. 


$$
\begin{gathered}
\frac{E}{E_{d}} t_{f}^{z}=0.005-----S n 3.5 \mathrm{Ag} \\
\frac{E}{E_{d}} t_{f}^{z}=0.00392------S n 37 P b \\
\frac{E}{E_{d}} t_{f}^{z}=0.00178------S n 5 S b
\end{gathered}
$$

Table 5.2 Stress Exponents

\begin{tabular}{|l|l|l|l|}
\hline \hline Materials & $\begin{array}{l}\text { Young's } \\
\text { Modulus }\end{array}$ & $\begin{array}{l}\text { CCSR Parame- } \\
\text { ter L }\end{array}$ & Average $t_{f}$ \\
\hline Sn37Pb & 29.3 & 0.00392 & $3.52 \pm 0.37$ \\
Sn3.5Ag & 52.2 & 0.005 & $4.10 \pm 0.60$ \\
Sn5Sb & 47.7 & 0.00178 & $2.98 \pm 0.39$ \\
\hline
\end{tabular}

The values from the Equations 5.105.115.11, creep rupture time can be predicted for these three solders utilizing the CCSR technique.

As discussed the application of these models to analyze the experimental data of rupture time was quite successful to a certain degree for the given solders alloys. In order to estimate the rupture time with young's modulus normalized by the damage modulus.

\subsection{Conclusions}

In this research, material time-dependent behavior of Sn3.5Ag, Sn37Pb and Sn5Sb solder alloys were studied by a unique depth sensing micro-indentation method at room temperature. Stress exponent values were determined through a constant loading process utilizing a spherical micro indentation method, where the strain rate is extracted from the indentation 
rate. The measured stress exponent values are in good agreement with conventional creep experiments. Utilizing a multiple loading and partial unloading micro-indentation testing procedure, time-dependent stiffness changes of these materials could be measured. This continuous stiffness responses during a creep test can be correlated to test materials micro structural changes during creep, therefore making it capable to predict onset of tertiary creep failure. Test results show a correlation between measured continuous stiffness response and creep damage with the capability to predict the onset of tertiary creep of these solder alloys.

The indentation experimental setup studied in this research has a number of advantages

- Specimens can be small in size and simple in shape

- Mechanical properties can be studied for a selected localized region

- High-Temperature and inert gas test atmosphere can be prepared easily

- Material Stiffness response during creep can be evaluated

\subsection{Future Work}

Indentation creep under high temperature condition has received little to no attention due mainly to the inherent difficulties in measuring the small indentation displacements at elevated temperatures. Constant Creep Stiffness Response and high temperature indentation discussed in Chapter 3.4 introduced in this research can bridge the gap in technology required to study micro-indentation at elevated temperatures. 


\section{BIBLIOGRAPHY}

[1] Baoxing Xu, Zhufeng Yue, and Xi Chen. An indentation fatigue depth propagation law. Scripta Materialia, 60(10):854 - 857, 2009.

[2] Ian N. Sneddon. The relation between load and penetration in the axisymmetric boussinesq problem for a punch of arbitrary profile. International Journal of Engineering Science, 3(1):47 - 57, 1965.

[3] X. Baoxing and X. Chen. Determining engineering stress-strain curve directly from the load-depth curve of spherical indentation test. Journal of Materials Research, 25:2297-2307, 2010.

[4] W. C. Oliver and G.M.Pharr. An improved technique for determining hardness and elastic modulus using load and displacement sensing indentation experiments. Journal of Materials Research, 7:1564-1583, 1992.

[5] M. F. Doerner and W.D. Nix. A method for interpreting the data from depth-sensing indentation measurements. Journal of Material Sciences, 1(4), 1986.

[6] Jared Michael Tannenbaum. Progression in Non-Destructive Spallation Prediction and Elevated Temperature Mechanical Property Evaluation of Thermal Barrier Coating Systems by use of a Spherical Micro-Indentation Method. PhD thesis, West Virginia University, 2011.

[7] C. Feng. and B. Kang. A transparent indenter measurement method for mechanical property evaluation. Experimental Mechanics, 46(1):91-103, 2006.

[8] C Feng. Development of a Transparent Indenter Measurement System and Indentation Analysis for Material Mechanical Property Evaluation. PhD thesis, West Virginia University, 2005. 
[9] Dumbi Azubuike Otunyo. Mechanical property evaluation of thermal barrier coating systems at elevated temperatures by use of a spherical micro-indentation method. Master's thesis, West Virginia University, 2012.

[10] C Anthony Fischer-Cripps. Introduction to Contact Mechanics. Springer US, 2007.

[11] Kwangsoon Lee. Numerical Simulation of a Load-Based Microindentation Technique for Nde on Thermal Barrier Coating Systems. PhD thesis, West Virginia University, 2011.

[12] J.S Field and M.V.Swain. A simple predictive model for spherical indentation. Journal of Materials Research, 8(0):297-306, 1993.

[13] D N Jarrett and P W McMillan and. Hertzian strength measurements of opaque brittle materials. J Phys E Sci Instrum, 7(913):0, 1974.

[14] G.M. Pharr, W.C. Oliver, and F.R. Brotzen. On the generality of the relationship among contact stiffness, contact area, and elastic modulus during indentation. Journal of Materials Research, 7(0):613-617, 1992.

[15] Jack C. Hay and G. M. Pharr. Experimental investigations of the sneddon solution and an improved solution for the analysis of nanoindentation data. In Symposium $T$ Fundamentals of Nanoindentation 83 Nanotribology, volume 522 of MRS Online Proceedings Library, 1998.

[16] D J Strange and A K Varshneya. Finite element simulation of microindentation on aluminum. J. Mater. Sci, 36, 1943.

[17] I S Choi, M Dao, and S Suresh. Mechanics of indentation of plastically graded materials - i analysis. J Mech Phys Solids, 56(157):0, 2008.

[18] X Deng, N Chawla, K K Chawla, and M Koopman. Deformation behavior of (cu, ag)-sn intermetallics by nanoindentation. Acta Mater, 52(0):4291, 2004. 
[19] Manhong Zhao, Nagahisa Ogasawara, Norimasa Chiba, and Xi Chen. A new approach to measure the elastic-plastic properties of bulk materials using spherical indentation. Acta Materialia, 54(1):23 - 32, 2006.

[20] K L Johnson, K Kendall, and A D Roberts. Surface energy and contact mechanics of elastic solids. Proceedings of the Royal Society of London, 324:1558, 1971.

[21] C Feng. Development of a Transparent Indenter Measurement System and Indentation Analysis for Material Mechanical Property Evaluation. PhD thesis, West Viirginia University, 2005.

[22] ASTM Standard. Standard practice for instrumented indentation testing, designation: E2546-07, 2007.

[23] Fischer-Cripps. Nanoindentation 2nd ed and. Springer, 2002.

[24] D Dorner amd B Stckhert. Plastic flow strength of jadeite and diopside investigated by microindentation hardness. Tests, Tectonophysics, 379:1-4, 2004.

[25] ASM. Steel Heat Treating Fundamentals and Processes. Library of Congress, 2013.

[26] G Krauss. Physical Metallurgy and Heat Treatment of Steel, in Metals Handbook Desk Edition. American Society for Metals, 1985. p 28-2 to 28-10 editor:H.E. Boyer and T.L Gall, Ed.

[27] P. Panagiotidis, A.S. Antonatos, and G.M. Tsananas. Case depth determination by using vickers micro-hardness test method at trsc / ppc sa. In 4th ICDNT of HSNT, 2007.

[28] Suvi Santa-aho, Minnamari Vippola, Aki Sorsa, Kauko Leivisk, Mari Lindgren, and Toivo Lepist. Utilization of barkhausen noise magnetizing sweeps for case-depth detection from hardened steel. $\{$ NDT\} $\&$ E International, 52(0):95 - 102, 2012. 
[29] J. Gauthier, T.W. Krause, and D.L. Atherton. Measurement of residual stress in steel using the magnetic barkhausen noise technique. $\{N D T\} \& \mathcal{E}$ E International, 31(1):23 $-31,1998$.

[30] V. Moorthy, S. Vaidyanathan, T. Jayakumar, and Baldev Raj. Microstructural characterization of quenched and tempered 0.2steel using magnetic barkhausen noise analysis. Journal of Magnetism and Magnetic Materials, 171(12):179 - 189, 1997.

[31] M S Good, G J Schuster, and J R Skorpik. Ultrasonic material hardness depth measurement. United States Patent, Patent No 5646351, 5646351(5646351), 1997.

[32] R. Baqeri, F. Honarvar, and R. Mehdizad. Case depth profile measurement of hardened components using ultrasonic backscattering method. In 18th World Conference on Nondestructive Testing, 2012.

[33] Yu N Rabotnov. Creep Problems in Structural Members. American Elsevier Publishing Company, 1969.

[34] S K Mitra and D McLean. Work hardening and recovery in creep. proceedings of the royal society of london. Series A, Mathematical and Physical Sciences, 295(1442):288299, 1966. Retrieved from http://www.jstor.org/stable/2415420.

[35] Barry Neal Lucas. An Experimental Investigation of Creep and Viscoelastic Properties using Depth-Sensing Indentation Techniques. PhD thesis, The University of Tennessee, 1997.

[36] T. Vreeland. Dislocation Dynamics, volume 1. Jaffee (McGraw-Hill Book Company), 1968.

[37] W. D. Nix and B. Ilschner. Strength of Metals and Alloys, volume 1. Pergammon Press, 1980. 
[38] W D Nix and J C Gibeling. Flow and Fracture at Elevated Temperatures, volume 1. American Society for Metals, 1983.

[39] D Tabor. The Hardness of Metals. Clarendon Press, Oxford, 1951.

[40] S Hannula, D S Stone, C Y Science, eds A Geiss, K N Tu, and D R Uhlmann. Electronic packaging materials science. Mater. Res. Soc. Symp. Proc, 40(1):7, 1985.

[41] M J Mayo, W D Alloys, eds P O Kettunen, T K Lepisto, and M E. Nix in strength of metals and. Lehtonen (Pergamon Press, 1415, 1988.

[42] R. Roumina, B. Raeisinia, and R. Mahmudi. Room temperature indentation creep of cast pbsb alloys. Scripta Materialia, 51(6):497 - 502, 2004.

[43] A.R. Geranmayeh and R. Mahmudi. Room-temperature indentation creep of lead-free sn-5 Journal of Electronic Materials, 34(7):1002-1009, 2005.

[44] H M Pollock, D Maugis, and M Barquins. Microindentation Techniques in Materials Science and Engineering, volume 1. ASTM, 1986.

[45] Y.J. Liu, B. Zhao, B.X. Xu, and Z.F. Yue. Experimental and numerical study of the method to determine the creep parameters from the indentation creep testing. Materials Science and Engineering: A, 456(12):103 - 108, 2007.

[46] Y.J. Liu, B. Zhao, B.X. Xu, and Z.F. Yue. Experimental and numerical study of the method to determine the creep parameters from the indentation creep testing. Materials Science and Engineering: A, 456(12):103 - 108, 2007.

[47] Chih-Kuang Lin and De-You Chu. Creep rupture of lead-free sn-3.5ag and sn-3.5ag0.5cu solders. Journal of Materials Science: Materials in Electronics, 16(6):355-365, 2005.

[48] C MONKMAN and N J GRANT. Proc. ASTM 56, 56:593, 1956. 
[49] F R LARSON and J MILLER. Trans. ASME 74, 74:765, 1952.

[50] C. Feng and B. S. Kang. Young's modulus measurement using a simplified transparent indenter measurement technique. Experimental Mechanics, 48(1):9-15, 2007.

[51] C Anthony Fischer-Cripps. A review of analysis methods for sub-micron indentation testing. Vacuum, 58(4):0, 2000.

[52] H Hertz. On the contact of elastic solids. page 0, 1896.

[53] S Basu, A Moseson, and M W Barsoum. On the determination of spherical nanoindentation stress-strain curves. J Mater Res, 21(10):0, 2006.

[54] B S-J Kang, Z Yao, and E J Barbero Web. Post-yielding stress-strain determination using spherical indentation. Mechanics of Advanced Materials \& Structures, 13(2):129$38,2006$.

[55] V Raman and R Berriche. Thin Films: Stresses and Mechanical Properties, volume 188. Mater.Res.Soc.Symp.Proc, 1990.

[56] A I Lure. Three-Dimensional Problems in the Theory of Elasticity. Gostekhizdat, 1964.

[57] C. Feng, J.M. Tannenbaum, B.S. Kang, and M.A. Alvin. A load-based multiple-partial unloading micro-indentation technique for mechanical property evaluation. Experimental Mechanics, 50(6):737-743, 2010.

[58] Atsuko Takita, Katsuhiko Sasaki, and Ken-ichi Ohguchi. A method to identify steady creep strain from indentation creep using a new reference area of indentation. Journal of Electronic Materials, 43(7):2530-2539, 2014.

[59] Hidenari Takagi, Ming Dao, and Masami Fujiwara. Analysis on pseudo-steady indentation creep. Acta Mechanica Solida Sinica, 21(4), 2008. 
[60] Aki Sorsa, Kauko Leivisk, Suvi Santa-aho, Minnamari Vippola, and Toivo Lepist. An efficient procedure for identifying the prediction model between residual stress and barkhausen noise. Journal of Nondestructive Evaluation, 32(4):341-349, 2013.

[61] S.B. Liu, A. Peyronnel, Q.J. Wang, and L.M. Keer. An extension of the hertz theory for three-dimensional coated bodies. Tribology Letters, 18(3):303-314, 2005.

[62] Hyungyil Lee, Jin Haeng Lee, and George M. Pharr. A numerical approach to spherical indentation techniques for material property evaluation. Journal of the Mechanics and Physics of Solids, 53(9):2037 - 2069, 2005.

[63] Jin Haeng Lee, Taehyung Kim, and Hyungyil Lee. A study on robust indentation techniques to evaluate elasticplastic properties of metals. International Journal of Solids and Structures, 47(5):647 - 664, 2010.

[64] S. Djordje, B Srdjan, M Sava, and H Stanley. Barkhausen noise: Elementary signals, power laws, and scaling relations. Center for Polymer Studies Physical Review, 54(3):2531-2546, 1996.

[65] Santa aho Suvi. Barkhausen Noise Method for Hardened Steel Surface Characterization - The Effect of Heat Treatments, Thermal Damages and Stresses. PhD thesis, Tampere University of Technology, 2012.

[66] Catherine A. Tweedie and Krystyn J. Van Vliet. Contact creep compliance of viscoelastic materials via nanoindentation. Journal of Materials Research, 21:1576-1589, 2006.

[67] J Betten. Creep Mechanics. Springer-Verlag Berlin Heidelberg, 2008.

[68] Rocio Seltzer and Yiu-Wing Mai. Depth sensing indentation of linear viscoelasticplastic solids: A simple method to determine creep compliance. Engineering Fracture Mechanics, 75(17):4852 - 4862, 2008. Fundamentals of Fracture. 
[69] Surya R. Kalidindi and Siddhartha Pathak. Determination of the effective zero-point and the extraction of spherical nanoindentation stress-strain curves. Acta Materialia, 56(14):3523-3532, 2008.

[70] F Lei. Development and Applications of Electrical Instrumented Indentation. PhD thesis, The Pennsylvania State University, 2009.

[71] Ziheng Yao. Development of an Indentation Method for Material Surface Mechanical Properties Measurement. PhD thesis, West Virginia University, 2005.

[72] B. Taljat and G.M. Pharr. Development of pile-up during spherical indentation of elasticplastic solids. International Journal of Solids and Structures, 41(14):3891 3904, 2004.

[73] V. Moorthy, B.A. Shaw, and J.T. Evans. Evaluation of tempering induced changes in the hardness profile of case-carburised $\{$ EN36\} steel using magnetic barkhausen noise analysis. $\{$ NDT\} $\mathscr{E}$ E International, 36(1):43 - 49, 2003.

[74] M. Beghini, L. Bertini, and V. Fontanari. Evaluation of the stress-strain curve of metallic materials by spherical indentation. International Journal of Solids and Structures, 43(78):2441 - 2459, 2006.

[75] YuebinCharles Lu, SivaN.V.R.K. Kurapati, and Fuqian Yang. Finite element analysis of deep indentation by a spherical indenter. Journal of Materials Science, 43(18):63316336, 2008.

[76] S. Kucharski and Z. Mrz. Identification of plastic hardening parameters of metals from spherical indentation tests. Materials Science and Engineering: A, 318(12):65 - 76, 2001.

[77] S. Kucharski and Z. Mrz. Identification of yield stress and plastic hardening parame- 
ters from a spherical indentation test. International Journal of Mechanical Sciences, 49(11):1238 - 1250, 2007.

[78] K. Zeng and Y. W. Zhang. Indentation creep of polymeric materials: experimental and analysis. In 11th International Congress on Fracture.

[79] A. F. Bower, N. A. Fleck, A. Needleman, and N. Ogbonna. Indentation of a power law creeping solid. Proceedings: Mathematical and Physical Sciences, 441(1911):97-124, 1993.

[80] X. Hernot, O. Bartier, Y. Bekouche, R. El Abdi, and G. Mauvoisin. Influence of penetration depth and mechanical properties on contact radius determination for spherical indentation. International Journal of Solids and Structures, 43(1415):4136 - 4153, 2006.

[81] X. Hernot, O. Bartier, Y. Bekouche, R. El Abdi, and G. Mauvoisin. Influence of penetration depth and mechanical properties on contact radius determination for spherical indentation. International Journal of Solids and Structures, 43(1415):4136 - 4153, 2006.

[82] A. Bolshakov and G. M. Pharr. Influences of pileup on the measurement of mechanical properties by load and depth sensing indentation techniques. Journal of Materials Research, 13:1049-1058, 1998.

[83] J. Hay. Introduction to instrumented indentation testing. Experimental Techniques, 33(6):66-72, 2009.

[84] R. Mahmudi, A. Rezaee-Bazzaz, and H.R. Banaie-Fard. Investigation of stress exponent in the room-temperature creep of sn40pb2.5sb solder alloy. Journal of Alloys and Compounds, 429(12):192 - 197, 2007. 
[85] Mats Eskner and Rolf Sandstrm. Measurement of the elastic modulus of a plasmasprayed thermal barrier coating using spherical indentation. Surface and Coatings Technology, 177178(0):165 - 171, 2004. Proceedings of the 30th International Conference on Metallurgical Coatings and Thin Films.

[86] Mats Eskner and Rolf Sandstrm. Mechanical properties and temperature dependence of an air plasma-sprayed nicocraly bondcoat. Surface and Coatings Technology, 200(8):2695 - 2703, 2006.

[87] B. Taljat, T. Zacharia, and F. Kosel. New analytical procedure to determine stressstrain curve from spherical indentation data. International Journal of Solids and Structures, 35(33):4411 - 4426, 1998.

[88] A. Nayebi, R. El Abdi, O. Bartier, and G. Mauvoisin. New procedure to determine steel mechanical parameters from the spherical indentation technique. Mechanics of Materials, 34(4):243 - 254, 2002.

[89] E.G Herbert, G.M Pharr, W.C Oliver, B.N Lucas, and J.L Hay. On the measurement of stressstrain curves by spherical indentation. Thin Solid Films, 398399(0):331 - 335, 2001. Proceedings of the 28th International Conference on Metallurgic Coatings and Thin Films.

[90] A Rusinko and K Rusinko. Plasticity and Creep of Metals. Springer Berlin Heidelberg, 2011.

[91] Michelle L. Oyen. Spherical indentation creep following ramp loading. Journal of Materials Research, 20:2094-2100, 2005.

[92] Sinisa Dj. Mesarovic and Norman A. Fleck. Spherical indentation of elastic-plastic solids. Proceedings: Mathematical, Physical and Engineering Sciences, 455(1987):2707$2728,1999$. 
[93] A.E. Giannakopoulos and A. Triantafyllou. Spherical indentation of incompressible rubber-like materials. Journal of the Mechanics and Physics of Solids, 55(6):1196 1211, 2007.

[94] B. Karpuschewski, O. Bleicher, and M. Beutner. Surface integrity inspection on gears using barkhausen noise analysis. Procedia Engineering, 19(0):162 - 171, 2011. 1st $\{\mathrm{CIRP}\}$ Conference on Surface Integrity (CSI).

[95] Y.D. Han, H.Y. Jing, S.M.L. Nai, L.Y. Xu, C.M. Tan, and J. Wei. Temperature dependence of creep and hardness of sn-ag-cu lead-free solder. Journal of Electronic Materials, 39(2):223-229, 2010.

[96] Olivier Bartier, Xavier Hernot, and Grard Mauvoisin. Theoretical and experimental analysis of contact radius for spherical indentation. Mechanics of Materials, 42(6):640 $-656,2010$.

[97] N Ogbonna, N.A Fleck, and A.C.F Cocks. Transient creep analysis of ball indentation. International Journal of Mechanical Sciences, 37(11):1179 - 1202, 1995.

[98] T Hyde, K Yehia, and A Becker. Int J Mech Sci, 35(6):45, 1993.

[99] Hamid Reza Ghorbanzadeh and Abolfaz Rezaee Bazzaz. Enhanced superplasticity in aa2024 aluminium alloy processed by multiple compressions in a channel die. In 6 th International Conference on Nanomaterials by Severe Plastic Deformation, 2014.

[100] Tasndi P. \& Kovcs I Juhsz, A. Superplastic indentation creep of leadtin eutectic. Journal of Materials Science Letters, 1986.

[101] Sargent P. M. and M. F. Ashby. Indentation creep. Materials Science and Technology, 1992. 